اثر تطبيق المراجعة المشتركة على جودة عملية المراجعة (1)

\author{
إعداد \\ دـ ـ إبراهيم عبد الحفيظ عبد الهادي (Y) ، وكيل كلية التجارة \\ لشئون الطلاب \\ هند محمد أمين
}

(1) هذا البحث مكمل لرسالة الماجستير بعنوان (اثر تطبيق برامج المراجعة المشتركة

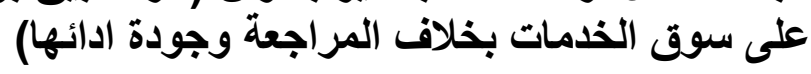

( إ) ( المشرف على البحث 


\section{The Effect of Appling the audit on audit quality}

\section{Dr : Ibrahim Abed Al Hafez}

Hend Mohammed Amen 
المستخلص

يهرف هذا البحث إلي معرفـة أقر تطبيق المراجعة المشتركة علي جودة عمليـة

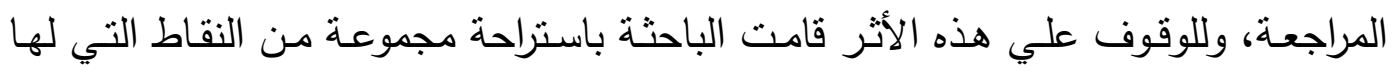

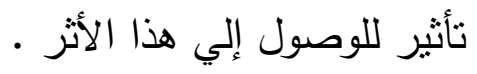

لذلك قامت الباحثة بعمل إطار مفاهيمي للمراجعة المشتركة لعرض كلاً من نشأتها ومفهومها وخطوات تطبيقها وأهميتها .

تم تتاولت الباحثة أثز المراجعة المشتركة علي جودة الأرباح المحاسبية وقيم المنشأة للعميل

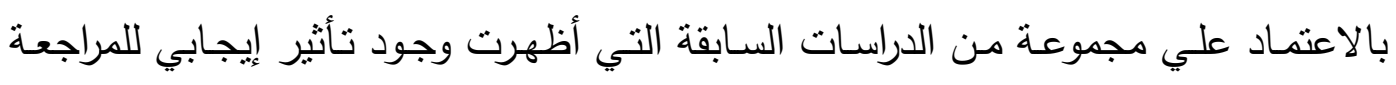

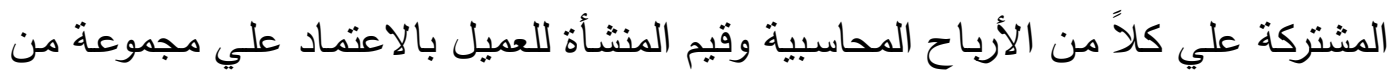

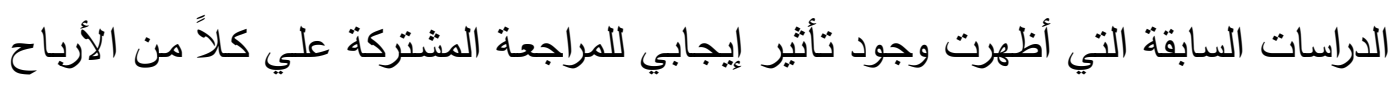

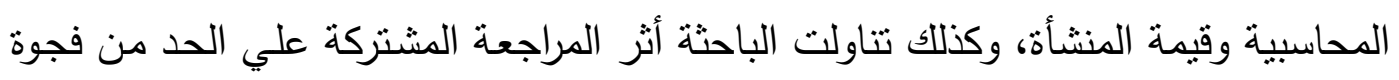

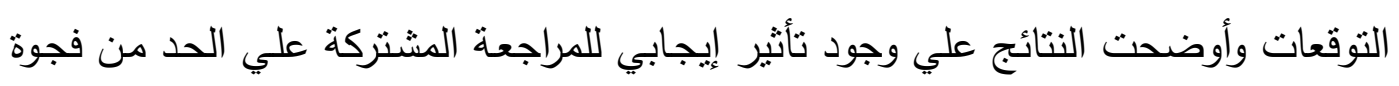

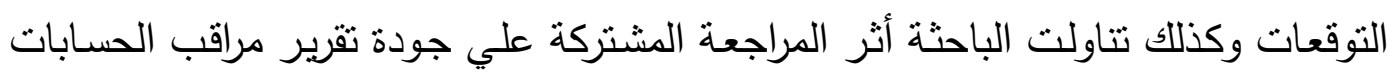

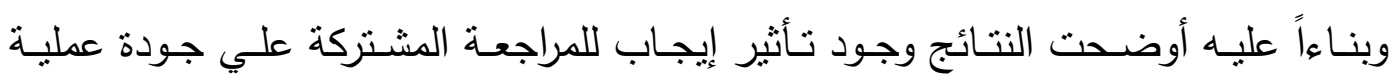

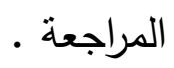

الكلمات الدالـة : المراجعـة المشتركة - الأربـاح المحاسبية - قيم المنشـأة - تقرير مراقب الحسابات - جودة عملية المراجعة 


\section{Abstract :}

The he searcher aims to Examine the effect of applying the joint audit on audit quality.

The hazarder contacted a conceptual framework for the joint audit to explore its history, concepts, applying procedures audits importance.

The he searcher examine also the effect of joint audit on availably of accounting earnings and firm value based or literature review whit show a positive effect of joint audit upon the accounting earnings and firm value.

Moreover the he seedier examines the effect of joint audit upon the gap expectation and shows that the joint audit has a positive effect on tighten this gap .

The he searcher examine the effect of joint audit on the quality and it Keyport finally. The he searcher shows a positive effect of joint audit upon quality of audit process.

Keywords: Appling the audit - audit quality 
يتمثل الهدف الأساسي للمراجعة الخارجية فى تحسين جودة ومحتوى المعلومات لخدمة متخذى القرارات، وذلك لهدف إضفاء النقة والمصداقية على المعلومات التى تحتويها

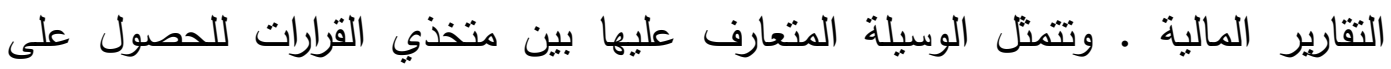
معلومات موثوق فيها Reliable Information في قيام مراقب الحسابات بمراجعة القوائم

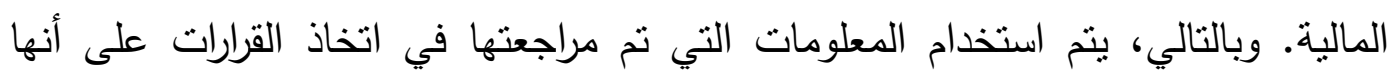

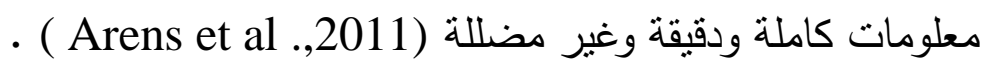

ولقد أثنار مجمع المحاسبين القانونين الأمريكي (AICPA,1972 ) إلى أن مراقب

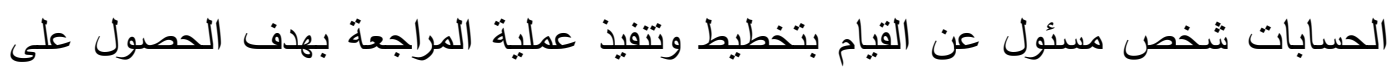
نوكيد معقول Reasonable Assurance وليس مطلقاً Reasonable Absolute عما إذا كانت القوائم المالية، في كافة جوانبها الجوهرية، خالية من التحريفات الجوهرية Material Misstatements AICPA,2001)

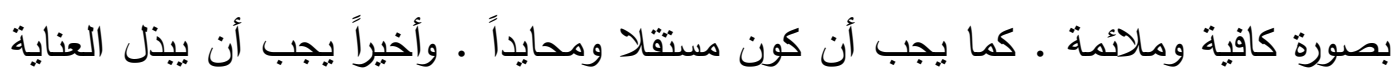

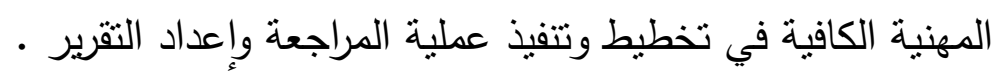

ولقد أثنارت الفضائح المالية التي واكبت الأزمة المالية العالمية التي شهدها العالم

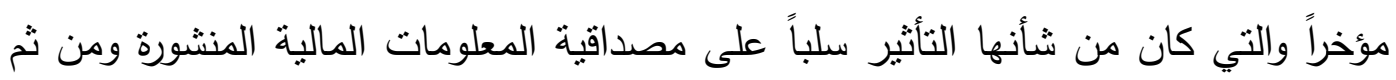

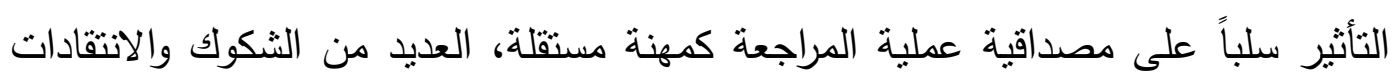
لاى مستخدمي القوائم المالية تجاه استقلال مراقب الحسابات عند مراجعته للقوائم المالية

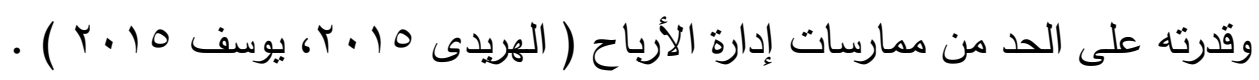

ونتيجة لذلك ازدادت المطالب المهنية والأكاديمية بتطبيق رقابة أكبر وتفعيل دور

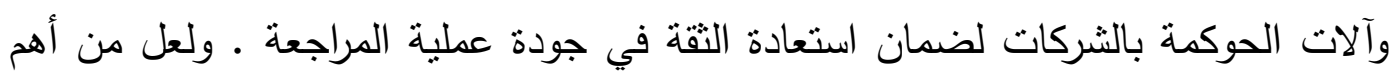
المحاولات التي هدفت إلى تحسين جودة المراجعة، وضمان استقلالية مراقبي الحسابات،

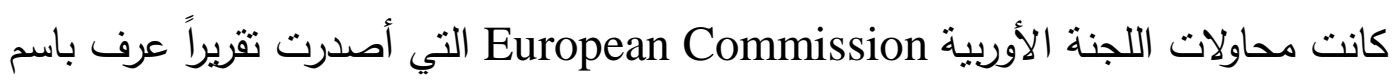

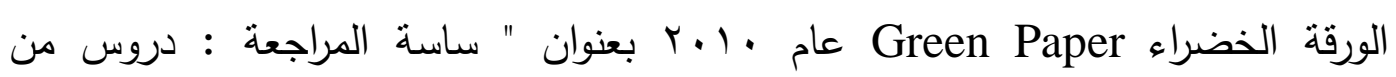


الأزمات" واقترحت فيه عدداً من الإجراءات والآليات التتظيمية للعمل على استعادة الثقة في

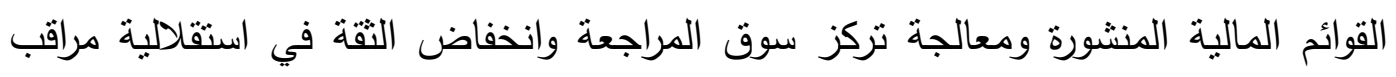

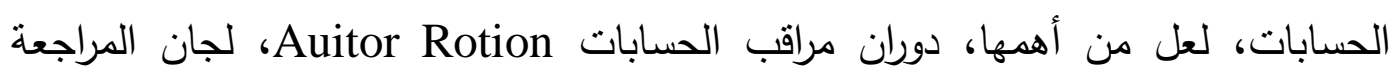
Audit Committee

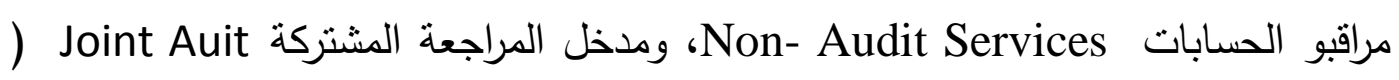

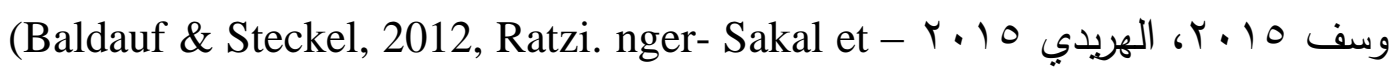
. al .,2013)

ويمكن تعريف المراجعة المشتركة على أنها " أسلوب لأداء عملية المراجعة الخارجية

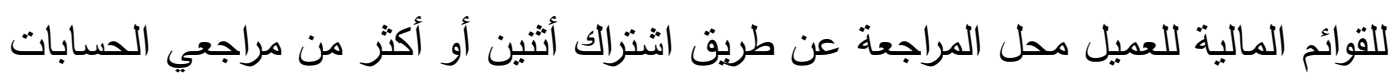

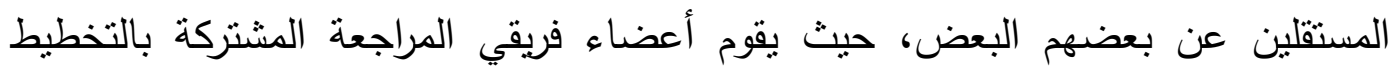

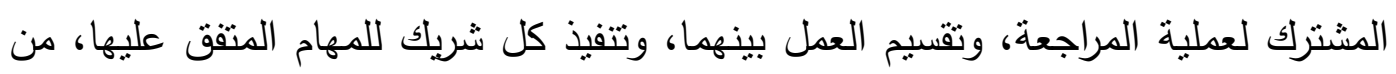
أجل اصدار تقرير مراجعة مشترك يتضمن توقيع كل منهما بشأن الرأي الفني المحايد بشأن

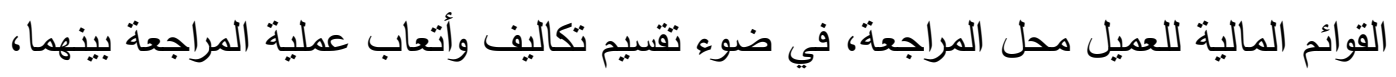
بالإضافة إلى تحمل كل مراجع لمسؤولية تضامنية بشأن الرأى الفني الوارد بتقرير المراجعة". Joint Audit وبعد تقديم هذا المقترح أثبرت فكرة إحياء تطبيق المراجعة المشتركة

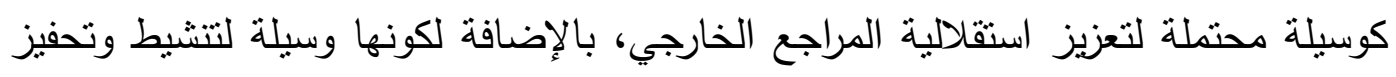

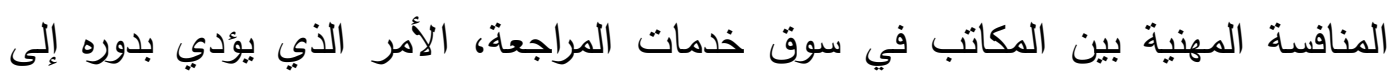
تحسين جودة عملية المراجعة .

\section{طبيعة المشكلة :}

أصبحت القوائم المالية لا تعبر بصدق عن المركز المالي الحقيقي للشركة وأدائها

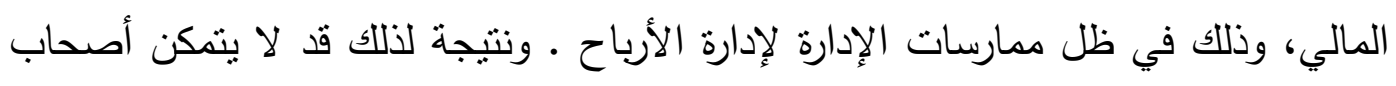

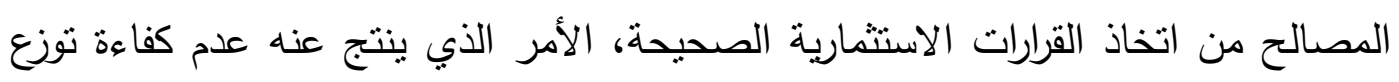

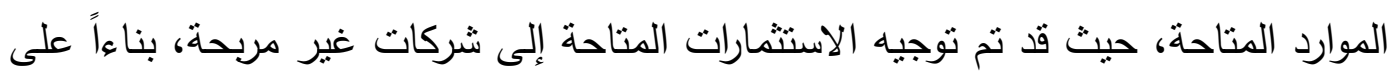

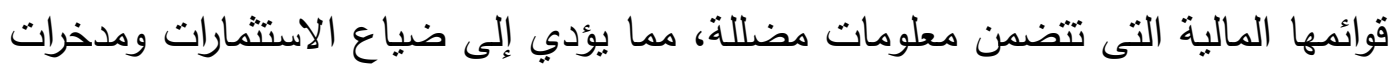

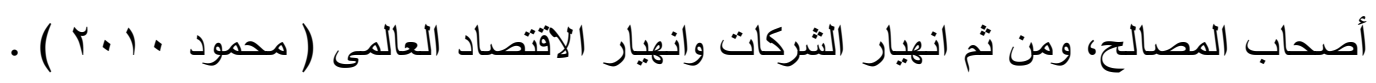


نتيجة لذلك، أوضحت بعض الدراسات Alsaoun\& Aliaber,2014 , Lobo et al 2013, Zerni et al .,2012,. Baldauf\& Steckel, 2012,. Paugam \& Casta, 2012,. Ittonen \& Tronnes, 2015., Karjalainen2011., Marmousez (2009 ) قيام أثنين أو أكثر، من مراقبي الحسابات بمراجعة القوائم المالية واستعادة ثقة أصحاب

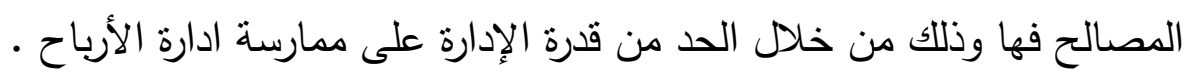

ولذلك تكمن مشكلة البحث في أنه من الرغم من أن المراجعة المشتركة يتم تطبيقها

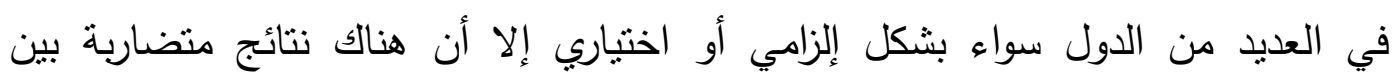

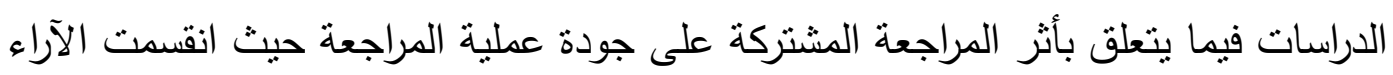

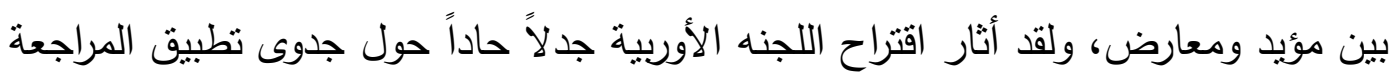

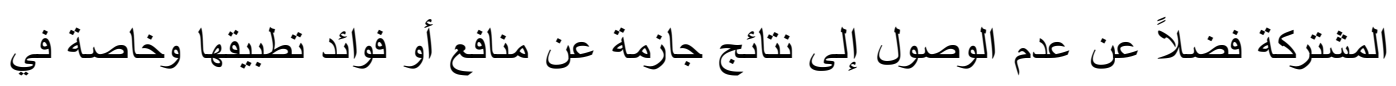
الدول العربية .

واستتادا على ما سبق حاول الباحث التوصل الى إجابة عن سؤال البحث الرئسى

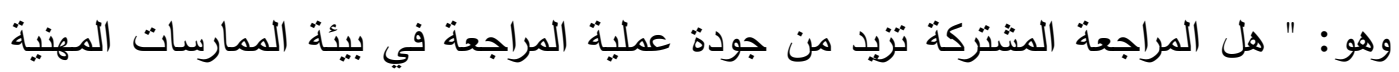

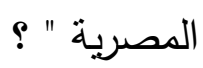

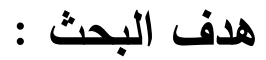

يهدف البحث بصفه أساسة إلى دراسة أثر تفعيل مدخل المراجعة المشتركة على

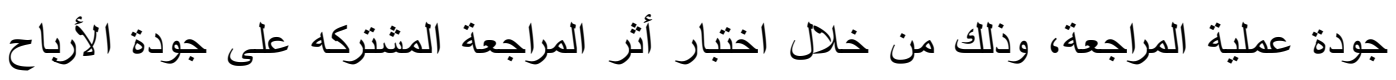

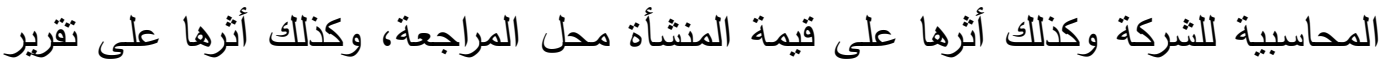

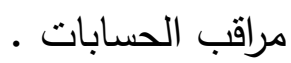

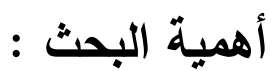

تتبع أهمية البحث الأكاديمية من ندرة البحوث الأكاديمية المصرية، التي تتاولت أنثر

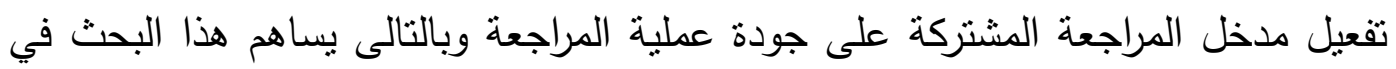

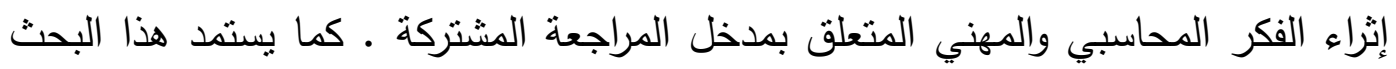


أهميته العملية فى البحث عن دليل عملى بشأن العلاقة بين تفعيل مدخل المراجعة المشتركة وجودة عملية المراجعة .

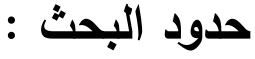

يقتصر البحث على تحليل أثز تفعيل مدخل المراجعة المشتركة على جودة عملية المراجعة من خلال دراسة أثرها على جودة الأرباح المحاسبية، وكذللك قيمه المنشأة، وتأثيره

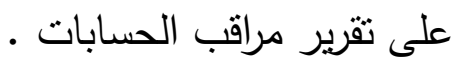
خطة البحث : - 1 1- الإطار المفاهيمي للمراجعة المشتركة .

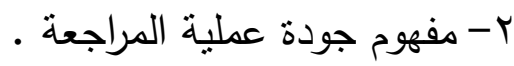

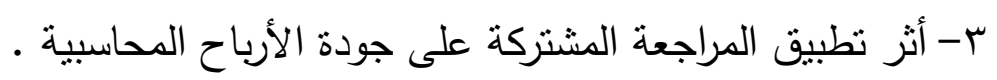
ع - أثر تطبيق المراجعة المشتركة على قيمة المنشأة .

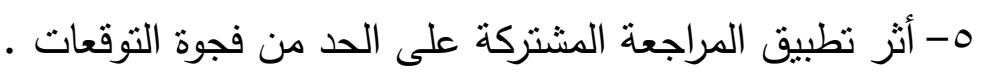

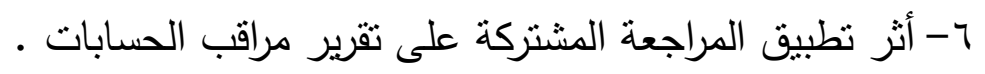

\section{ا ب-الإطار المفاهيمي للمراجعة المشتركة :}

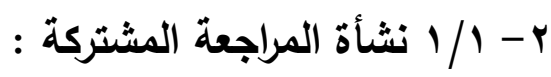

بالرغم من الاهتمام بالدور المعاصر لمهنة المراجعة الخارجية والتي ظهرت من

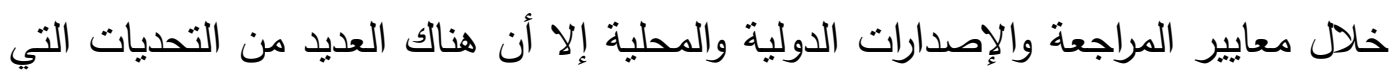

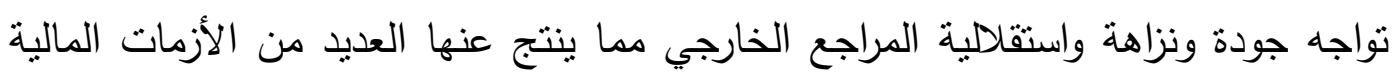

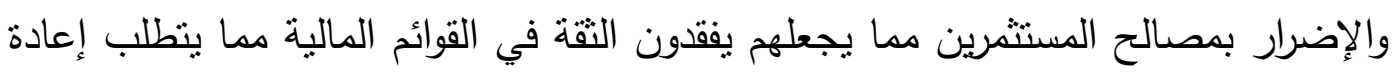

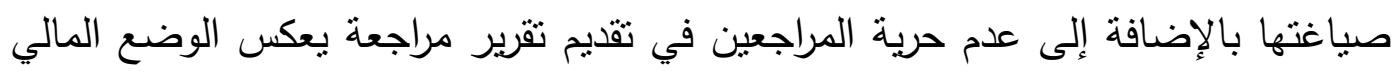
الحالي والمستقبلي بصورة سابقة .

كما لم تلق عمليات إعادة صياغة القوائم المالية، وكذلك كثرة التعديلات في تقرير مراقب الحسابات الاهتمام الكافي من الجانب الأكاديمي أو التطبيقي على حلى حد سواء

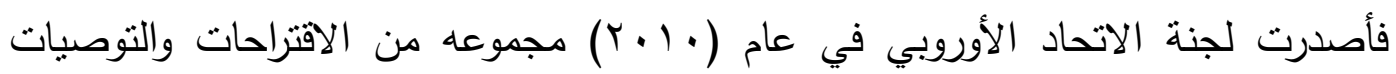


(green paper : والآليات لتنظيم عملية المراجعة وتضماناً لاستقلالية المراجع من خلد ) audit policy lessons from the crisis ) شركة أو مكتب مراجع خارجي لمراجعة الثقارير المالية (joint audit) وقد اثأر اقتراح

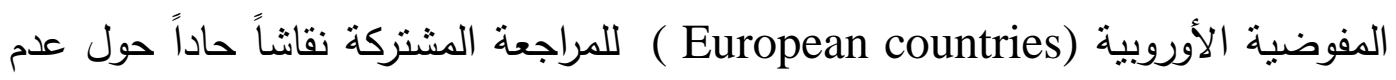

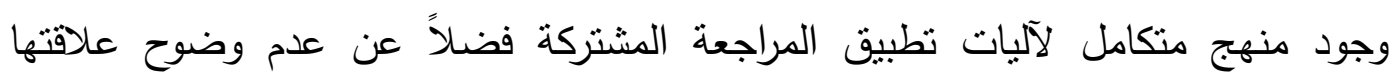

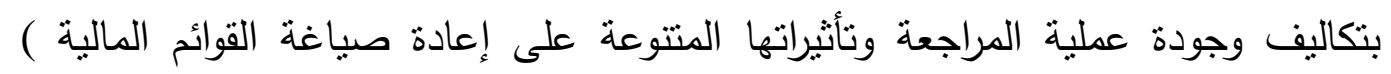
modified والآراء المعدلة لتقرير مراقب الحسابات Restated financial statement), audit opinion (MAO)

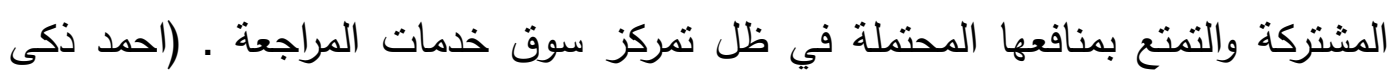

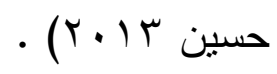

وقد تمنل الدافع الرئيسى وراء قيام المفوضية الأوربية بذلك في العمل على معالجة

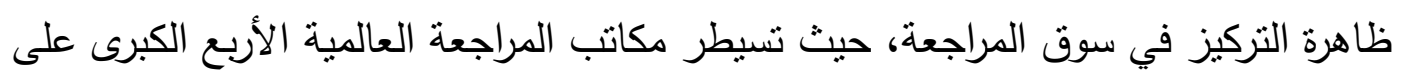

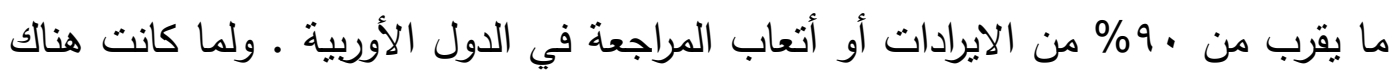

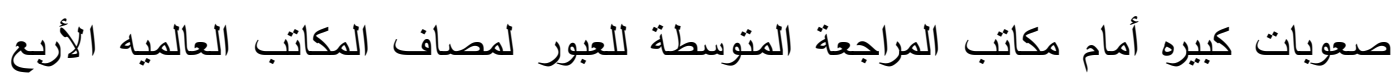

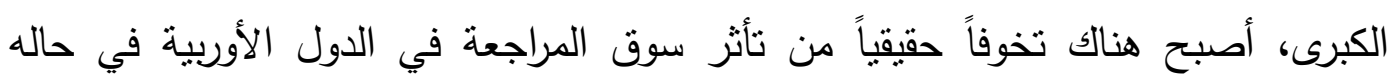

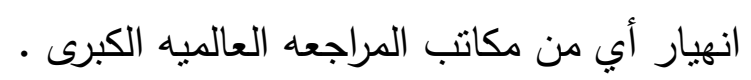

وبناء على ذللك، اقترحت الورقة الخضراء أن تتم عمليات المراجعه في دول الاتحاد الأوربي من خلال المراجعة المشتركة بواسطة اثثين من المراجعين يتشاركان في أعمال

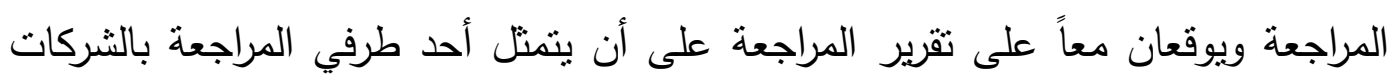

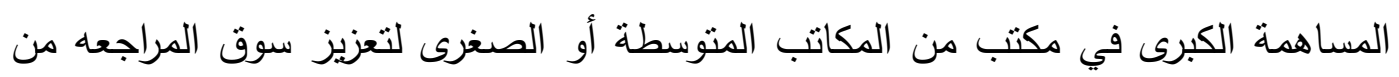
خلال تشجيع نمو المكاتب غير الكبرى .

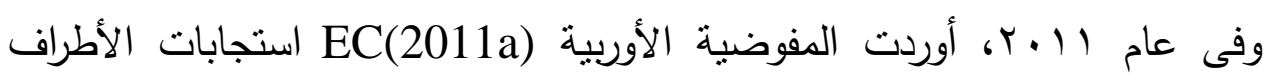

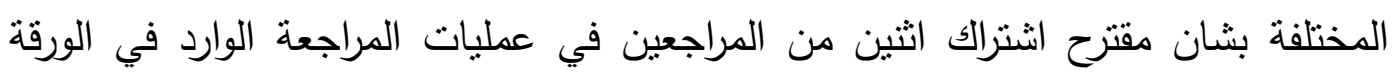
الخضراء. 
وقد أثنارت مكاتب المراجعة العالمية الكبرى في معرض استجابتها إلى أن ذلك

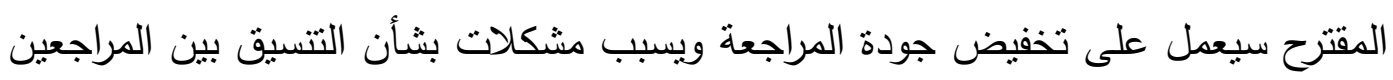

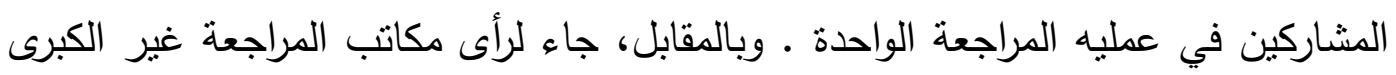

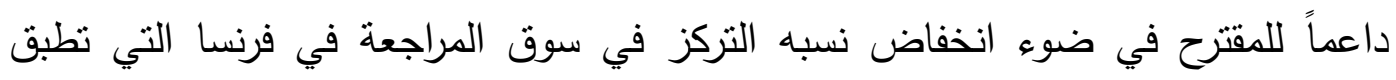

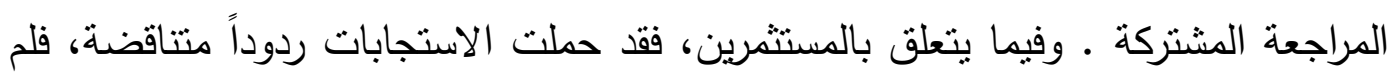

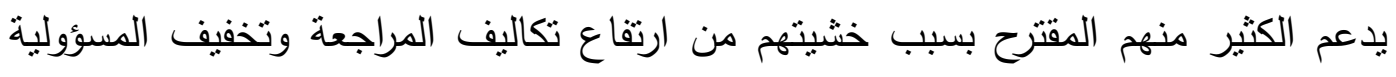

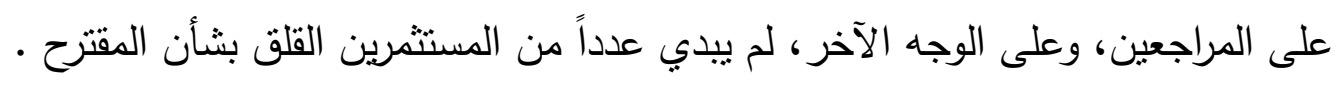
وبناء على ردود الفعل المختلفه قررت المفوضية الأوربية في •r نوفمبر EC( 2011b) r. II

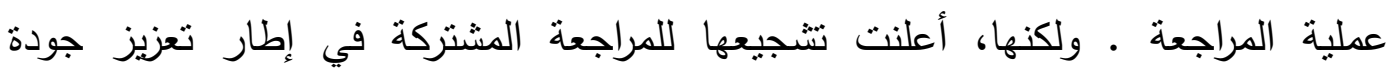
المراجعة ومحاولة التغلب على ظاهرة التركز في سوق المراجعة .

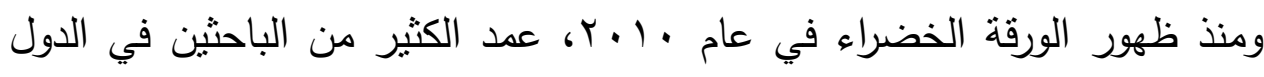

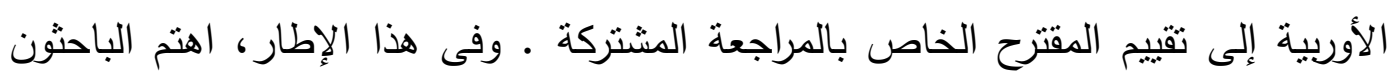

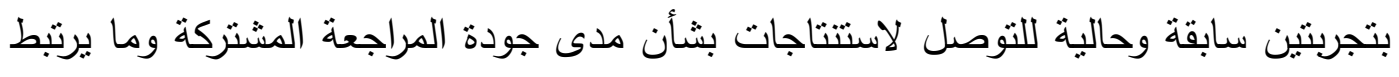

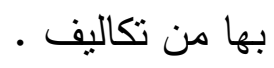

\section{1/ المراجعة المشتركة عالميا وعربيا :}

أن مفهوم المراجعة المشتركة لبس مفهوماً جديداً، فبالرغم من أن المراجعة المشتركة

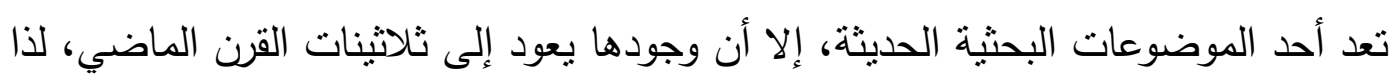
ستقوم الباحثة باستعراض التطور التاريخى لنشأة المراجعة المشتركة وأهم الدول التي تطبقها:

تعد الدنمرك من أقدم الدول التي تمارس المراجعة المشتركة، حيث أنها تطبقها

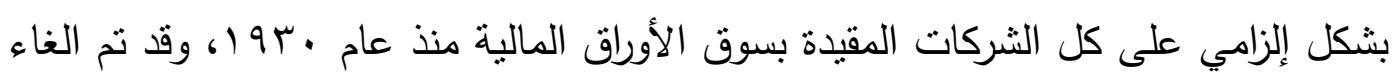

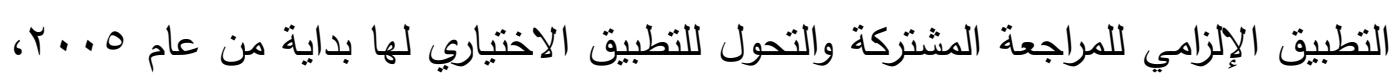


حيث أعطت الحرية للشركات المقيدة في بورصة الأوراق المالية بتطبيق المراجعة المشتركة

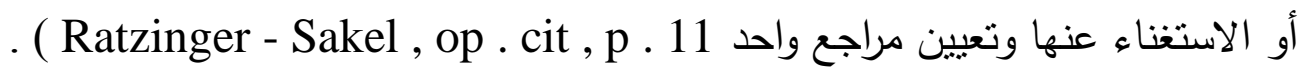

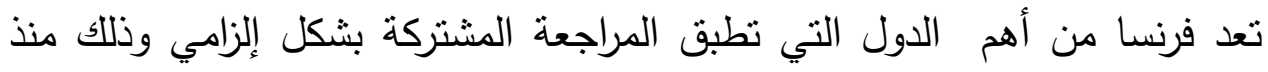

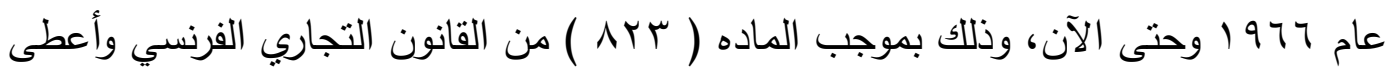

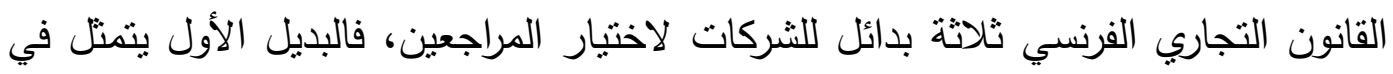

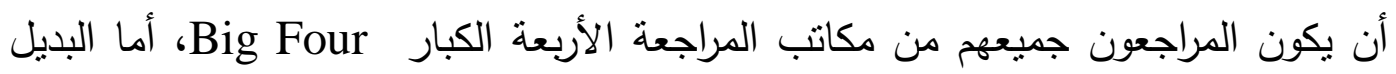

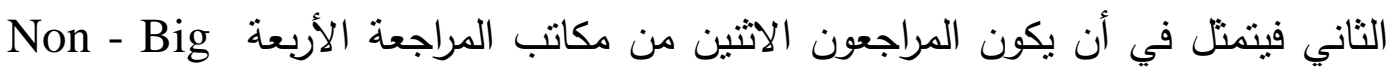

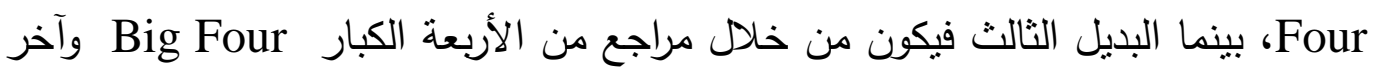

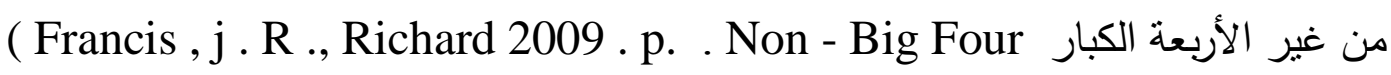

تعد من أهم الدول التي تطبق المراجعة المشتركة بشكل اختباري، ولكن كانت تطبق

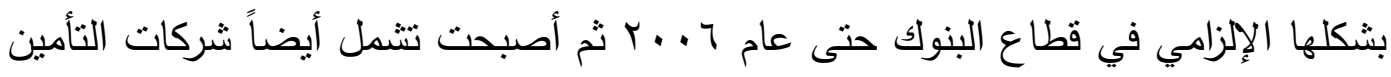
وذللك لضمان جودة مراجعة القوائم المالية لهذه القطاعات ويتم تعيين المراجع الثاني من قبل فئل

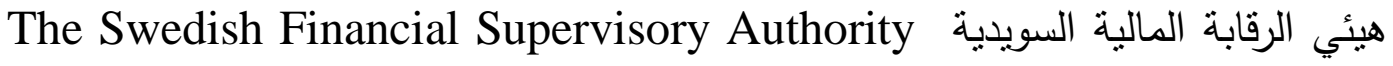
وليس من قبل الثركات ذاتها (Zerni , M., Jarvinen , T , op. cit , p , 3 )

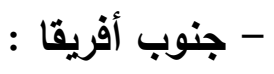
تطبق جنوب أفريقيا المراجعة المشتركة بشكل إلزامي، ولكن تقتصر فقط على قطاع

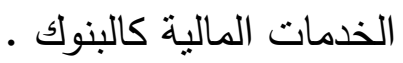

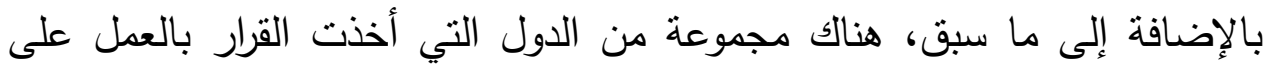
تطبيق المراجعة المشتركة ولكن بشكل اختياري ومن هذه الدول الهند، ألمانيا، سويسرا، والمملكة المتحدة . Deng , M., Lu , T., Simunic D . A ., Working paper 2013 , p 3) 
وهنالك أيضاً بعض الدول العربية التي تطبق المراجعة المشتركة سواء بشكلها

$$
\text { الإلزامي أو الاختياري، ومن هذه الدول : }
$$

تطبق الكويت المراجعة المشتركة الإلزامية منذ عام ه ... حيث ألزم القانون رقم

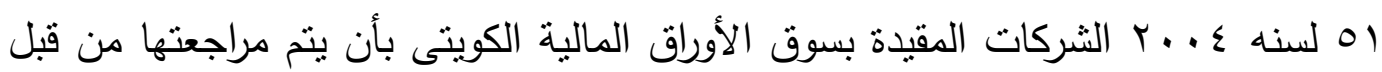

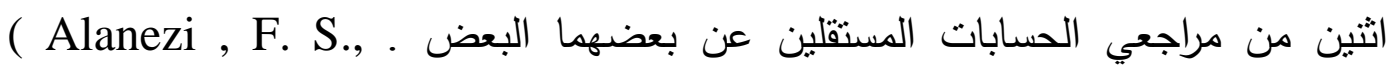
.Alfaraih 2012 , p 110 )

تطبق المراجعة المشتركة في المغرب على الثركات المقيدة بسوق الأوراق المالية

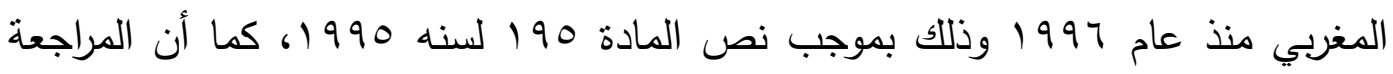

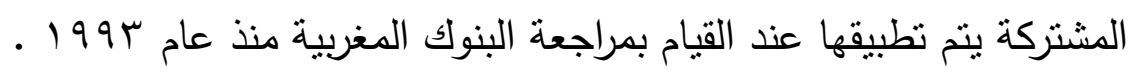

تمارس أيضاً المراجعة المشتركة بشكل إلزامي في قطاع البنوك والمؤسسات المالية

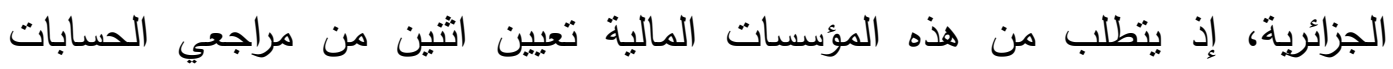

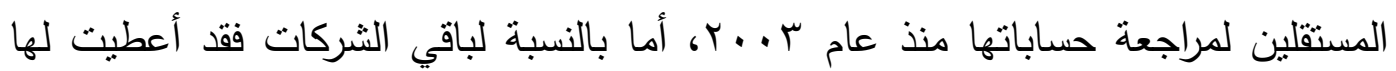

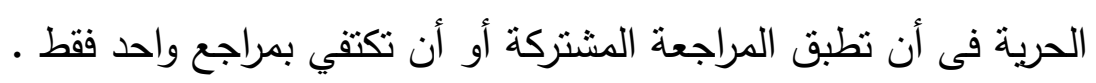

ويوجد أيضاً العديد من الدول العربية التي نطبق المراجعة المشتركة في مراجعة

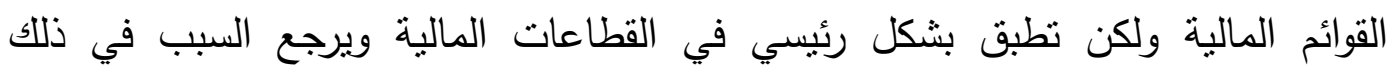

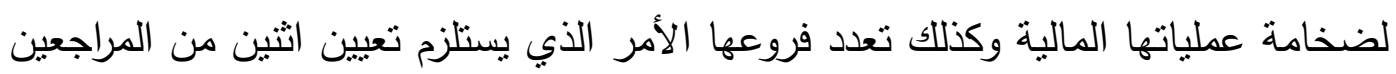

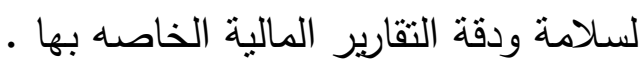
r/1 المراجعه المشتركة فى مصر : 
قد ينظر إلى مفهوم المراجعة المشتركة على أنه من المفاهيم والموضوعات الحديثة سواء في مجال البحث من ناحية أو في الحياة العملية في البيئة المصرية من ناحية أخرى، ولكن يرى الباحث أن موضوع المراجعة المشتركة ليس بجديد علي البيئة المصرية، وذلك لأن المراجعة المشتركة تمارس في البيئة المصرية والدليل علي ذلك ما يلي :

أولاً : ُُكر ضمن قواعد وسلوكيات المهنة أنه من الممكن أن يتواجد مراجع آخر بجانب مراجع الحسابات وذلك في الكثير من تلك القواعد مما يُشير إلى أن وجود أكثر مراجع للحسابات فهو أمر وارد في بيئة المراجعة المصرية ومن ثم يستتتج من هذا أنه من الممكن ان يقوم أكثر من مراجع باداء عملية المراجعة الخارجية لمنشأة واحدة .

ثانياً: نص قانون الجهاز المركزي للمحاسبات رقم (ع ( ) لسنة 191 المعدل بالقانون رقم (10V) لسنة 1991 في الفقرة الثانية والثالثة على التوالي من المادة الثالثة " أن الجهاز المركزي للمحاسبات هو المسؤول عن مراجعة حسابات الثركات المملوكة

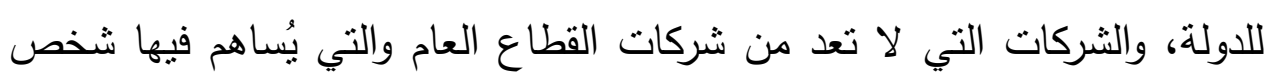
عام أو شركة من شركات القطاع العام أو بنك من بنوك القطاع العام بما لا يقل عن \% من رأسمالها" ، بالإضافة إلى ذلك فقد أوضح القانون في المادة الخامسة من الباب الثاني والمتعلق بمباشرة الجهاز لاختصاصاته أن الجهاز سيقوم بهذا الدور مع عدم الإخلال بحق الثركات التي لا تعد من شركات القطاع العام بأن يكون لها مراقبوا حسابات في ظل مباشرة الجهاز لاختصاصاته .

ثالثاً : وضع قانون الإبداع والقيد المركزي الصادر في عام ... مجموعة من الإجراءات الرقابية على الثركات العاملة في نشاطي الإبداع والقيد المركزي " ومن بين هذه الإجراءات ما ورد فى المادة (0؛) من هذا القانون والتى نصت على ضرورة أن الن يتولى مراجعة حسابات هذه الثركات مراقبان للحسابات يتم اختيارهما من مراجعي

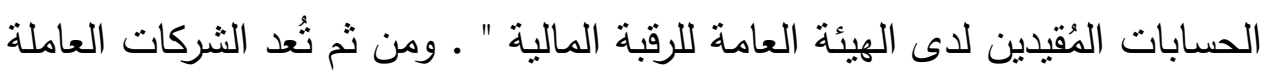
في أنشطة الإيداع والقيد المركزي من قبيل الثركات التي تطبق المراجعة المشتركة فى البيئة المصرية. 


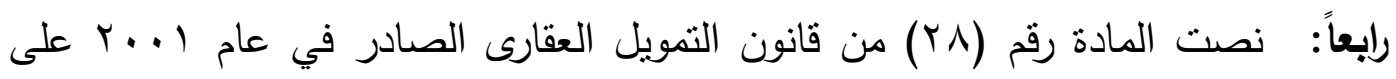

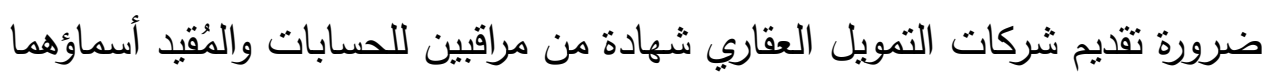
لاى الهيئة العامة للرقابة المالية بقبول مراجعة حسابات هذه الثركات كأحد مرفقات

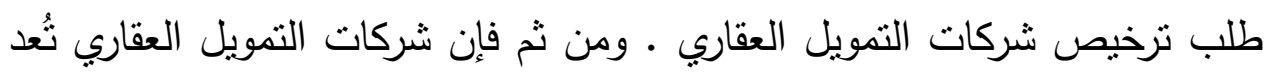

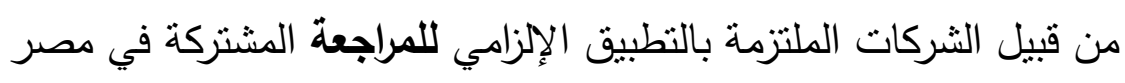

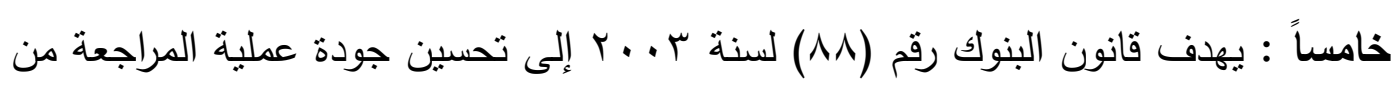

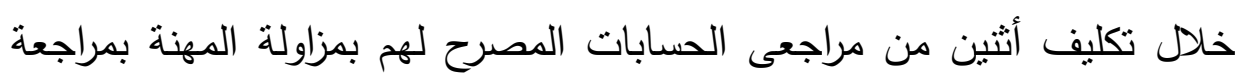

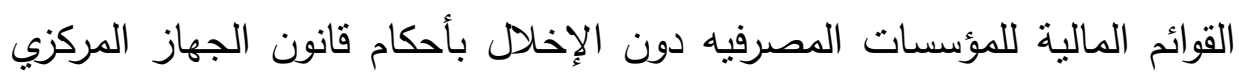

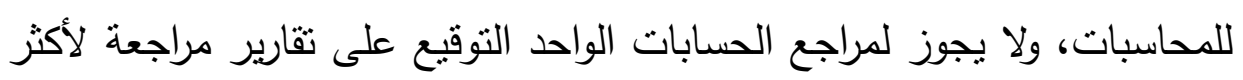

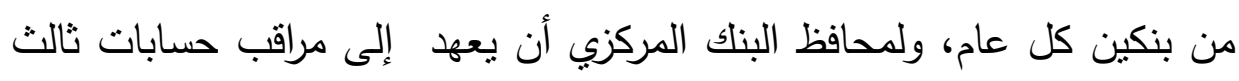

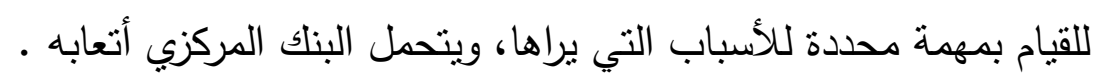

بالإضافة إلى ما سبق، توجد العديد من الثركات المقيدمة في البورصة المصرية

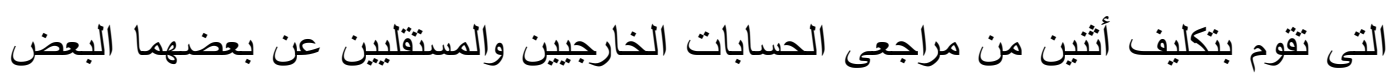

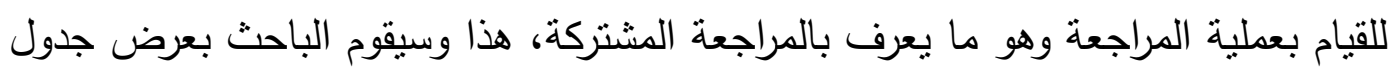

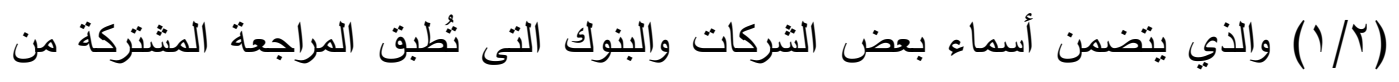

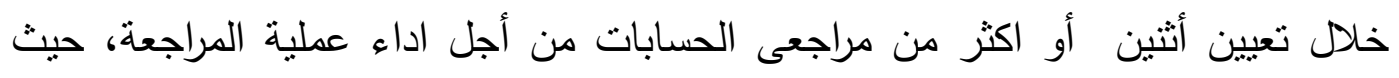

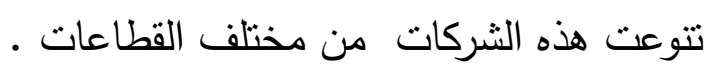

في ضوء ما سبق، يُكن القول بأن المراجعة المشتركة ليست جديدة على البيئة

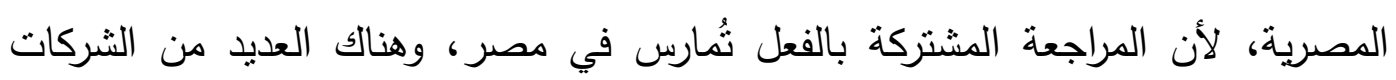

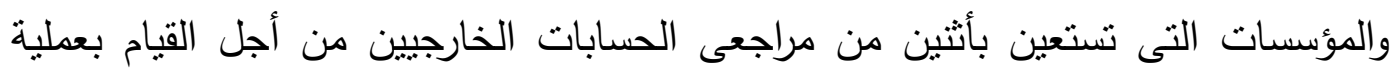

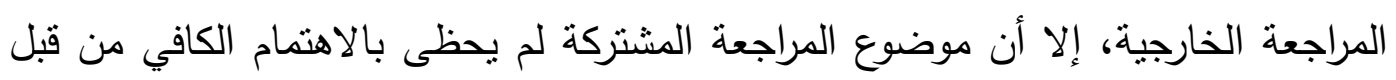

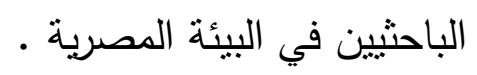

ع / إمهوم المراجعة المشتركة : 
تعددت آراء الباحثين حول مفهوم المراجعة المشتركة ، فقد رأت إحدى الدراسات (Baldent, junit steckl,R,2012)

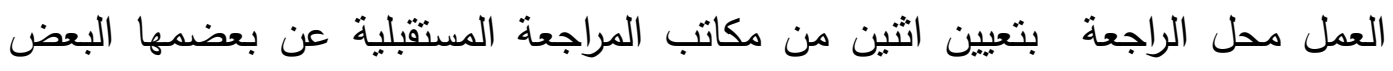

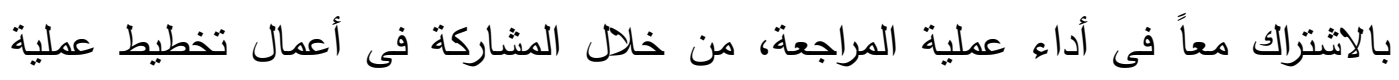

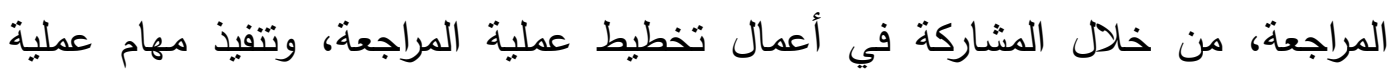
المراجعة بما في ذلك تفسير نتائج عملية المراجعة واصدار الرأي الفني المحايد بشأن القوائم

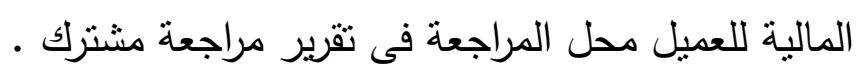

وقد عرفتها دراسة Cedric ,et ,al , 2012 على أن مفهوم المراجعة المشتركة

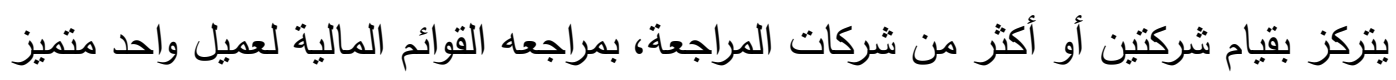

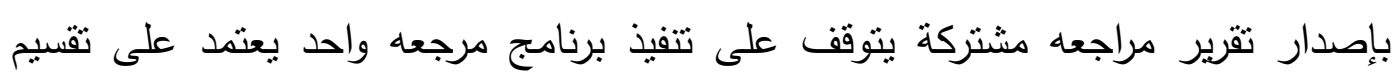

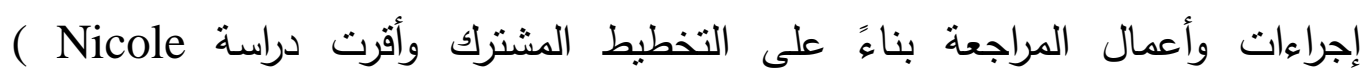
ratzingeret . al.,2012 بأنها شكل منقدم للحكم على القوائم المالية وأسلوب مدعم للمراجعة عند إبداء الرأي والذب يعزز عمليات المراجعة ويدعم استقال المراجعين وقادرة

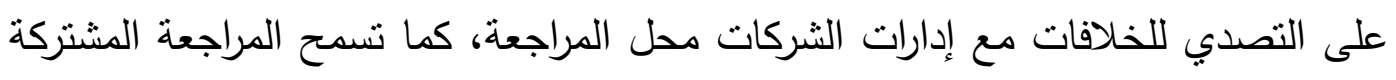

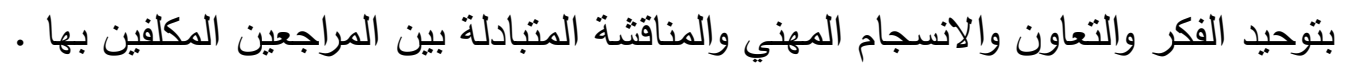
بينما وضعت دراسة (2012) مفهوماً للمراجعة الضريبية المشتركة، في إطار أهيتها ـ بأنها اتفاقيه نقوم من خلالها الدول المشاركة بالاتفاق على القيام بمراجعة

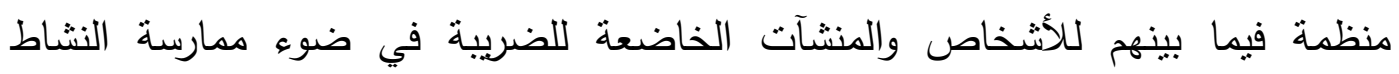

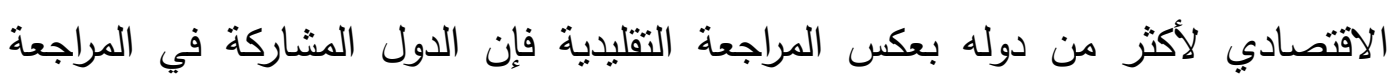

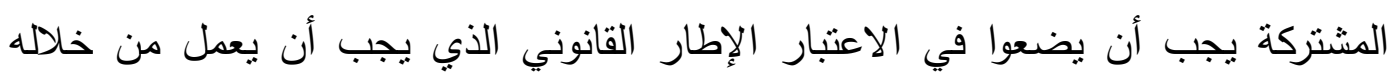
المراجع الضريبي حيث تكون الدول المشاركة مسئوله بصورة مشتركة في تنظيم وإدارة برامج الإنج المراجعة وسوف تطلب البيانات والمعلومات من العميل الذي قام بممارسة نشاط داخل نطاق

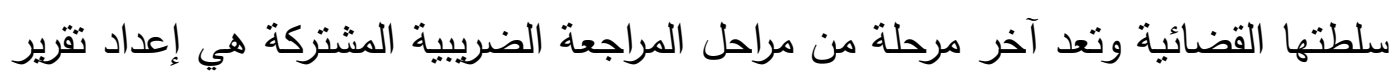
مراجعه موحد يتضمن المستحقات الخاصة بكل الدول المشاركة . 
وأكدت دراسة (Clause Holm 2012) أنه يوجد شكلين للمراجعة المشتركة وهما المراجعة المشتركة ( الطوعية، والإلزامية ) وقد عرضت الدراسه تجربه الدنمرك في التحول

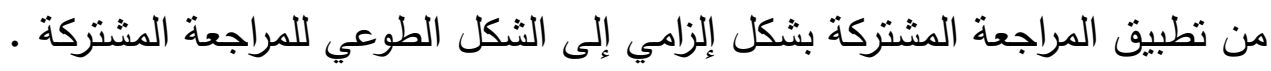

كما عرضت دراسة (Holm \& Thinggard 2012) أن هناك مجموعة من المحددات لاختيار المراجع فى سباق الانتقال من النطبيق الالزامى الى النطبيق الطوعي

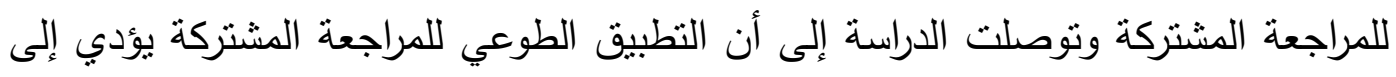
انخفاض تكلفه الخدمات الاستشاريه كما أنه ارتبط بالحد من المخاطر التى تهدد استقلاليه مراجعي الحسابات .

\section{ويمكن للباحثه مما سبق أن تستتتج تعريف للمراجعة المشتركة وأثكالها :}

المراجعة المشتركة الإلزامية وهي أحد الآليات المراجعة الذي يحتم القانون القام بها

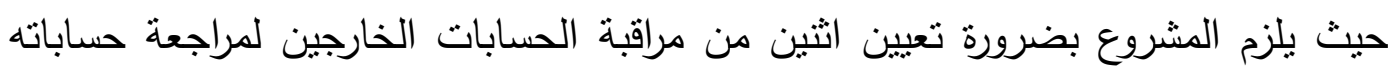

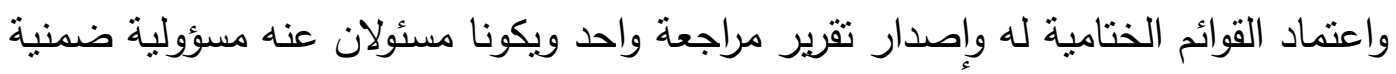

أي أن المراجعة المشتركة الإلزامية تتميز بوجود عنصر الجبر والإلزام ومن ثم يمكن

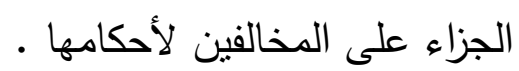
أما المراجعة المشتركة الطوعية وهو شكل المراجعه الذى يتم دون الزام قانونى يحتم

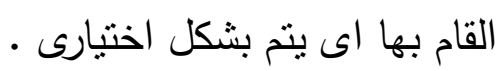

وفى ضوء ما سبق ترى الباحثة أن المراجعة المشتركة هي عبارة عن شكل منقام

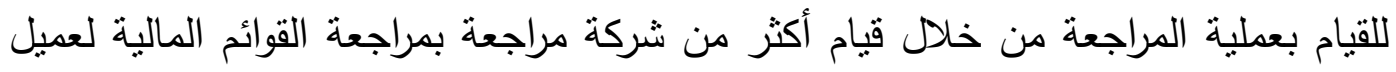

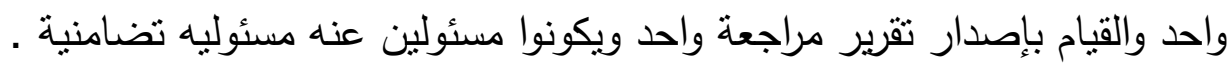


1/ أثكال ممارسة المراجعة المشتركة :

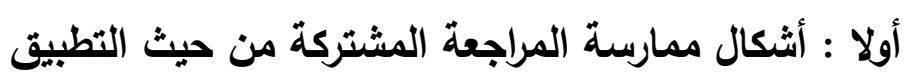

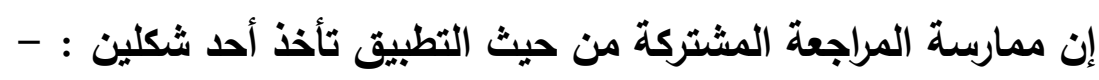
أ - المراجعة المشتركة الإلزامية : - - -

تُعد إلزامية تطبيق المراجعة المشتركة أحد أثنكال ممارستها، حيث ينسم فيها

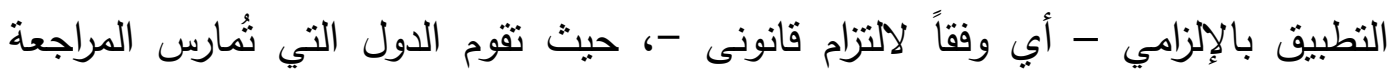

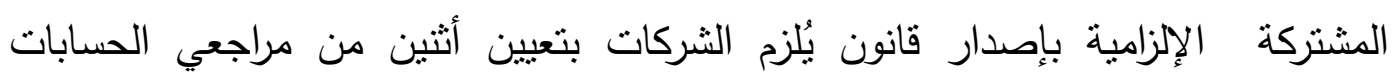

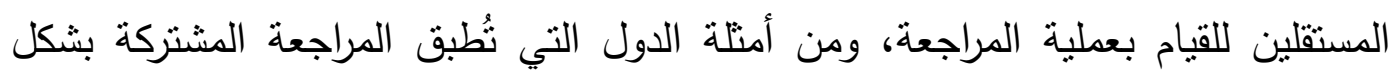

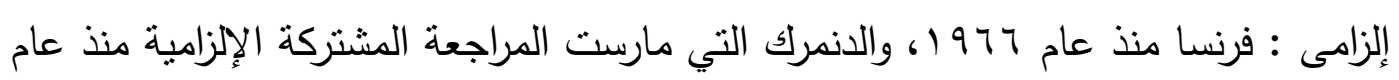

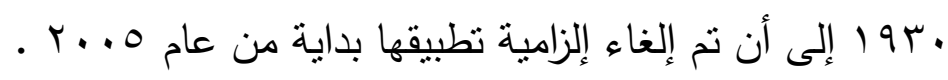

ب - المراجعة المشتركة الاختيارية :

تُعتبر اختبارية تطبيق المراجعة المشتركة الثنكل الآخر من أنشكال ممارستها، حيث

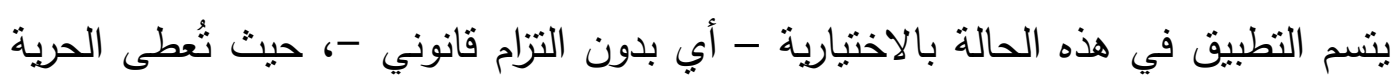

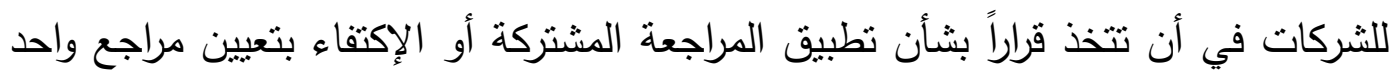

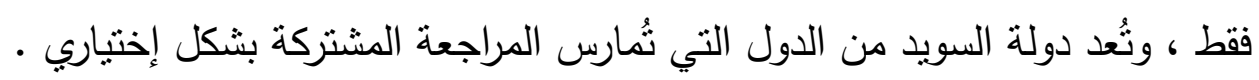
ثانيا : أشكال ممارسة المراجعة المشتركة من حيث القائمين بها : يقوم هذا التقسيم على أساس اختلاف نوعية أو حجم مكاتب المراجعة التي ستشارك

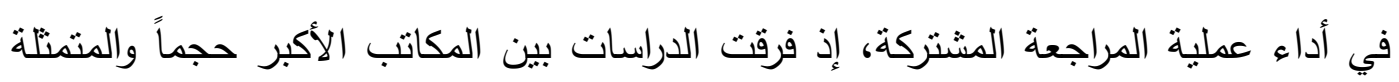

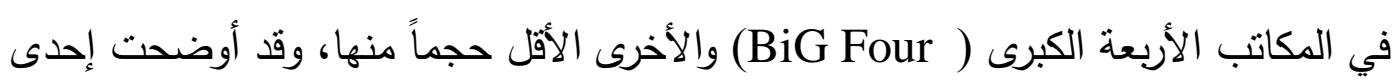
الدراسات ان المراجعة المشتركة يتم تقديمها من خلال ثلاثة أثنكال هى : -

Big Four تقديم المراجعة المشتركة من قبل مكتبين من المكاتب الأربعة الكبرى 
Big تقديم المراجعة المشتركة من قبل مكتبين احدهما من المكاتب الأربعة الكبرى

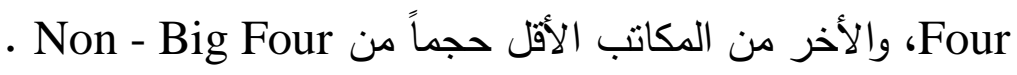
•ققديم المراجعة الششتركة من قبل مكتبين من المكاتب بخلاف المكاتب الأربعة الكبرى Non - Big Four

برى بعض الباحثين أن الفهم السليم لأثكال ممارسة المراجعة المشتركة، ومعرفة

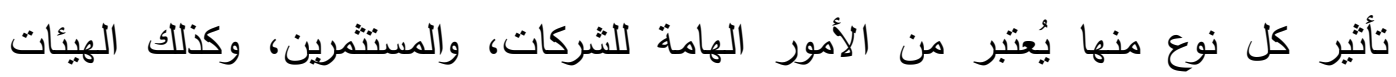

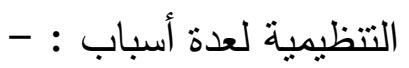

1- مساعدة واضعي السياسات في معرفة ما إذا كان هناك شكل معين من أنشكال

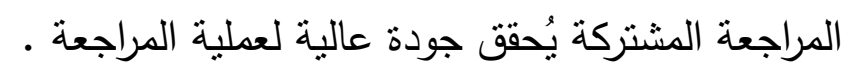
r- التحقق من صحة ما رود في اقتراحات المفوضية الأوروبية حول ضرورة مُشاركة

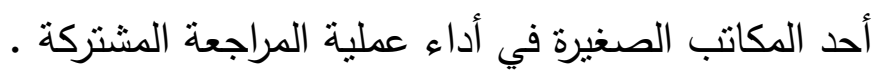
r- تساعد لجان المراجعة في الثركات المختلفة في إنخاذ القرار المناسب بشأن نوعية

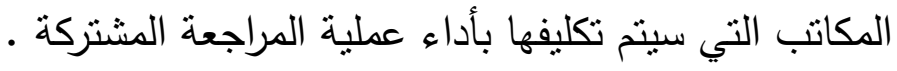

وفي هذا الصدد، اهتمت العديد من الدراسات بمناقتشة الثكل الأفضل لممارسة

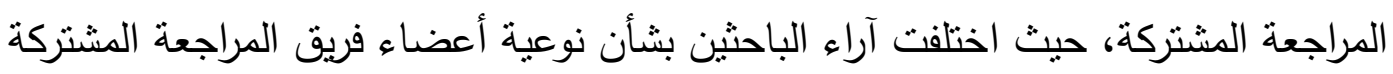

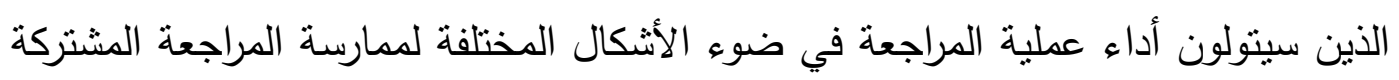

هذا، وقد أوضحت إحدى الدراسات أن أداء المراجعة المشتركة من خلال اثثين من

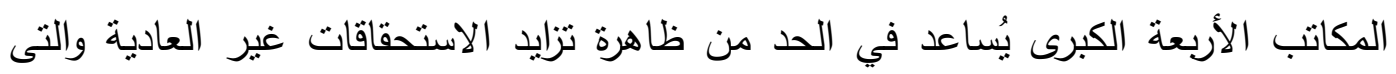

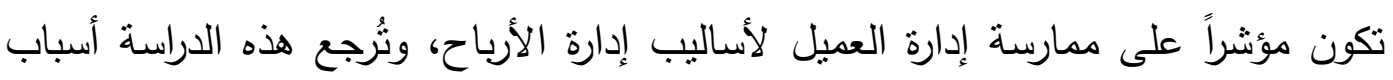

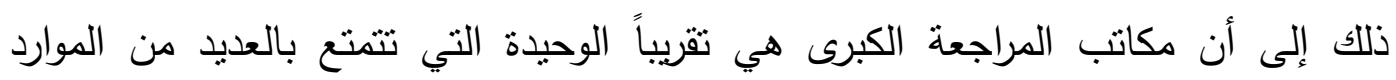

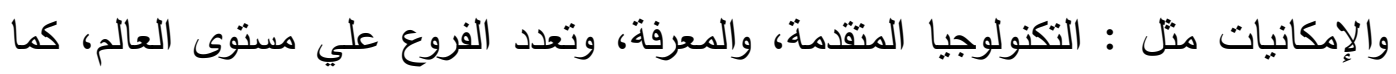
أكدت دراسة أخرى أن هذا الثكل من أنثكال تطبيق المراجعة المشتركة يُعتبر الخيار 
الاقتصادي الأفضل للشركات الكبيرة أو الثركات متعددة الجنسيات، لأن المكاتب الكبرى

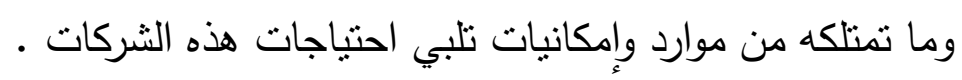

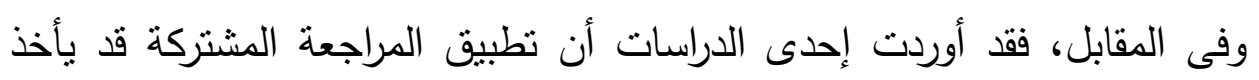

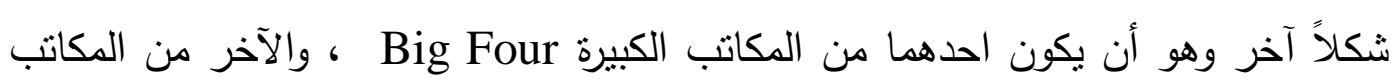

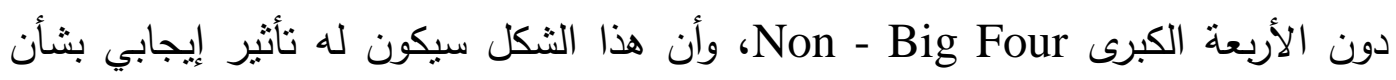

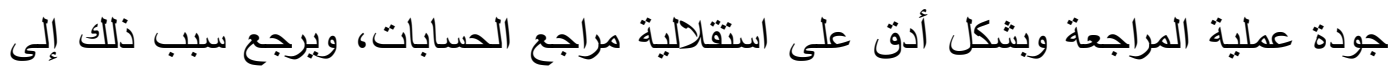

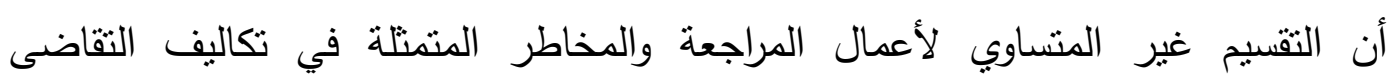
وانخفاض السمعة بين المكتب الكبير والمكتب الأقل حجماً قد يُحقق درجة أعلى لاستقلالية

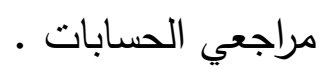

ومن منظور أثز تتكيل فريق المراجعة المشتركة على جودة التقرير المالي، فقد

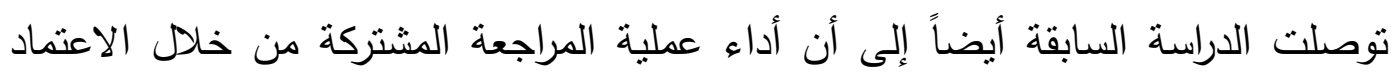
على أحد مكاتب المراجعة الكبرى وأحد المكاتب الصغرى يؤدي إلى زيادة مستوى الإفصاح عن خسائر اضمحلا الأصول Imairment Loss، وبالتالي تحسين جودة التقارير المالية، بينما الاعتماد على مكاتب المراجعة الصغرى فقط يؤدي إلى انخفاض مستوى الإنى

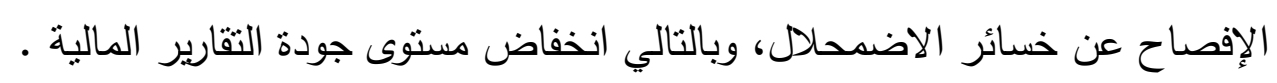

كما توصلت دراسة أخرى إلى ان تطبيق المراجعة المشتركة من خلال الاعتماد

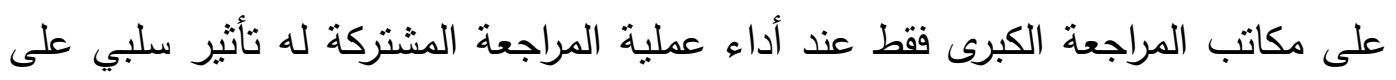

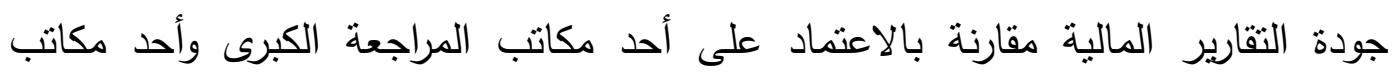

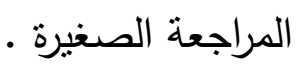

وهذا وتتميز مكاتب المراجعة الكبيرة بانخفاض تكاليف تجميع الأدلة بالمقارنة

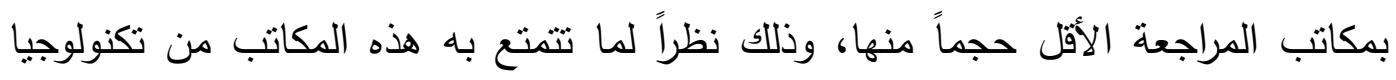

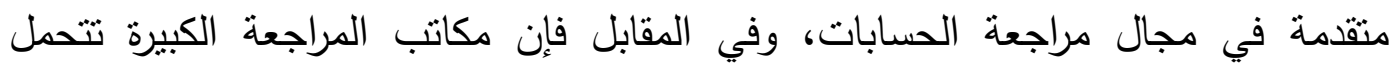

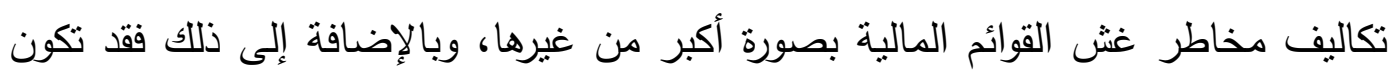

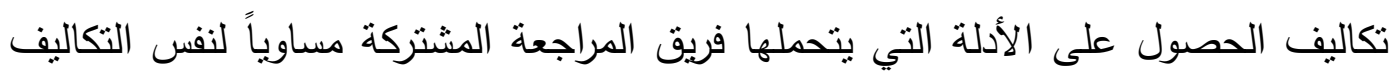

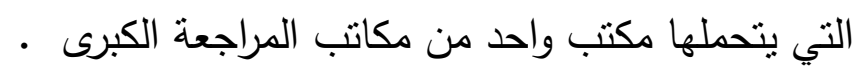


ويرى أحد الباحثين أن قرار اختيار أحد مكاتب المراجعة الكبرى بمشاركة أحد

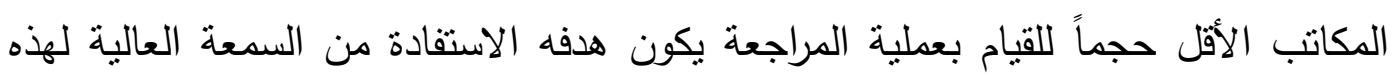

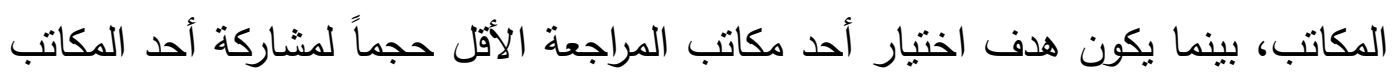

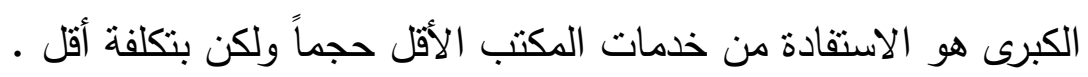

وبناءً على ماسبق فإنه ليس من الضروري أن تزداد تكاليف المراجعة المشتركة عن

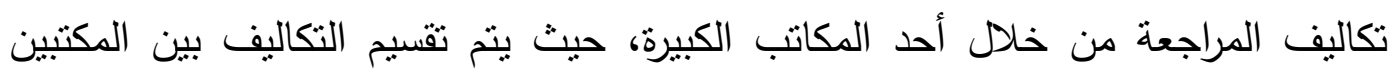

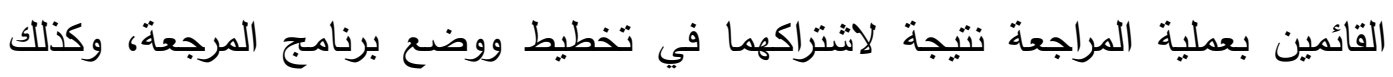
الاشتراك في إعداد تقرير المراجعة المشترك الذي يتضمن الرأي الفني بشأن القوائم المالية للعميل محل المراجعة.

أوضحت إحدي الدراسات أن هناك مجموعة من العوامل التي تبرر الاستعانة بأحد

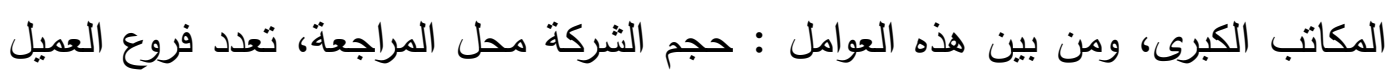

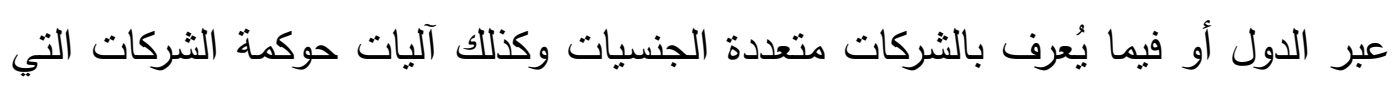

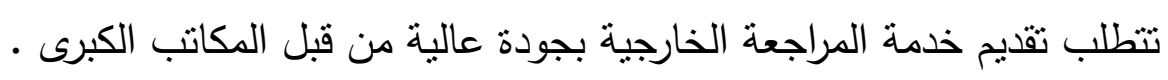

كما أضافت دراسة أخرى أحد العوامل الأخرى المؤثرة في الاستعانة بالمكاتب الكبيرة

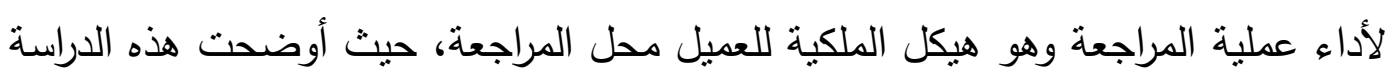
أن الثركات التي تكون أقل نركيزاً في هيكل ملكيتها، وأقل في معدلات الميكلة الملكية العائلية

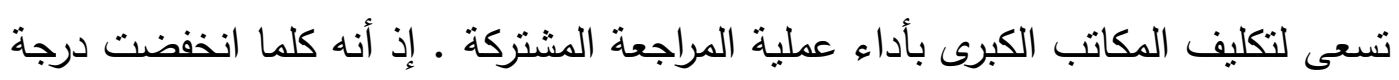

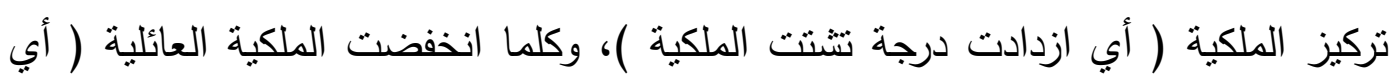

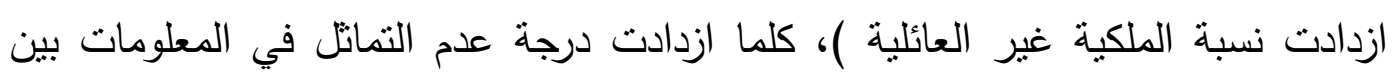

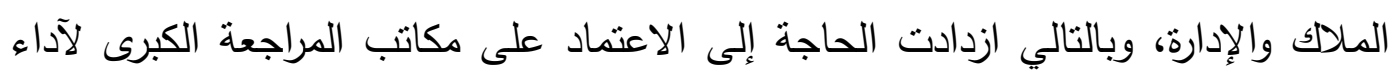

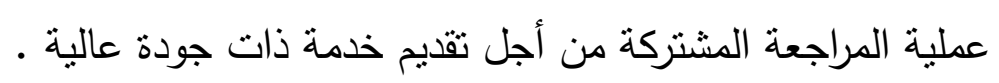

في ضوء ما سبق، يرى الباحث أن تحديد الثكل الأفضل من أنشكال ممارسة

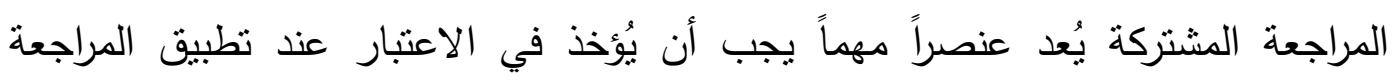

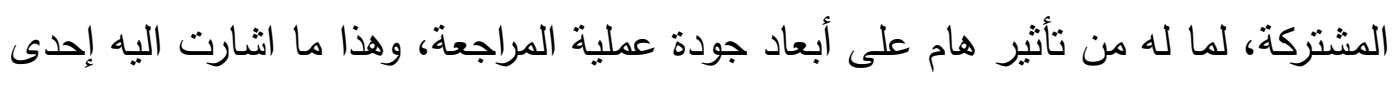

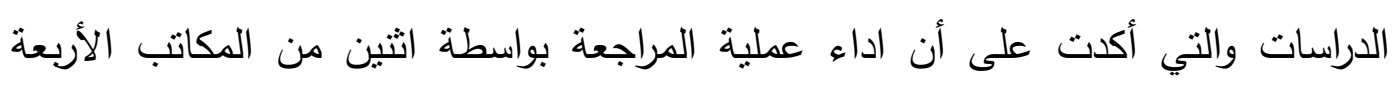


الكبرى يُسهم في زيادة كفاءة عملية المراجعة، لأنهما يمتلكان الخبرات المهنية العالية، بينما

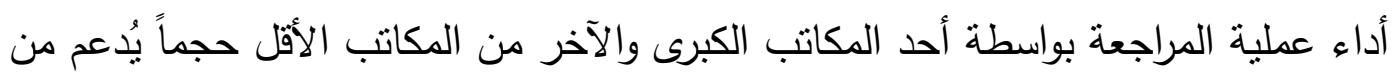

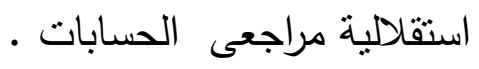

\section{1/7/ الجوانب السلبية والإيجابية لتطبيق المراجعة المشتركة :}

في ضوء ما سبق للجوانب المختلفة للمراجعة المشتركة، فقد تعددت وجهات نظر

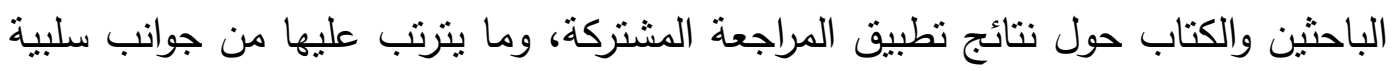

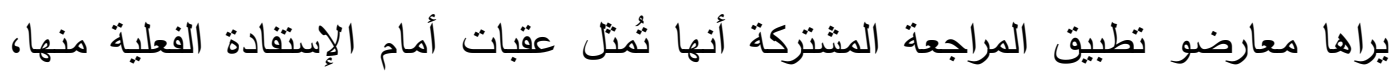
وأخرى إيجابية براها مؤيدوها أنها تمثل مزايا هامة عند تطبيق المراجعة المشتركة .

\section{اولاً : - الجوانب السلبية لتطبيق المراجعة المشتركة :}

يرى معارضو تطبيق المراجعة المشتركة أن هناك مجموعة من السلبيات التي قد تتتج عند اتباع المراجعة المشتركة ، ومن بين هذه السلبيات:-

1- قد يُؤدى تطبيق المراجعة المشتركة إلى ارتفاع تكاليف الإثراف والتتظيم خلال اداء

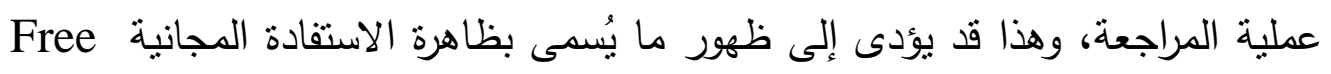

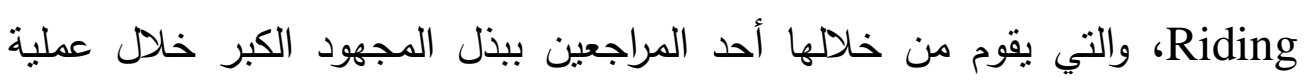

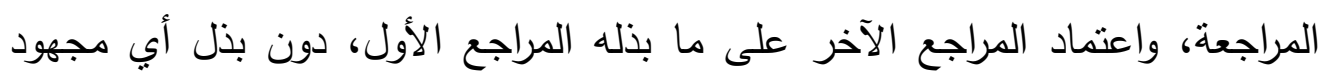

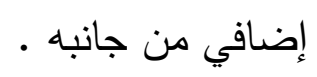

r- هنالك آراء نرى أن تطبيق المراجع المشتركة قد يُؤدي إلى نثأة صراع بين مكتبى الئى

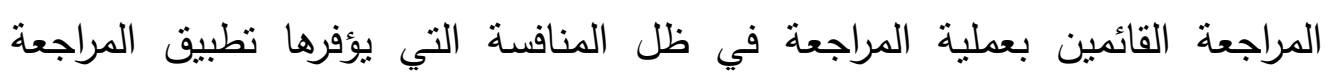

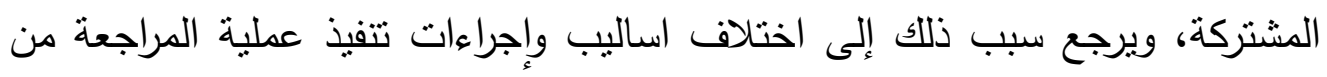

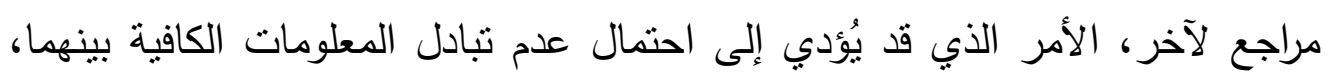

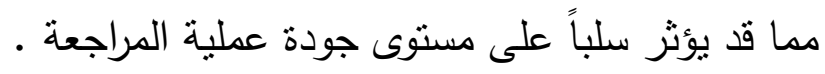

Opinion بـ يؤدى تطبيق المراجعة المشتركة إلى ظهور ما يُسمى بظاهرة تسوق الرأي

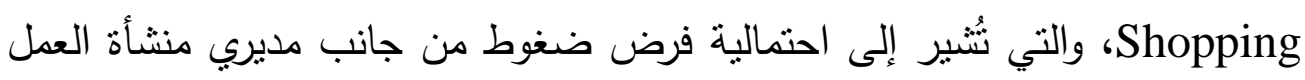

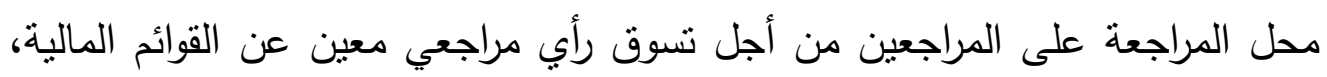


مما يؤدي إلى تهديد عنصر الاستقلالية الذي يعتبره كثير من الباحثثن أنه جوهر جودة عملية المراجعة .

ع - قد تؤدي المراجعة المشتركة إلى جعل عملية المراجعة أكثر تعقيداً بالاضافة إلى وجود

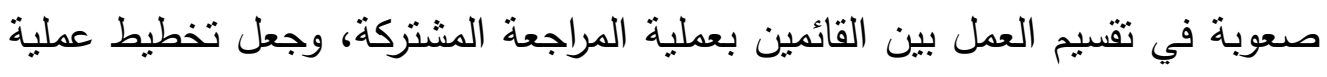

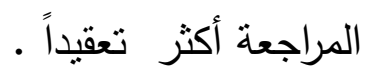

ه- قد يُؤدى تطبيق المراجع المشتركة إلى زيادة في نكاليف عملية المراجعة على العميل محل المراجعة .

4- جد يؤدي تطبيق المراجعة المشتركة إلى زيادة فترة تأخر إصدار تقرير المراجعة Report Lag

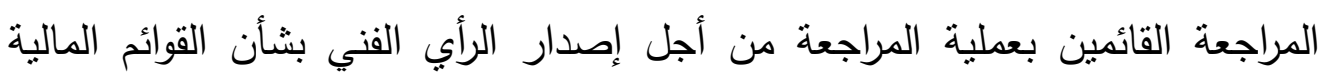

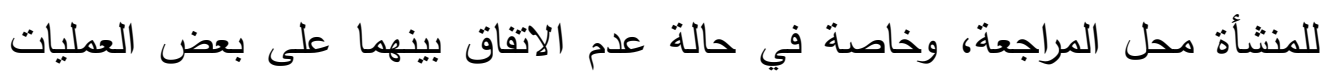

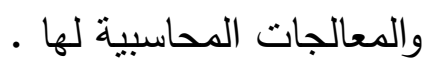

\section{ثانياً : - الجواتب الإيجابية لتطبيق المراجعة المشتركة}

على الرغم من وجود بعض الجوانب السلبية التى يراها معارضوا تطبيق المراجعة

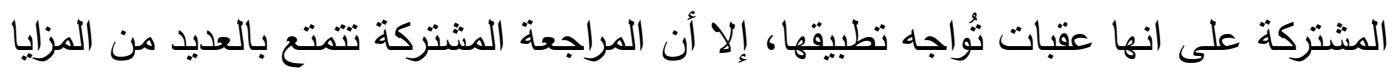
يُمكن توضيحها كالآتى : -

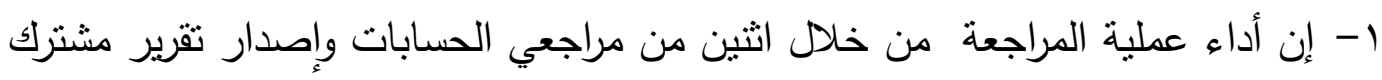

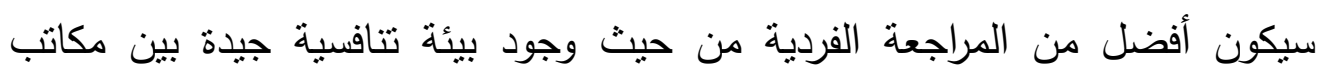

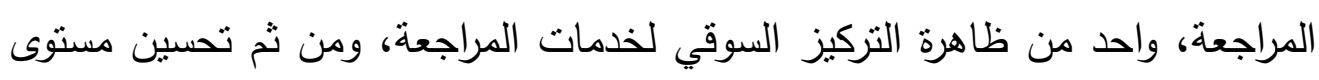

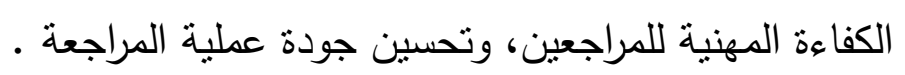

r- تُساهم المراجعة المشتركة في تتوع خبرات المراجعين والاستفادة منها، وذلك نظراً لأطلاع كل منهم على الاساليب المنطورة في المراجعة نتيجة للمنافسة المهنية التى فئي

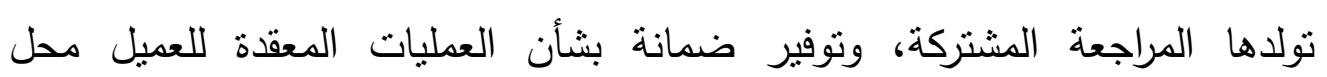
المراجعة، الأمر الذب سينعكس على جودة المراجعة بالإيجاب . 
r- قد تُحقق المراجعة المشتركة التوازن في تقسيم العمل بين القائمين بعملية المراجعة ولكن

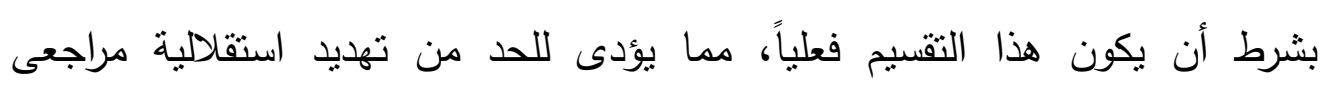
الحسابات.

ع- أن المراجعة المشتركة تُحسن من استقالية مراجع الحسابات مقارنة بالمراجعة الفردية،

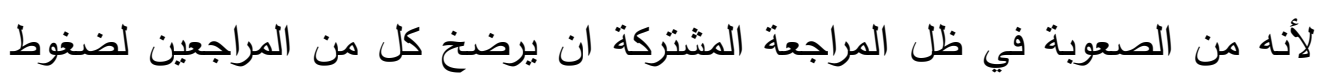

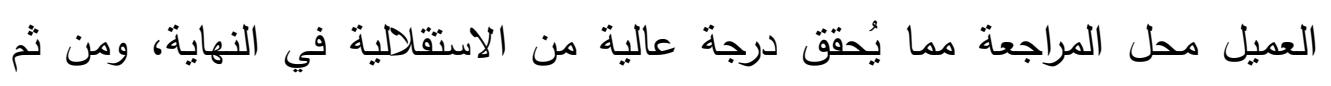
تحسين جودة المراجعة .

0- المشاركة في المسؤولية القانونية التضامنية لنتائج عملية المراجعة ونقرير المراجعة المشترك تؤدي إلى وجود يقظة من جانب كل طرف لمقاومة أي تدخلات من شأنها تهديد استقلاله .

1- تطبيق المراجعة المشتركة يوفر في حد ذاته ميزة هامة عند القيام بمراجعة بعض فل

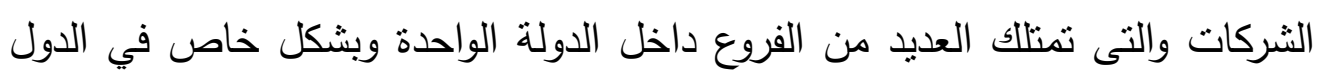

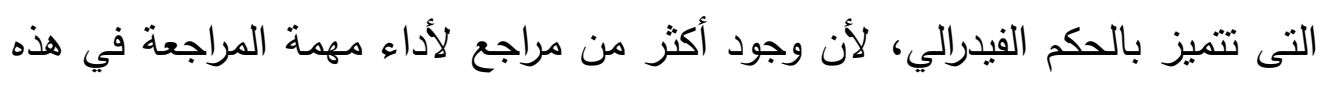

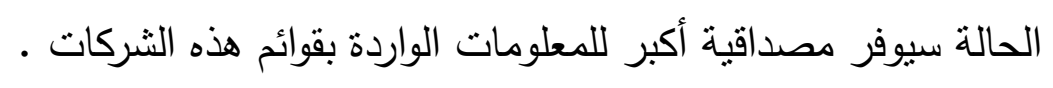

V - نُساهم المراجعة المشتركة في التخفيف من فقدان المعرفة بالعميل محل المراجعة عند

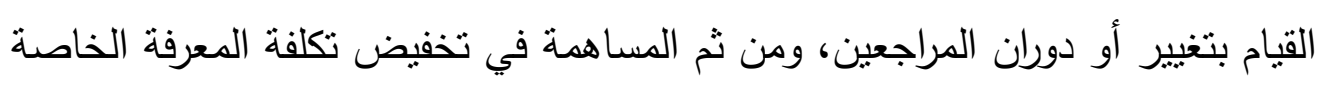

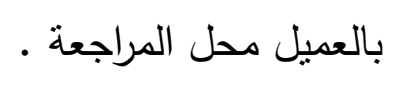

1- تُساعد المراجعة المشتركة على عدم مضاعفة مهام المراجعة، وبالتالي تفادي أي

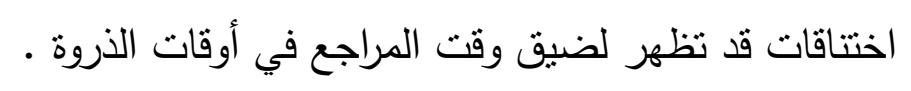

9- إن تطبيق المراجعة المشتركة لا يعنى بالضرورة تضاعف تكاليف المراجعة، لأن هذه

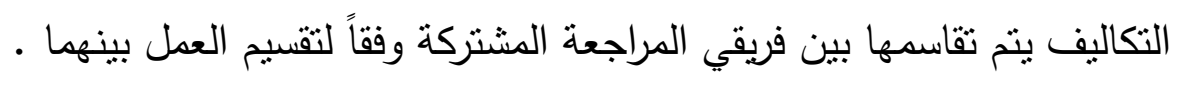

• 1- يوفر تطبيق المراجعة المشتركة ميزه هامة وهى قيام كل مراجع بالتحقق المتبادل من

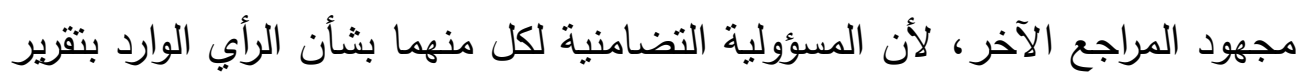

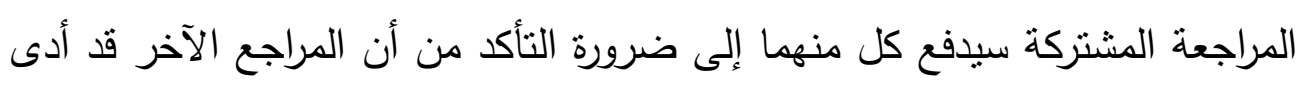


المهام المُكلف بها باعلى مستوى مُكن من الجودة، مما سينعكس على جودة عملية

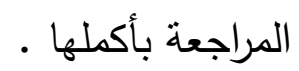

1/V

يقصد بخطوات المراجعة المشتركة تلك الأجراءات التى يجب على المراجعين

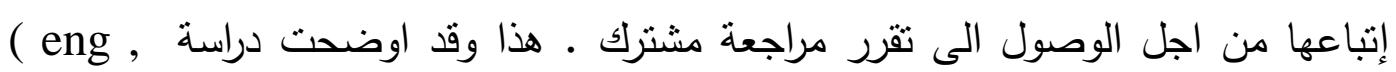
M.,T Simunic 2013)

أن خطوات المراجعه المشتركه تختلف عن خطوات المراجعة الفردية ولقد لخصتها فيما يلي:

1- بعد قبول عمليه المراجعة يتقق المكتبان على تقسيم العمل فيما بينهما، يأتي هذا في

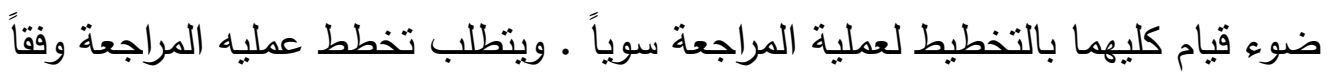

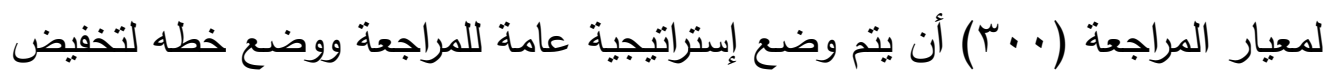
خطر المراجعة حيث ينم اعمال المراجعة بين فريقي المراجعة المشتركة، وقد يتم تقسيم

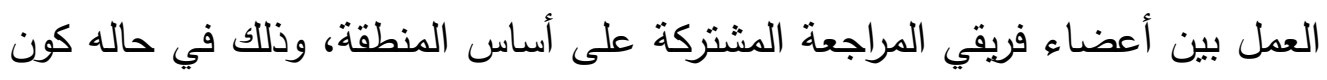

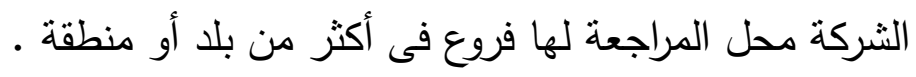

ץ- بعد توزيع العمل يبدأ المكتبان بمراجعه القوائم المالية فى وقت واحد، حيث يقوم كل

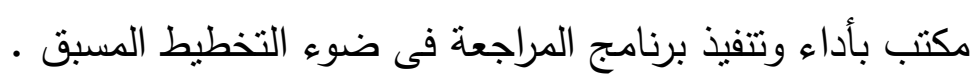

ب- بعد انتهاء كل مكتب من مراجعة الجزء المكلف به، تم مراجعة أعمال بعضهما البعض البه

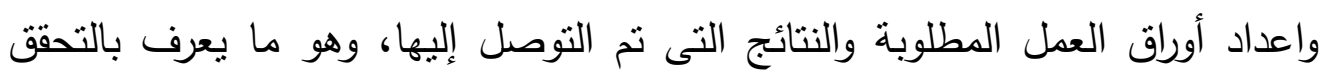

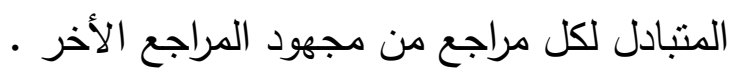

ع - في نهاية عمليه المراجعة وقع المكتبان على تقرير المراجعه المشتركة، حيث تحمل كل

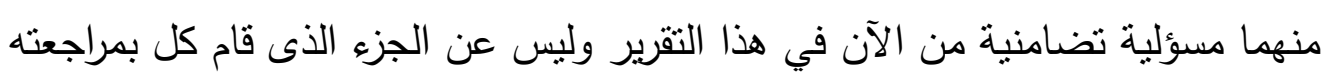
فقط . 
أوضحت دراسة ( احمد زكى با بـ ) أن كل مكتب من مكاتب المراجعة يكون

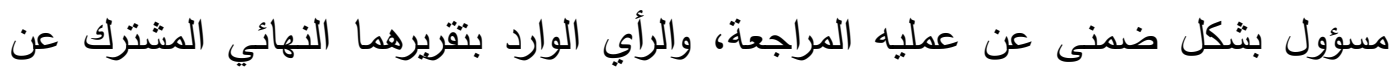

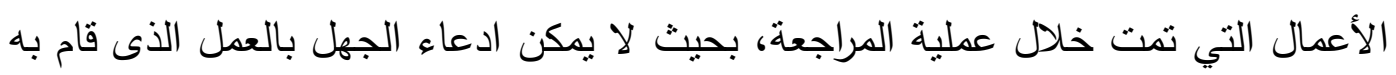
إحداهما، ويجب على كل مكتب هنهما أن يتاكد من أن عملية المراجعة قد تم أداؤها وفقاً لمعايير المراجعة، وأن أدلة المراجعة التى حصل عليها كل كل منهها كانت كافية وملائمه

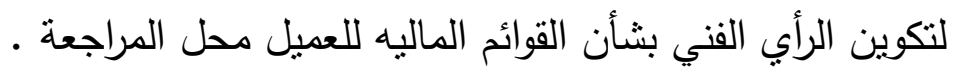

كما أكلت دراسة ( Andre ., P ,Broye 2013 ) أن نوثيق أعمال المراجعة المشتركة يكون أكثر كفاءه وفاعلية في تحقيق جوده عملية المراجعة، حيث يجب أن أن ينت

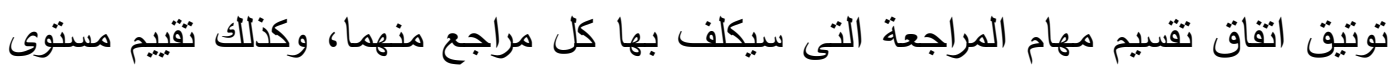

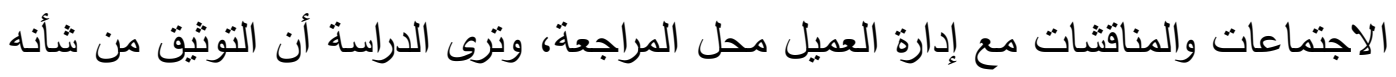

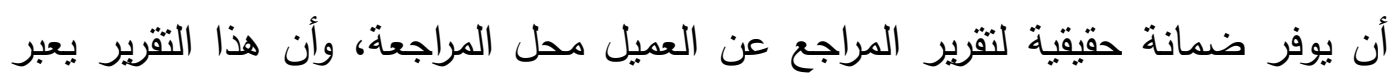
بصدق عن حقيقه القوائم المالية للعميل محل المراجعة .

وترى الباحثة أن كلاً من التخطيط لعملية المراجعة المشتركة وكذلك توثيق أعمالها سوف يكون له دوراً ايجابيا في إتمام ونجاح عمليه المراجعة المشتركة بالثكل الصحيح وكذلك قيام كل فريق بمراجعة أعمال الفريق الآخر من دوره خفض درجة دونة الخطر لدرجة كبيرة مما يؤدى الى عمل تقرير مراجعه مشتركة خالي من الأخطاء الجوهرية وإظهار المركز

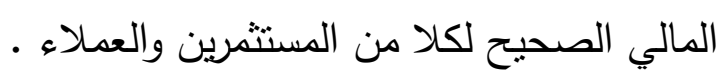

1/1 - اهداف وإهيه المراجعه المشتركه :

لقد واجهت مهنة المراجعة ضغوطاً متزايدة ومستمرة بسبب وجود حالات غش وتش وتحريف القوائم المالية، وتزايد الدعاوى القضائيه المرفوعة ضد المراجعين، وكذلك الأزمات

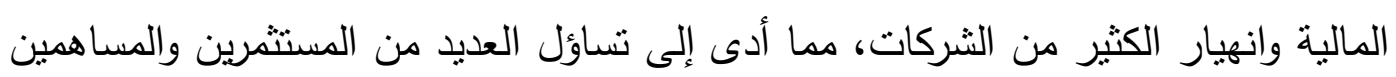

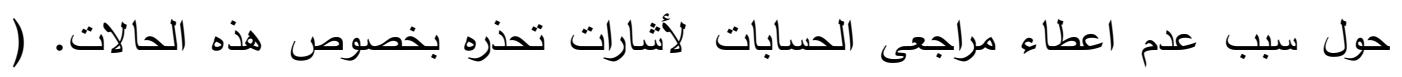

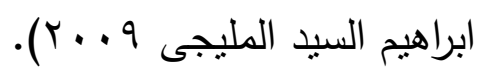


ووجد العديد من الأسباب التي دفعت العديد من الجهات والمنظمات وأيضاً الباحثين للعمل

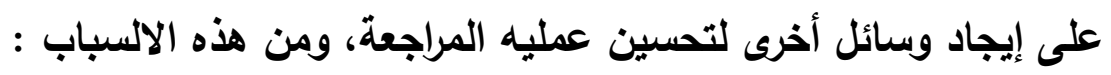
1- العمل على تعزيز إمكانية اكتثاف المخالفات والأخطاء الموجودة في القوائم المالية

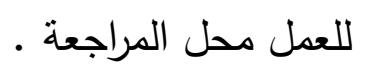

$$
\begin{aligned}
& \text { r- المساهمة في تضييق فجوة التوقعات في الأداء . } \\
& \text { r- الحد من عدم تمانل المعلومات . }
\end{aligned}
$$

ع - العمل على زيادة وتحسين مستوى جودة معلومات القوائم المالية، واستعادة تقة متخذي

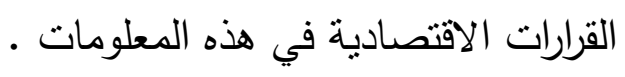

ومن هذه الوسائل المقترحة التي تساهم في تحسين جودة عمليه المراجعة هي

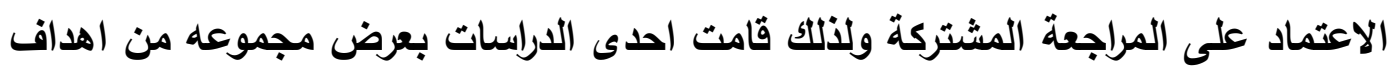
تطبيق المراجعه المشتركه Signapore 2015, p.3)

• تعميق الحصول على التأكيد المعقول حول ما إذا كانت القوائم المالية ككل خاليه من

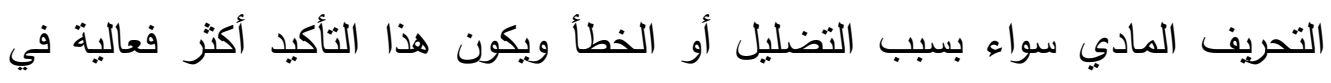

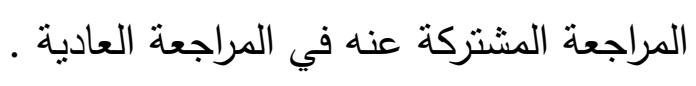
• زيادة فاعليه مناطق التتسيق والتعاون والتخطيط لعملية المراجعة من خلال شركات

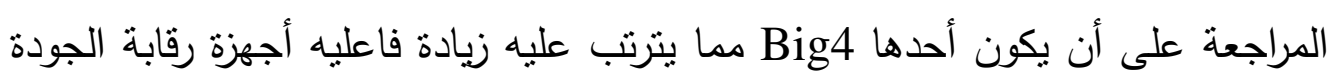

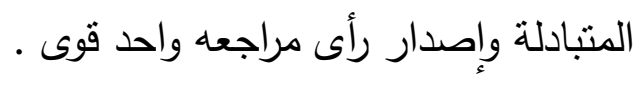
• استخدام نقاط القوة الدحددة وخبرة أعضاء الفريق ) خبراء التقسيم الاقتصادي أو خبراء

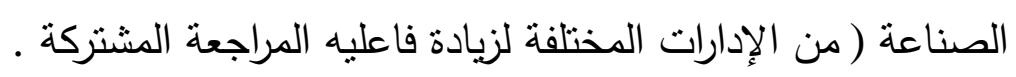
تعزيز استقاليه المراجع الخارجي وتحقيق مستوى مرتفع من جودة عمليه المراجعة عن

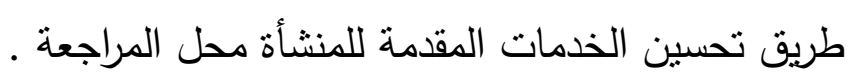


تقديم مراجعه مشتركة بجها مشترك مع تحمل مسئولية مشتركة .

تطبيق أفضل لإجراءات المراجعة مع الاستعانة بخبرة مشتركة في الاعتماد على معايير

مراجعه مقبولة النطبيق (Sophie Audousset \& Coulier 2012)

ومن الضروري وجود جوانب اتصال بين أطراف المراجعة المشتركة وإنما لابد أن تكون في إطار زمني ملائم وأن تشمل على :

• • المتطلبات الأخلاقية ومقتضيات الاستقلالية

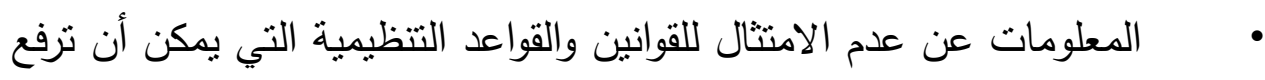
من مستوى التحريف المادي في القواسم المالية .

• دراسة مؤشرات الإدارة المحتملة مع عرض للثغرات في هيكل نظم الرقابة

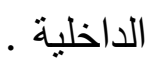

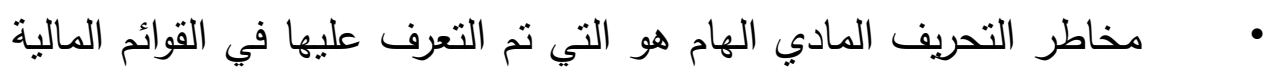
الناتجة من أحد أطراف عمليه المراجعة .

• إلمام المراجعين المشتركين بالقضايا التي تم مناقتنها مع الإدارة ومسئولي

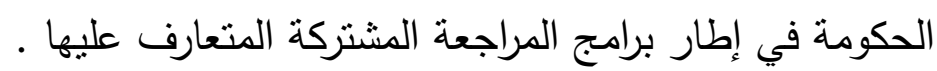

• أن كل الاجتماعات الهامة والجوهرية التي تتنمل على اجتماعات التخطيط

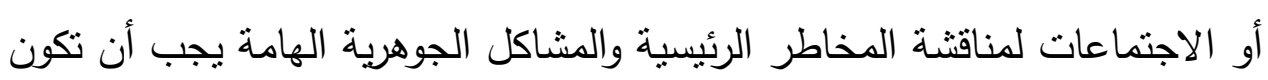

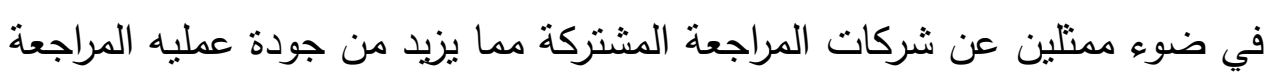

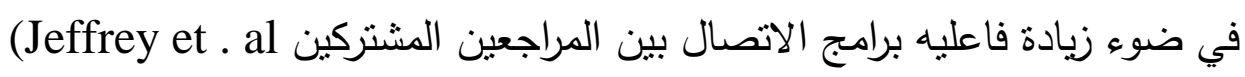

تعتبر المسؤلية تضامنية عن الأخطاء الماديه التى لم ينم اكتثافها والتقرر عنها، وعن

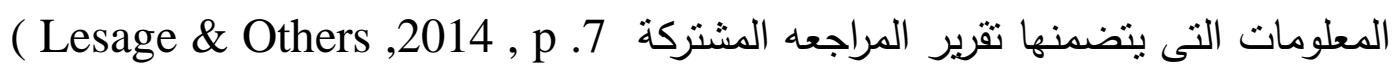
كما لاحظ ان مسئولية مكتب المراجعة لا تتوقف على حجم الأعمال

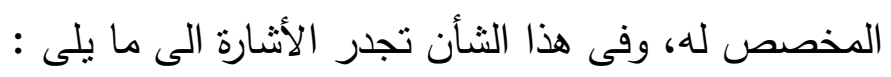


1 - تفيد المسئولية التضامنية في حرص كل مكتب من مكتبي المراجعة القائمين بالمراجعة

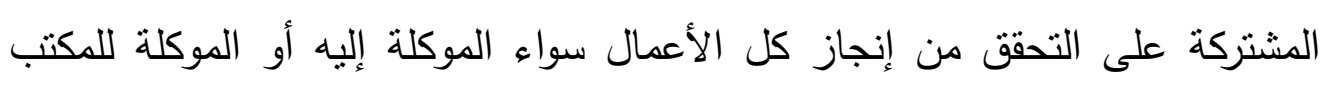

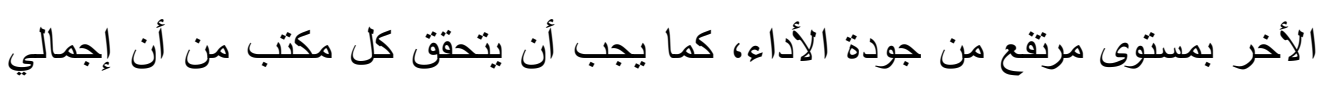

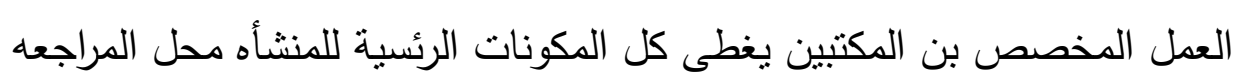
(Institute of Certified Public Accountants of Signapore) 2015 p5 r- يجب أن تقترن المسئولية التضامنيه بمسئولية مكتب المراجعة عن الجزء المخصص له

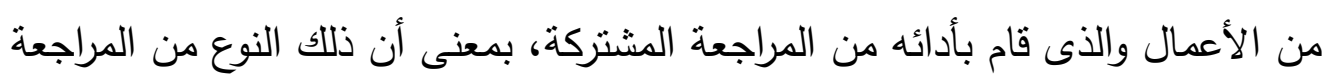

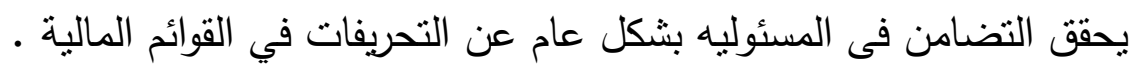

r- حتى تكون المسئولية التضامنية أكثر تأثيرها ايجابيا على جودة المراجعة فأنه يجب أن

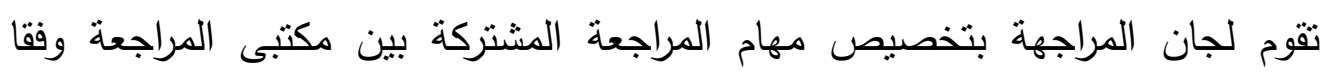

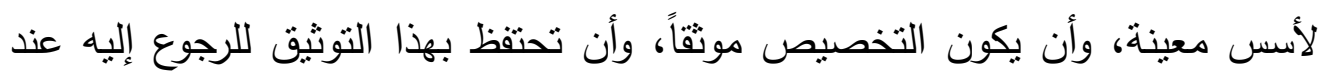
الحاجة مثل حالة القضايا المرفوعة ضد مكتبي المراجعة .

وعن الأدوار والمسئوليات في عمليات المراجعة المشتركة ترى الباحثة أن شركات

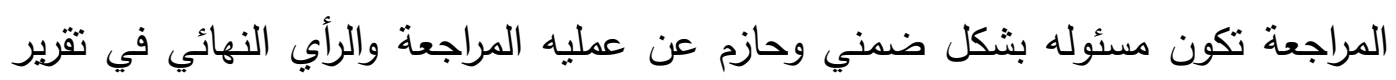

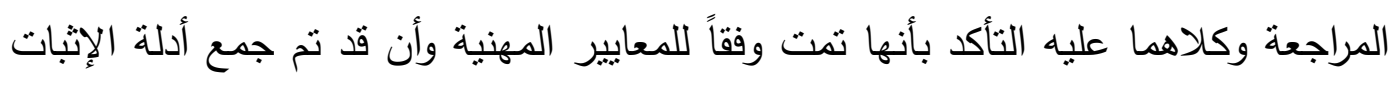

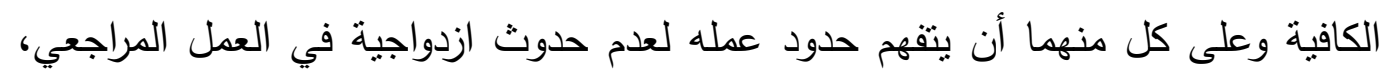

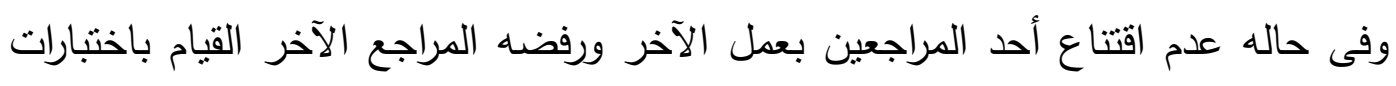

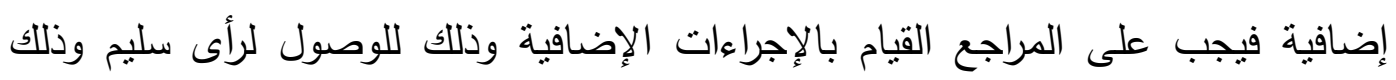

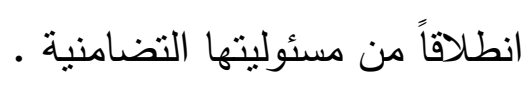
تحقق المراجعة المشتركة كآلية مجموعه من المزايا، وأهمها : 1- يحقق قيام أكثر من مراجع التوازن في تقسيم العمل بينهم خطه المراجعة، والعطليات والثقارير ، بشرط أن يكون الثقسيم فعلياً . 
r- تتوع خبرات المراجعين والاستفادة منها لاطلاعهم على الأساليب المتطورة في المراجعة

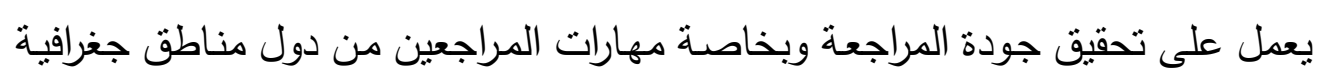
مختلفة، والتي تعد هامة في مراجعه عملاء مختلفون .

r- يساعد عمق المناقثنة في الأمور الجوهرية بين المراجعين المشتركين في التغلب على التى

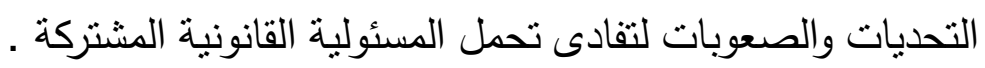

ع - لا مضاعفة مهام المراجعة بشكل تام مما يمكن من تفادى الاختتاقات الناتجة عن ضيق

$$
\text { وقت المراجع في أوقات الذروة . }
$$

○ـ يتم خفض تكاليف الخبرة الضائعة الناتجة من التدوير الإلزامي للمراجعين وخفض تكاليف المراجعة. 7- الحد من إعادة صياغة القوائم المالية وتحقيق جودة التقرير المالي مع زيادة دقه تقرير المراجعة وسرعه الاستجابة للآراء المعدلة في التقرير .

V- زيادة المسئولية القانونية والأخلاقية للمراجعة الخارجية المشتركة عن نتائج عمليه

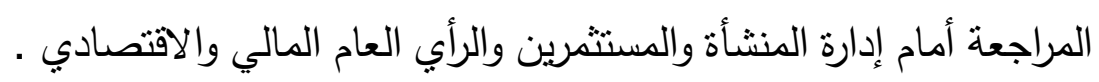
^- تعزيز استقلال المراجعة الخارجية المشتركة الأمر الذب يكسب الثركات القائمة بهذه

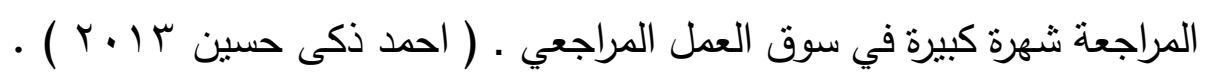

\section{مفهوم جودة عملية المراجعة :}

تتاولت العديد من الدراسات المحاسبية وضع مفهوم لجودة مراجعة القوائم المالية من

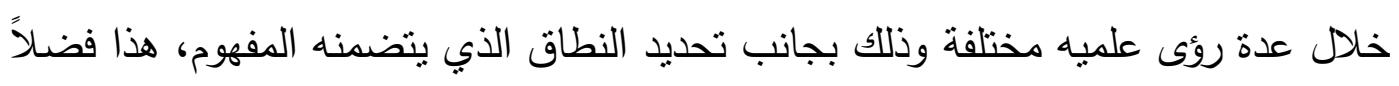
عن الكثير من الجهود البحثية التي تهدف لقياس الجودة في واقع الممارسة العملية لمهنة المراجعة .

وقبل التطرق إلى معنى الجودة اصطلاحاً نتطرق إلى المعنى اللغوي والذي يثير

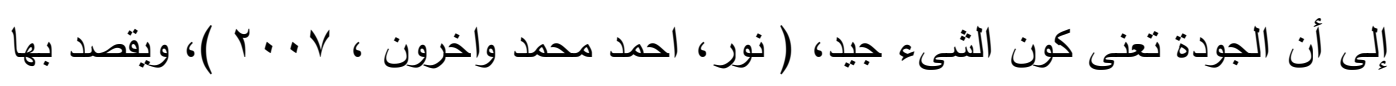


ايضا درجه الامتياز او التفوق التى يمتلكها شىء ما او منتج ما او بمعنى اخر درجه المطابقه مع المعايير الموضوعه . webster third new international dictionary )

وباستقراء الدراسات المحاسبية التي تتاولت وضع مفهوم للجودة يمكن القول بأنه دن الصعوبة بمكان وضع مفهوم محدد وذلك لاختلاف الرؤية التي يتم بها تتاول المفهوم، والتي تختلف باختلاف أصحابها وهم الأطراف المرتبطة بالمراجعة ( نور ، احمد محمد وآخرون

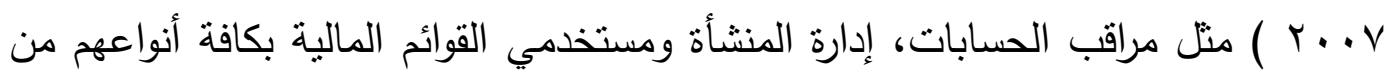
ملاك مقرضين وجهات رقابيه حكوميه .... الخ، حيث لكل طرف من هذه الأطراف رؤيته

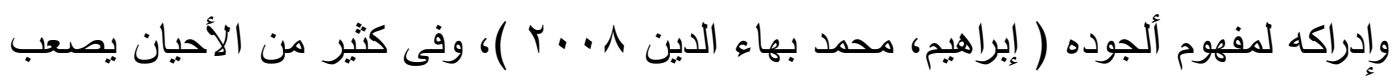

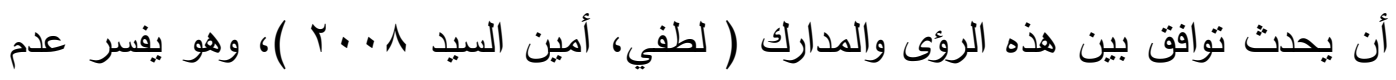
وجود إجماع على تحديد المفهوم سواء على المستوى المهنى أو الاكاديمي ( على، سامي حسن r r... (r)

وتثير بعض الدراسات الى ربط مفهوم جوده مراجعه القوائم الماليه باستقلل واداء مراقب الحسابات، حيث نشير دراسة ( نور V. V. P ) الى أن مفهوم الجودة بعني التزام مراقب الحسابات بالمعايير المهنية وقواعد وآداب السلوك المهني، وأضافت دراسة ) Giroux ,G.,2011) أن المفهوم يشمل أيضاً حرص مراقب الحسابات على دعم وتحسين الممارسات المحاسبيه الجيدة، بينما تؤكد دراسة ( طلبة، على إبراهيم ع 99 1 ) أن مفهوم

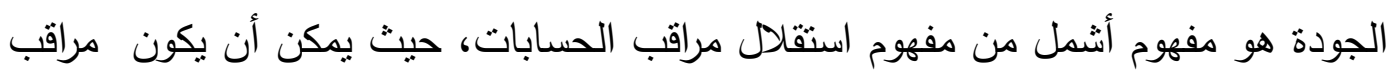

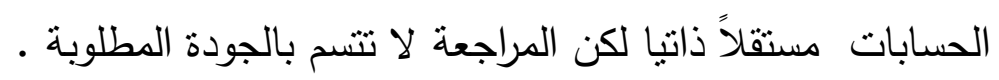

وقد حاولت دراسه ( إسماعيل، طارق حسنين وقطب وآخرون r... ) ) أن تضع مفهوماً يجمع كافة الأطراف المرتبطة بعملية المراجعة حيث نتير جودة مراجعة القوائم المالية إلى ضمان قيام المراقب بعمله بما يحقق للأطراف ذات الصلة مثل مستخدمي القوائم المالية، مكاتب المراجعة، المنظمات المهنية، الأجهزة الرقابية وإدارة المنشآت الأهداف المتوقعة من عمليه المراجعه . 
وترى الباحثة أن مفهوم جودة مراجعة القوائم المالية يتطلب وجود تكامل بين عدة

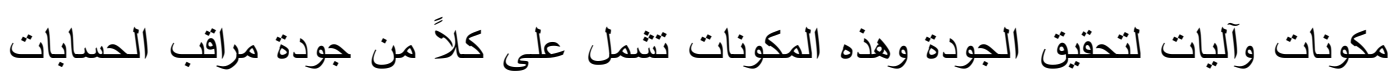
وجوده أداء إدارة مكتب المراجعة وهذه المكونات تعمل معاً للارتقاء بمستوى جودة الجنات القودائم المالية .

ويؤكد المفهوم على تبني رؤية مفادها أن الجودة تؤخذ من صانعيها وليس من عملائها أو المستقيدين منها وذلك لتتوع واختلاف مدارك وأهداف المستقيدين من تحقيق الجودة .

r/ اثر المراجعة المشتركة على جودة عملية مراجعة القوائم المالية :

في الآونة الأخير أثثرت الكثير من الثكوك فى مهنة المراجعة ـ وفي جودة أداء

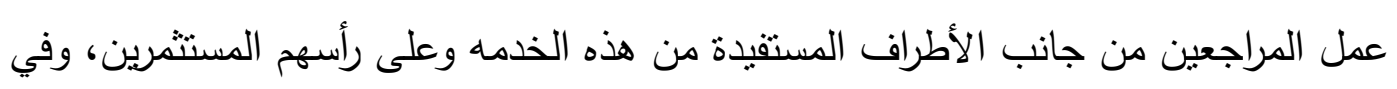

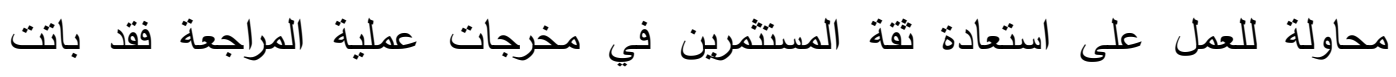
المنظمات المهنية تسعى جاهدة لإيجاد وسائل جديدة من شأنها استعادة هذه الثقة المفقودة،

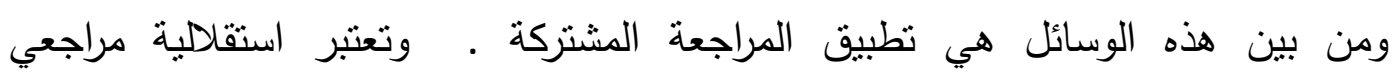

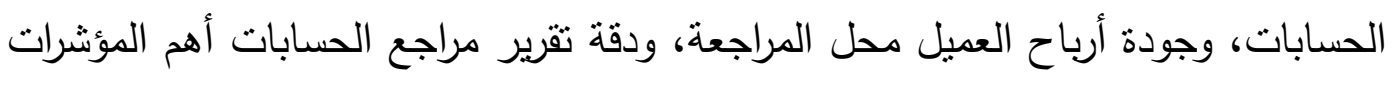

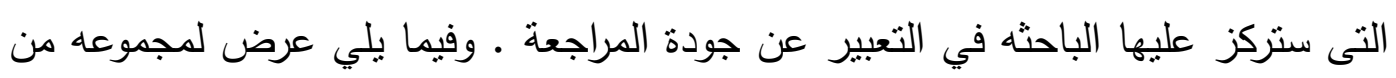

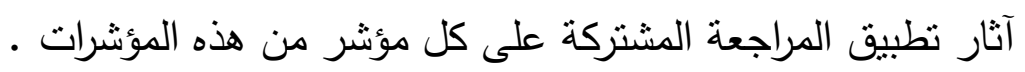

\section{أولاً : من حيث استقلالية مراجع الحسابات :}

لقد أظهرت سلسلة الأزمات المالية الأخيرة أن الحفاظ على استقالية مراجعي

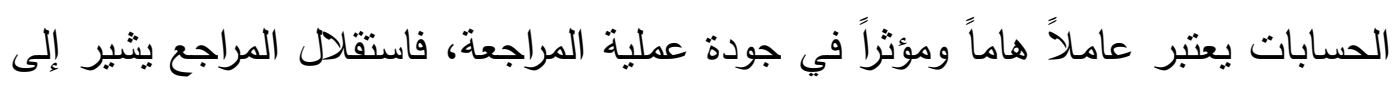

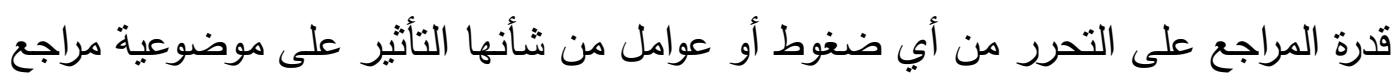

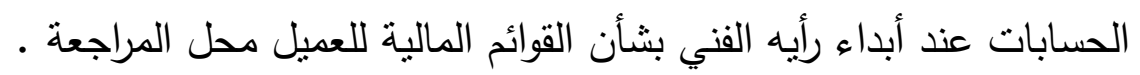

يرى أحد الباحثين ( Piot , C ., op.cit,2007 P.162 ) أن وجود اثثين من

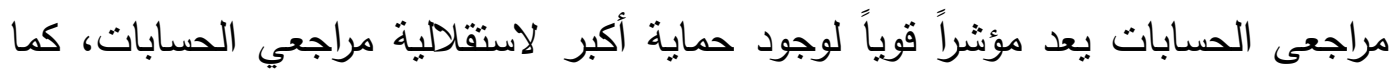

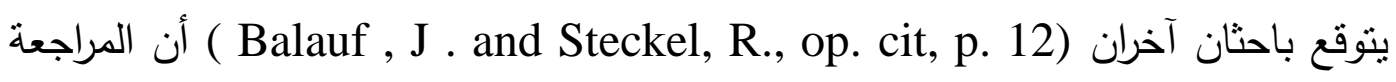


المشتركة تعزز من استقلالية مراجع الحسابات، لأن هذه الآلية من شأنها أعطاء فرصة

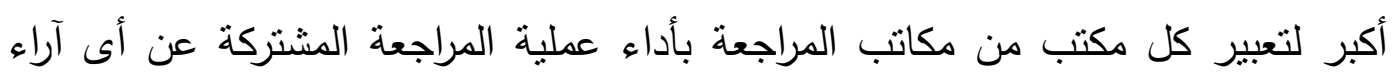

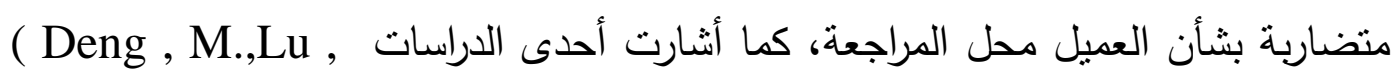
T.,Simunic2013,p.29) الحسابات مقارنة بالمراجعه الفردية .

هذا، وقد أرجع بعض الباحثين Zerni, M., Jarvinen ,T, Niemi 2012,P.33.)

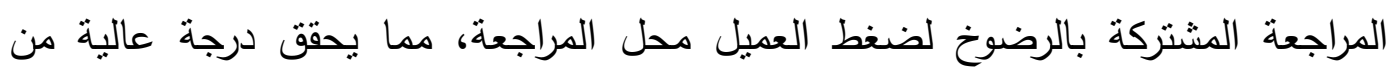

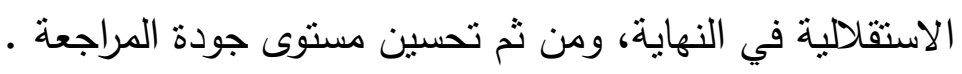

وترى الباحثة أن استخدام المراجعة المشتركة يحد من الضغوط على مراجعي

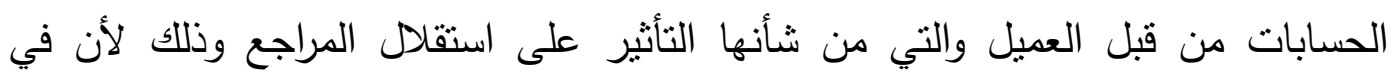

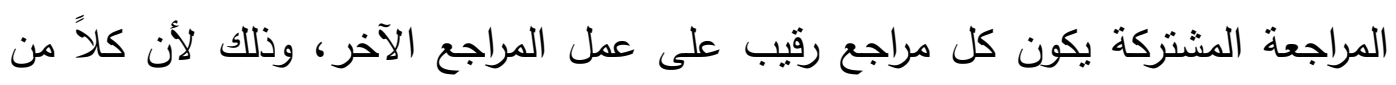

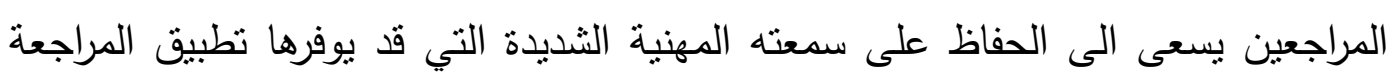

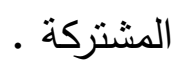

فى المقابل، يرى بعض الباحثن Lobo,G., Paugam, L., Zhang, D. and Casta, J .F. 2013) الأستفادة المجانية ( Free Riing ) والتي يقصد بها " بذل أحد المراجعين للمجهود الأكبر

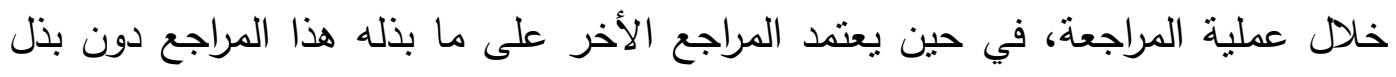

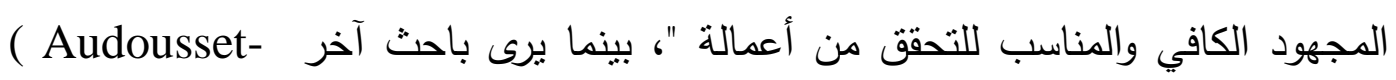

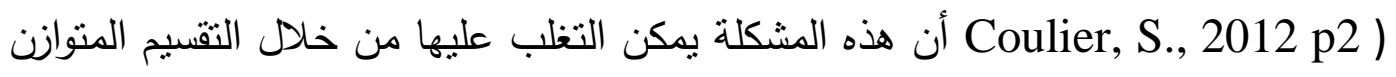

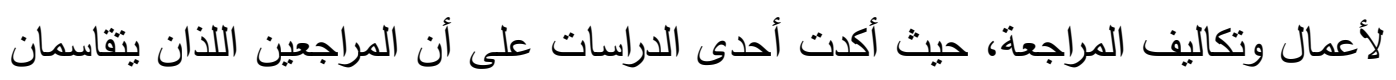

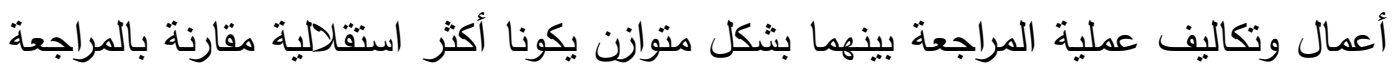
الفردية .

وتختلف الباحثة مع الرأى القائل بأن المراجعة المشتركة سيؤدى الى وجود ما يسمى

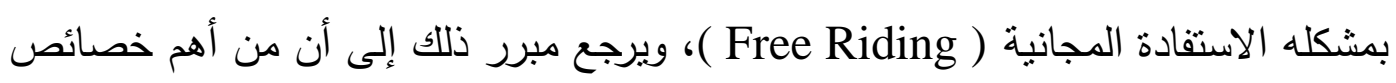


تطبق المراجعة المشتركة هي المسؤولية التضامنية لكل مراجع عن الرأي الوارد بتقرير

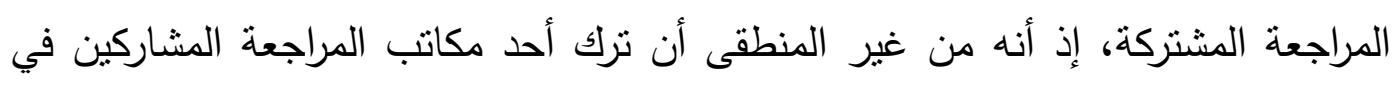

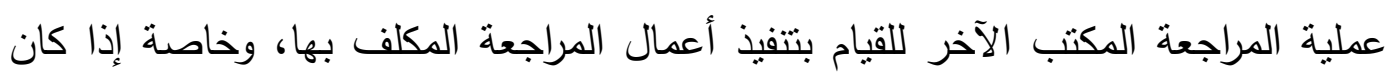

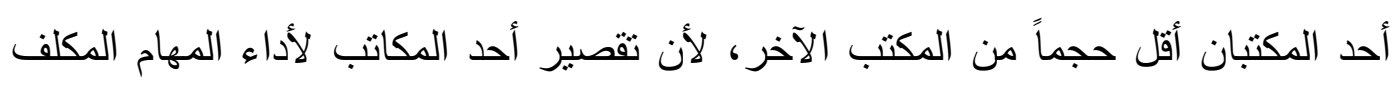

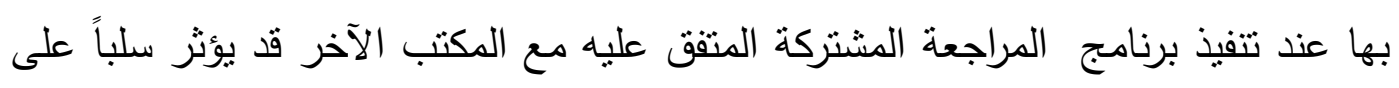

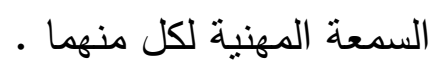

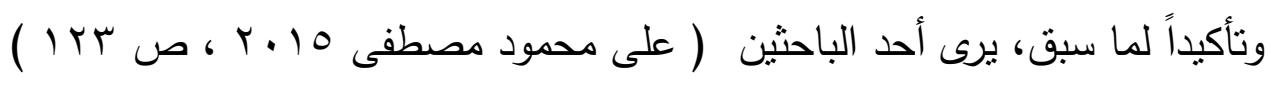

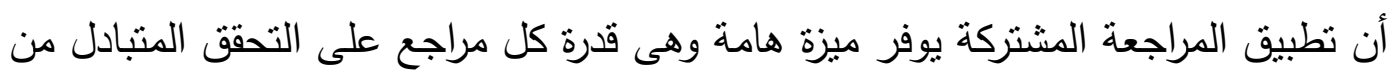

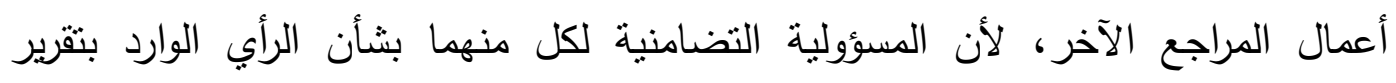

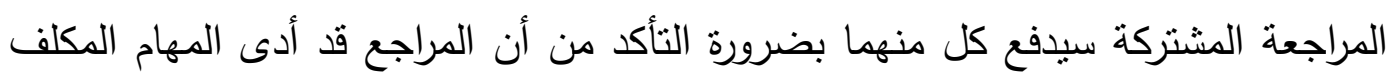
بها بأعلى مستوى مدكن من الجودة .

على جانب آخر، رأى البعض م Francis, J .R., Richard, C., and أن تطبيق المراجعة المشتركة قد ساهم في تعزيز مصداقية مهنة المراجعة في البيئة الفرنسية وذلك لما تقدمه من دور كبير فى الحفاظ على استقلالية

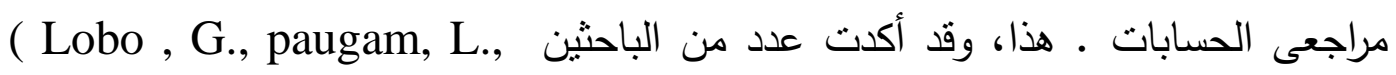
Zhang, D. and Casta .P.5.)

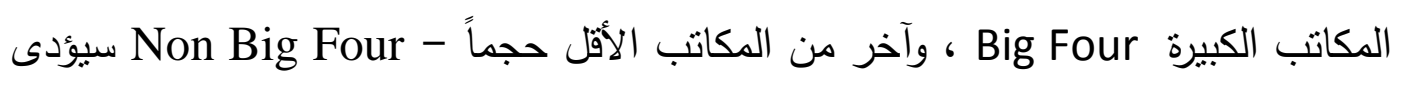

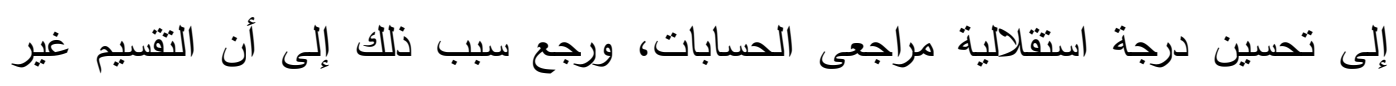
المنساوي للخطر بين المكتب الكبير والمكتب الأقل حجماً منه سيعمل على دعم استقالالية

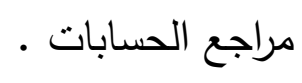

وتأكيداً لهذا الرأي، رأى آخران Ittonen , K. an Tronnes, p. C., 2015)

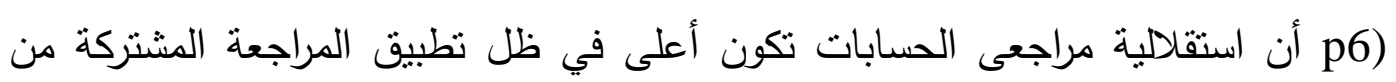

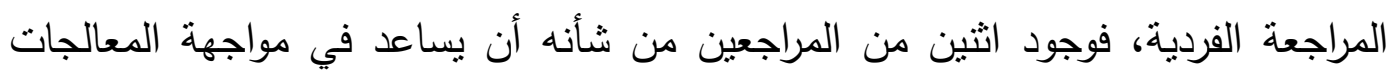

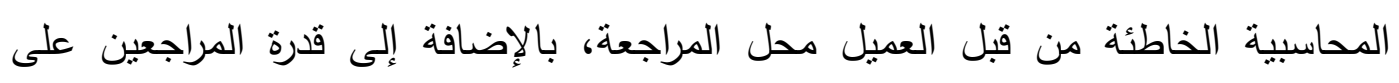

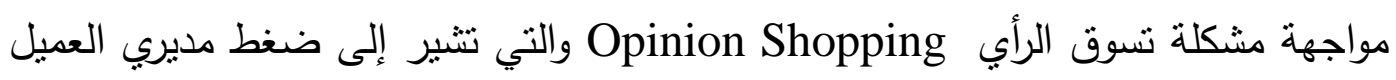

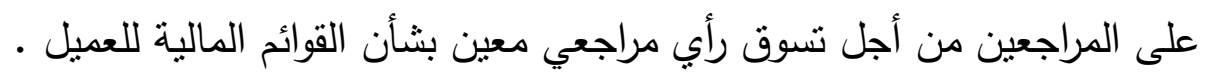


ونظراً لأهمية استقلال المراجع فقد تتاولت العديد من الدراسات بعض من الوسائل

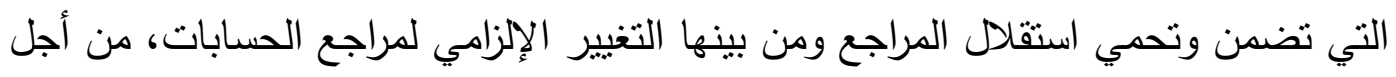

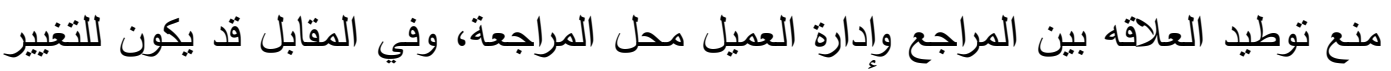

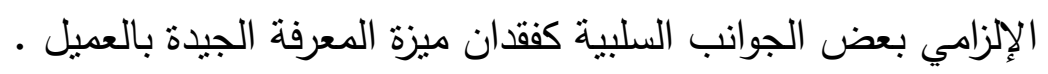

وقد أكدت إحدى الدراسات (P.8. Harris , K., 2012 ) أن تطبيق المراجعة المشتركة من شأنه تخفيف حدة الآثار السلبية للدوران أو التغيير الإلزامي لمراجعي الحسابات

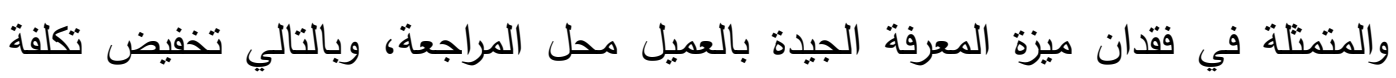

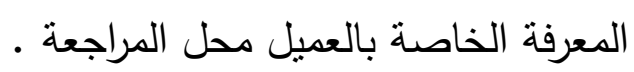

وتتفق الباحثة مع هذه الدراسة بأن التغيير الإلزامي لأحد المراجعين في ظل تطبيق المراجعة المشتركة سيدعم استقلال المراجع، ويعمل في نفس الوقت على تخفيف حدة الآثار

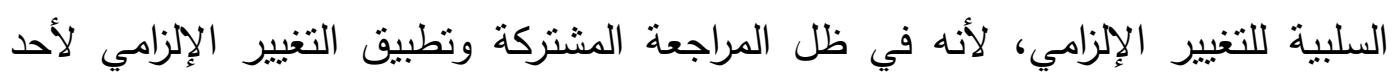

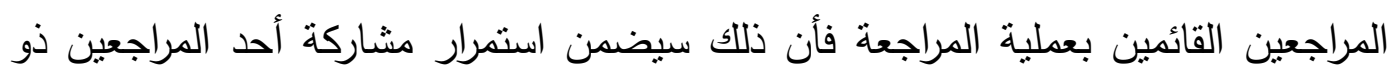

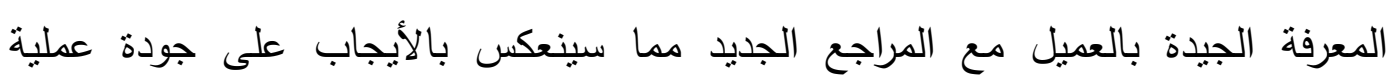
المراجعة.

\section{ثانياً : من حيث جودة ارياح العميل محل المراجعة :}

يقصد بجودة الأرباح Earning Quality بأن الأرباح التي تعلنها الثركة محل

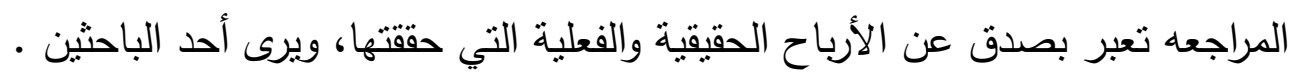

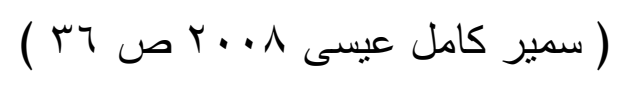

أنه كلما زادت جودة الأرباح كلما كان ذلك مؤشراً على جودة عملية المراجعة، حيث

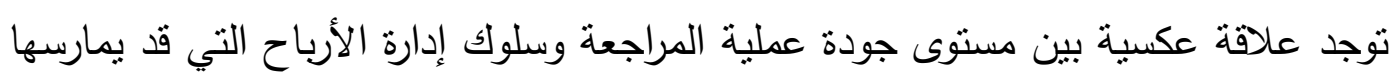

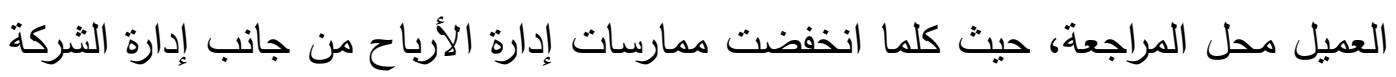

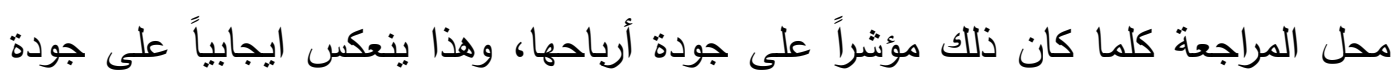

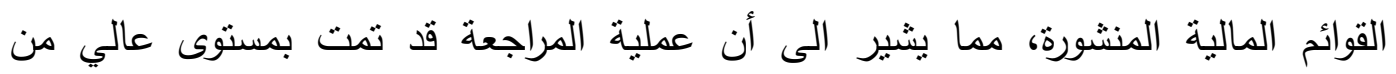

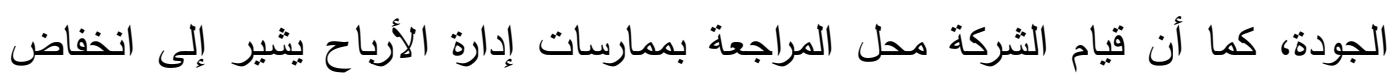
مستوى جودة أرباحها، وهذا ويشير أيضاً إلى انخفاض مستوى جودة عملية المراجعة . 


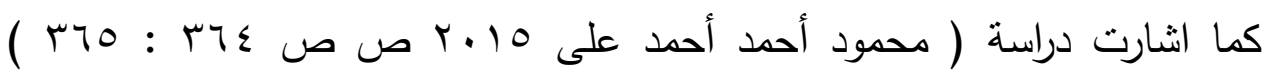
إلى أن الحد من ممارسات إدارة الأرباح من جانب الثركة محل المراجعة يعتبر من أهم

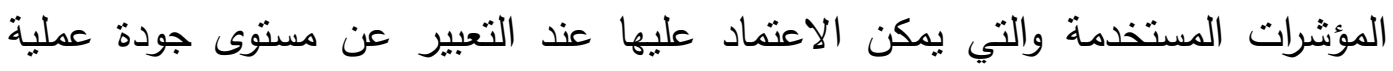
المراجعة .

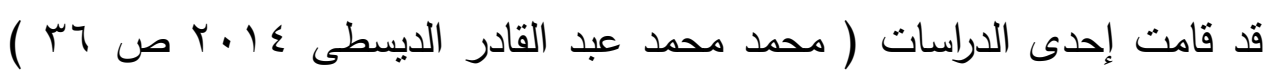
بالتعرف على نأثير تعيين الثركة محل المراجعة لأثثين من مراجعي الحسابات عند أداء

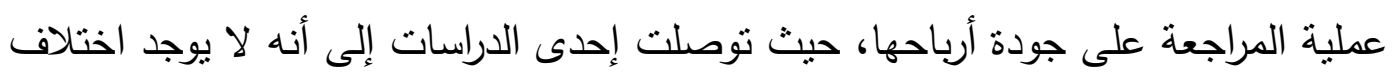

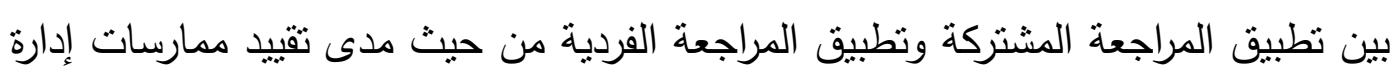
· الأرباح

في المقابل يرى باحثون آخرون Francis , J. R., Richar, C and Vanstraelen .p.58)

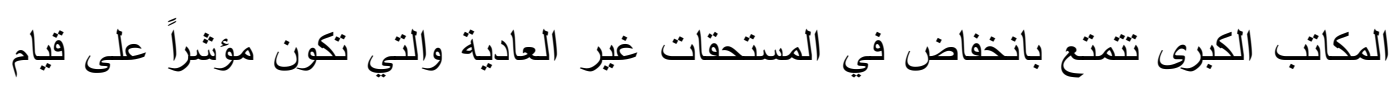

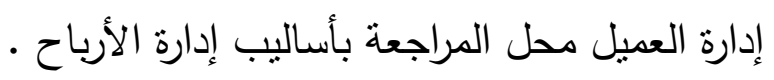

هذا وقد أكدت دراسة أخرى 3.ppodard ,J., piot, C. and Schatt 2012 .pp

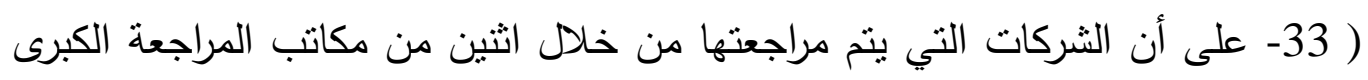
Big Four

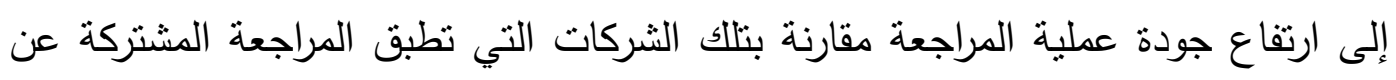

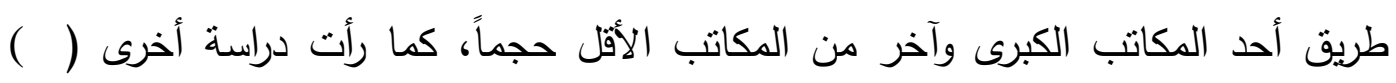
Lobo, G., Paugam, L., Zhang, D. and Casta P. 12

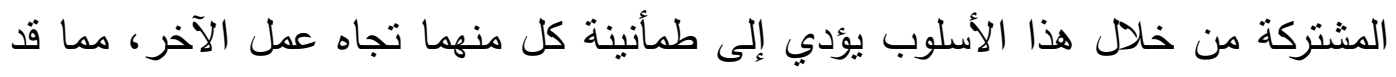

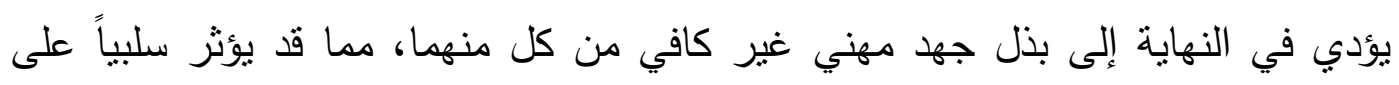
جودة المراجعة .

هذا، وقد رأي باحث آخر ( Chihi,H . andMhirsi ,N.,2013,p.23 ) أن الثركات التى تطبق المراجعة الششتركة من خلال تعيين أحد المكاتب الأربعة الكبار وأحد 
المكاتب الأقل حجماً منها تتتع بأرباح ذات جودة عالية في ضوء انخفاض المستحقات غير العادية لها ـ العال

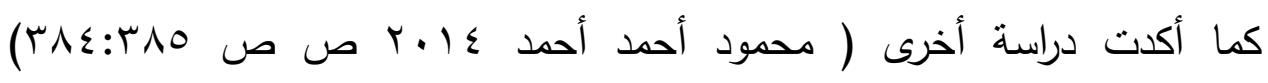
على اختلاف جودة التقارير المالية في ظل تطبيق المراجعة المشتركة مقارنة بالمراجعة

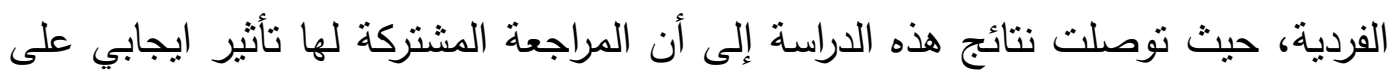

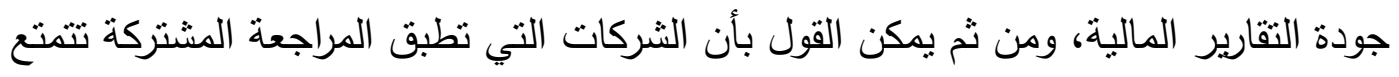

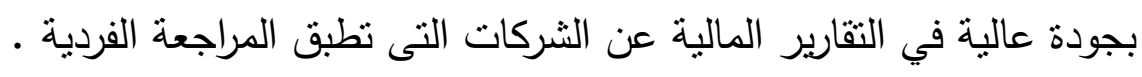

في المقابل يرى باحثان آخران( Velte, P . and Azibi , J2015, P. 549 ) أنه لا نوجد اختلافات في مستويات إدارة الأرباح التي قد تمارسها إدارة الثركة محل المراجعة

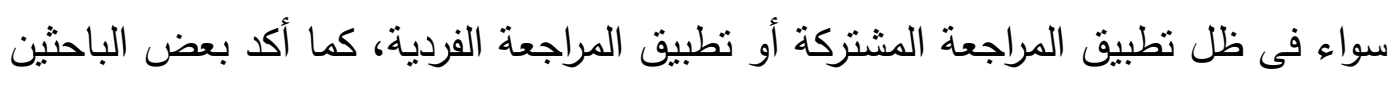
هذا (Lesage C., Ratzinger- Sakel, N. and Kettunen 2012 .pp. 26-27 ) الرأي في دراسة أخرى، حيث توصل الباحثون في هذه الدراسة إلى عدم وجود اختلاف في

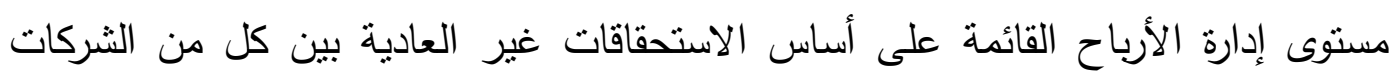

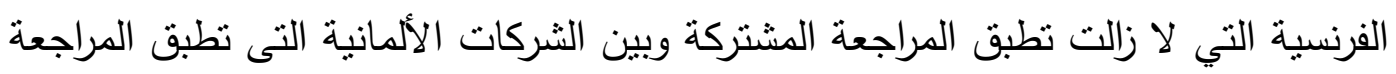
الفردية .

مما سبق، تضح أن هناك بعض الدراسات التي أكدت على وجود علاقة ايجابية بين

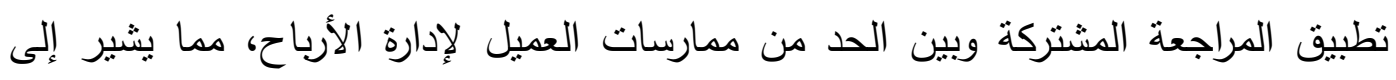

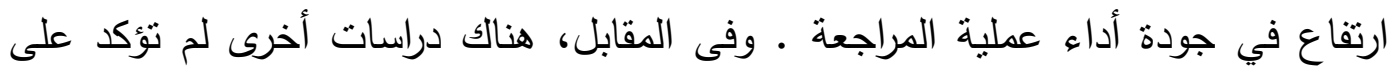

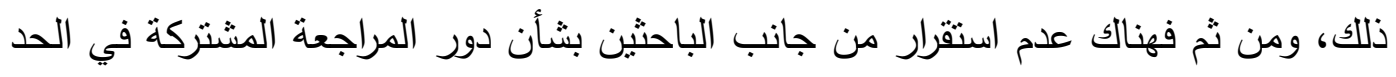

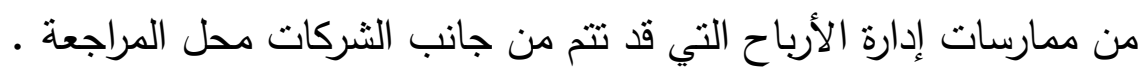

\section{ثالثا: من حيث دقة تقارير مراجع الحسابات وإعادة صياغة القوائم المالية :}

تمنتل الهذف الرئيسي لعملية المراجعة الخارجية في إبداء الرأي الفني بشأن مدى

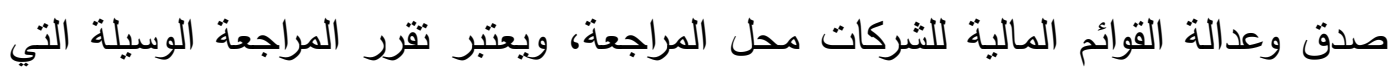

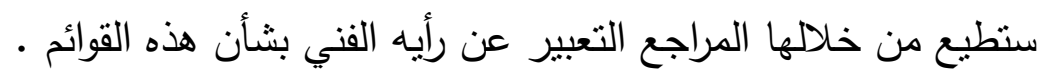


وفى هذا الصدد، فقد ناقثت أحدى الدراسات ( Baldauf , J . an Steckel )

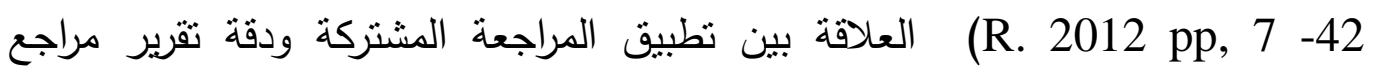

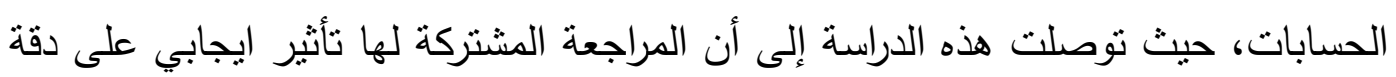

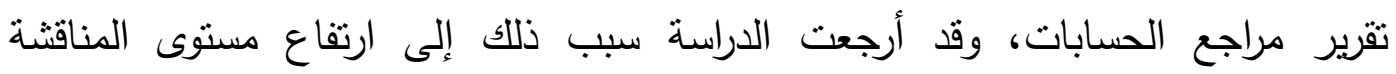

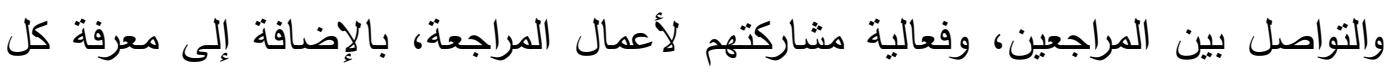

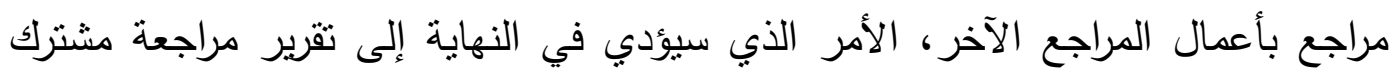

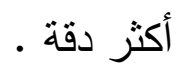

ومن حيث تأثير تطبيق المراجعة المشتركة على جودة تقرير مراجع الحسابات من

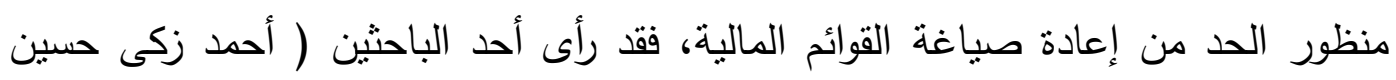

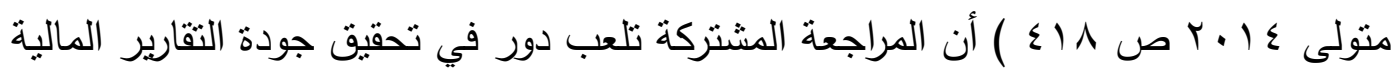

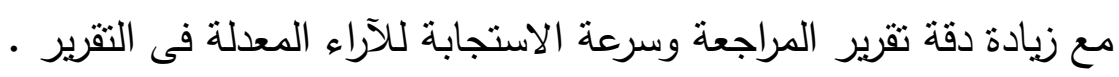
كما تساهم المراجعة المثتركة في الحد من إعادة صياغة القوائم المالية للأسباب التالية

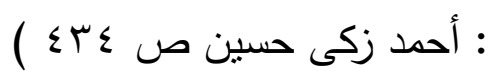

1 - تكلف أكثر من مراجع لأداء عملية المراجعة المشتركة بفحص أنظمة الرقابة الداخلية

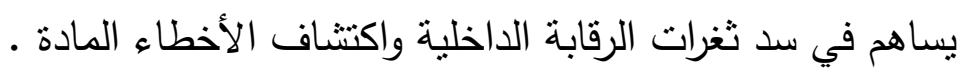

r- التتسيق والتعاون بين فريقي المراجعة المشتركة يحقق الفهم الكافي للأمور الجوهرية

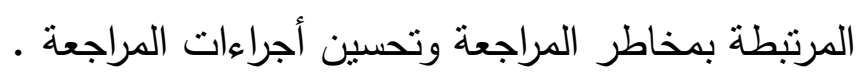

r- كثرة المشاورات بين فريقي المراجعة المشتركة يقلل من احتمال حدوث الأخطاء التي قد

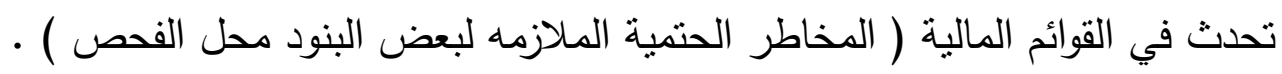

ورأى أحد الباحثين ( Ezat , A . N .M.,op.cit, p.52 ) أن المراجعة المشتركة

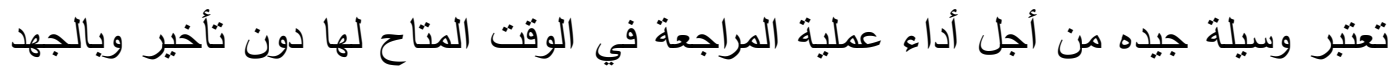

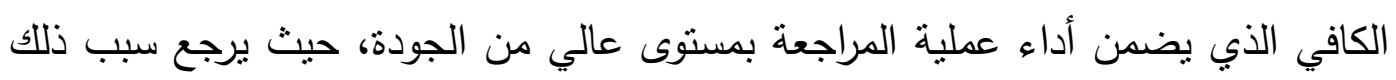

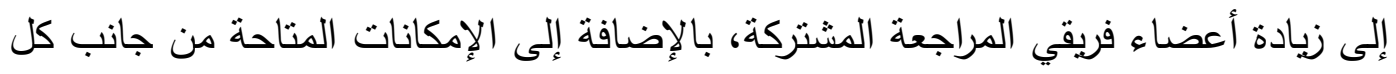


في ضوء ما سبق، فأن المراجعة المشتركة قد نساهم في تخفيض الوقت المستغرق

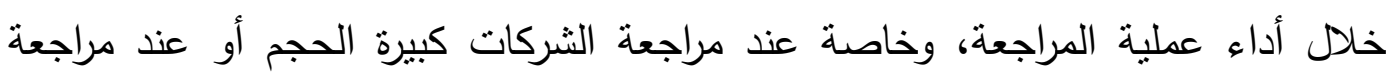
العمليات كبيرة الحجم والمعقدة والتي قد تؤدي إلى زيادة الوقت المستغرق عند أدية أداء عملية

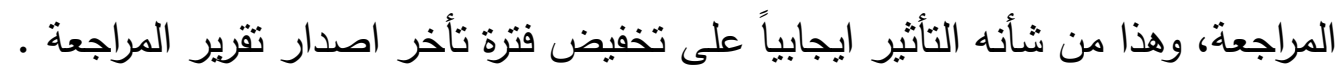
وترى الباحثة أن المسؤولية التضامنية التي توفرها المراجعة المشتركة هي من أهم

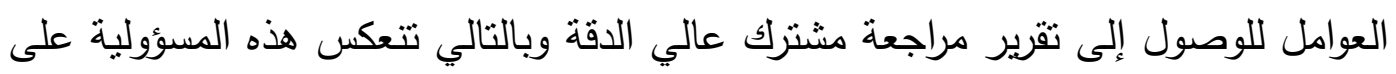

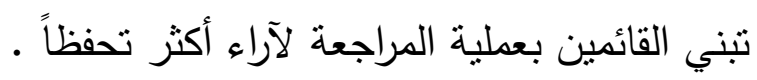

\section{r/Y أهداف تطبيق مدخل المراجعة المشتركة كأسلوب لتحقيق كفاعة وفاعلية}

\section{عملية المراجعة :}

وفى سياق الحديث عن أهداف نطبيق مدخل المراجعة المشتركة، أشارت دراسة كلاً من Sakel , et., al.,(2012); Audousset-Coulir, (2012) إلى أن اللجنة الأوربية قد أوردت العديد من الأهداف التي طمحت إلى تحقيقها من خلال تطبيق عملية المراجعة

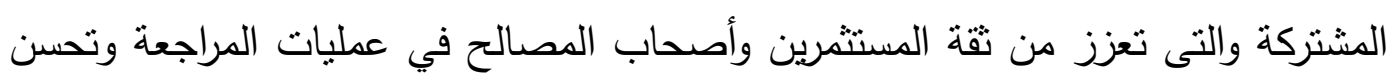
من كفاءة وفاعلية عملية المراجعة، ويمكن تلخيص هذه الأهداف فى النقاط التالية :

1 - الاستفادة من تتوع خبرات أعضاء فريق المراجعة المشتركة واستخدام نقاط القوة لديهر .

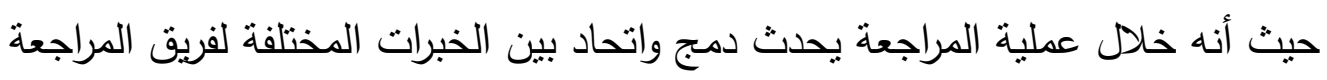

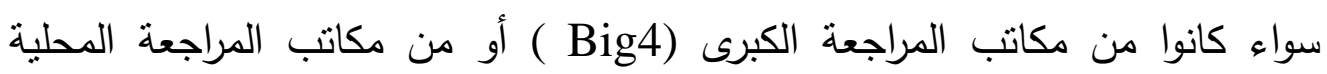

. ( Non Big4)

ץ- الحد من ظاهرة نركز سوق المراجعة خاصة في حالة تتفيذ اقتراح اللجنة الأوربية

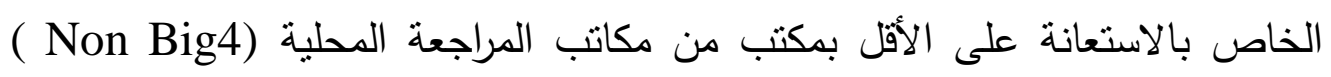
خلال عملية المراجعة المشتركة .

r- دعم وتعزيز استقلالية مراقب الحسابات وضمان مستوى جودة أعلى لعملية المراجعة . 
ع- تطبيق أفضل لإجراءات المراجعة عن طريق الأستعانة بخبرة مشتركة للمراقبين المشاركين فى عملية المراجعة . المراءت

ه- قيام كل مراقب بالتحقق من الأجراءات والأعمال التى قام بها المراقب الآخر مما يضمن

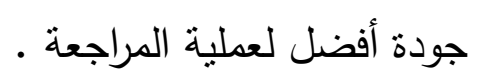

ד- تقيم تقرير مراجعة واحد مشترك يحمل نوقيع المراقبين المشاركين والذي يحملهم مسئولية قانونية وأخلاقية مشتركة عن نتائج عملية المراجعة .

وترى الباحثة أن أهم أهداف المراجعة المشتركة هو تحقيق استفادة لمكاتب المراجعة

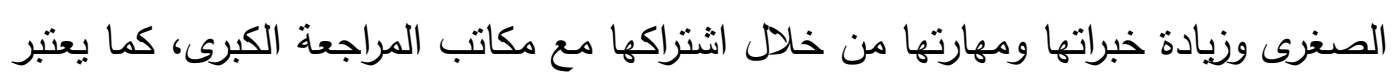
هدف تفعيل آلية العصف الذهني بين فريق المراجعة هدفاً يرجى تحقيقه من تطبيق المراجعة

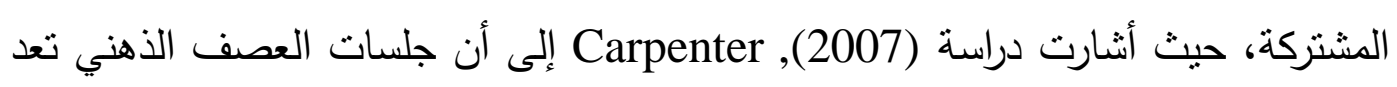

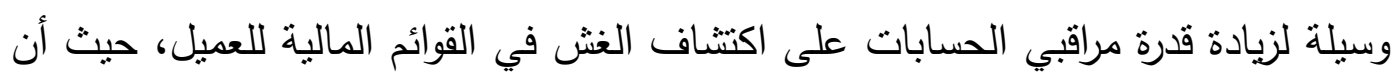

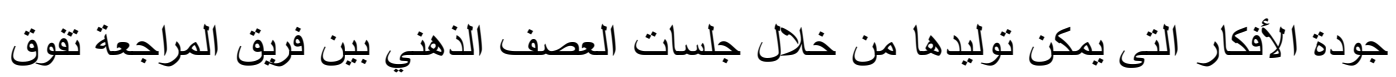

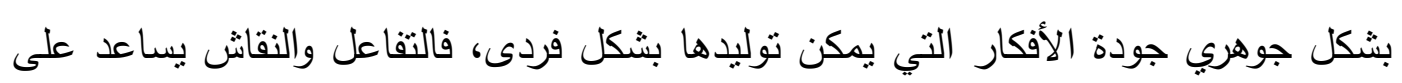

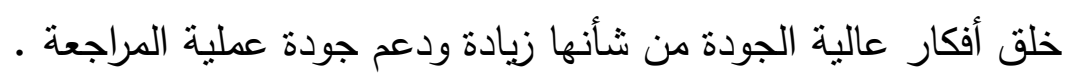

وتتقق الباحثة مع الفريق الثاني حيث ترى أن المراجعة المشتركة سوف نساعد على

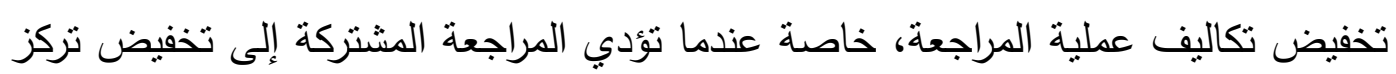

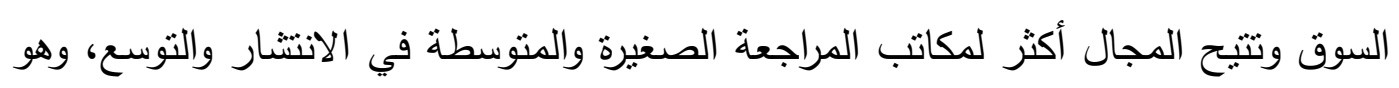

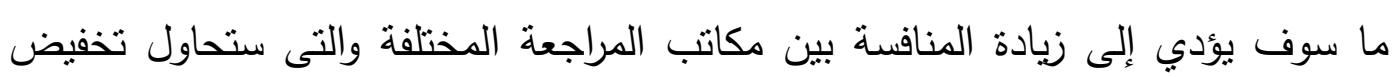

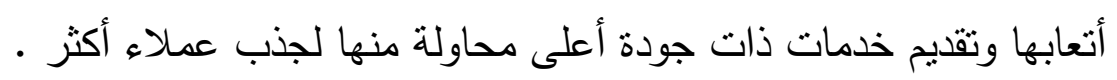

\section{r- أثر المراجعة المشتركة على جودة الأرباح المحاسبية :}

تعتبر القوائم المالية هي المصدر الرئيسي للمعلومات عن المنشأة، وهي الوسيلة

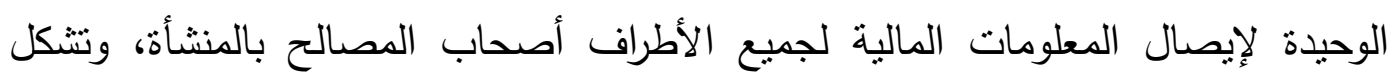

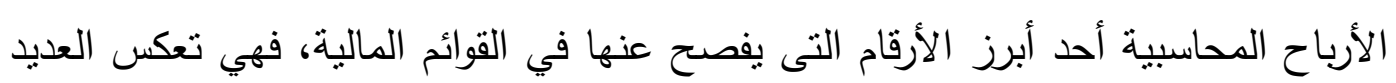

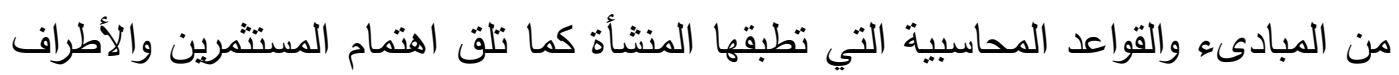


المختلفة ذات الصلة بالمنشأة حيث تعتمد تلك الأطراف على رقم الأرباح في اتخاذ الكثير

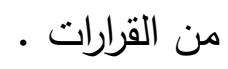

ومن المتعارف علية أن الإدارة مسئولة عن إعداد القوائم والتقارير المالية والتي يجب

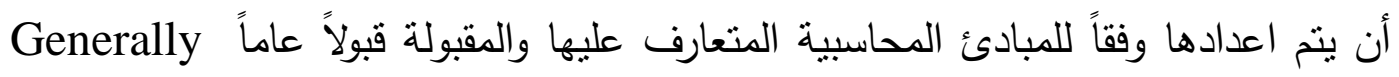
Accepted Accounting Principles (GAAP) للمديرين قدراً من المرونة والحرية للاختيار بين مجموعة من السياسات والبدائل المحاسبية الا أن الإدارة قد تستغل هذه المرونة في اتخاذ العديد من القرارات وإعداد التقديرات المحاسبية لتحقيق مصلحة خاصة بها أو لتضليل الأطراف أصحاب المصلحة في المنشأة .

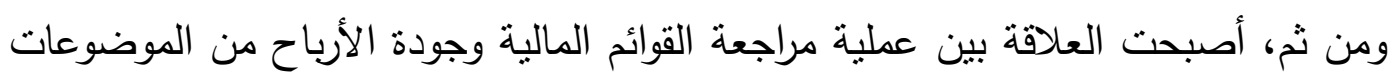

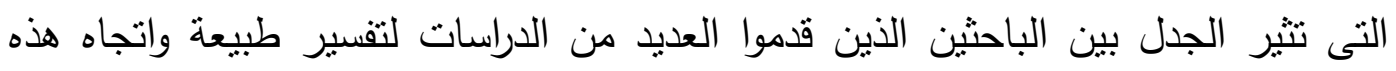

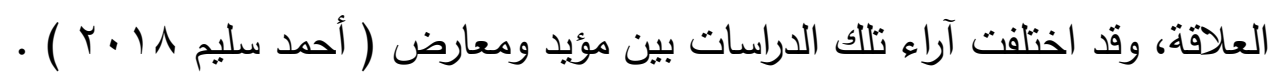

وقد تتاولت العديد من الدراسات مثل دراسة كل من : وقد نتاولت العديد من

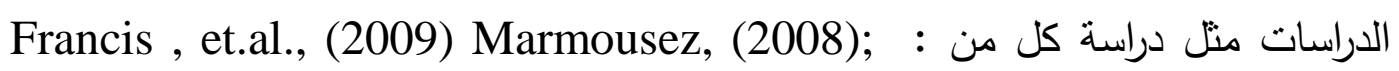
Lesage, et. al.,(2011) ; Zerni , et. al., (2012) ; Azzouzi (2014) ; Alsaoun and Aljaber, (2014); Ittonen and Tronnes, (2015) والاختبار أثز مدخل المراجعة المشتركة على جودة الأرباح المحاسبية ـ ولقد توصلت هذه

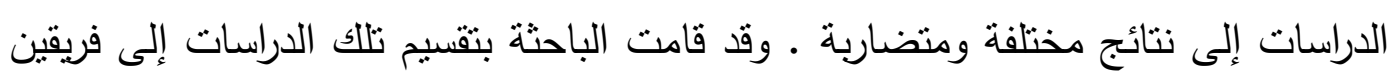

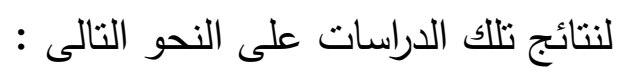

الفريق الأول : يرى عدم وجود تأثير معنوي أو وجود تأثير سلبي لمدخل المراجعة المشتركة على جودة الأرياح المحاسبية :

ويرى أنصار هذا الرأي أن تعيين اثثين من مراقبى الحسابات للقيام بعملية المراجعة

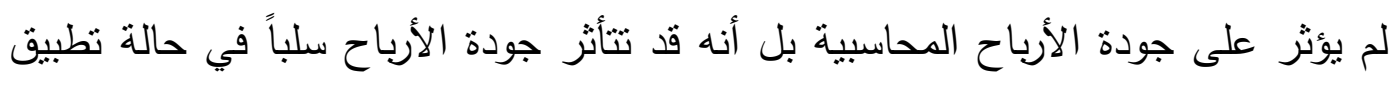

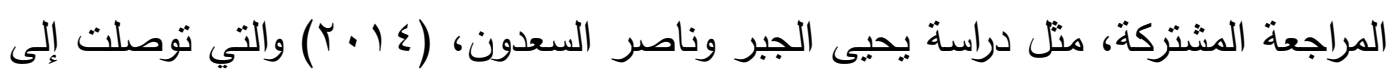

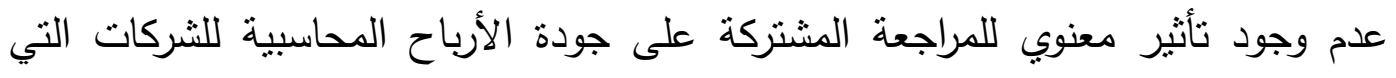

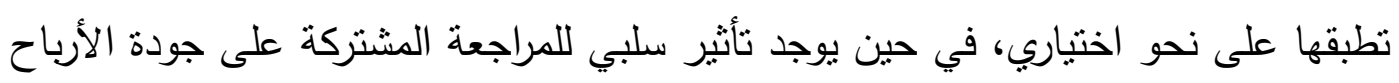


المحاسبية للشركات التى نطبقها على نحو إلزامي، وتعود تلك النتيجة في رأي الباحثان إلى الى التى

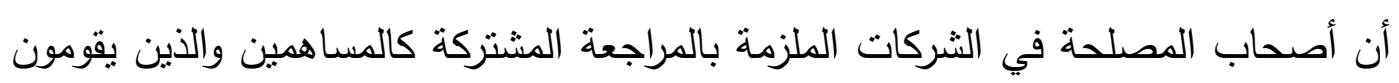

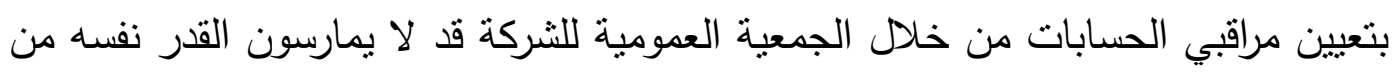

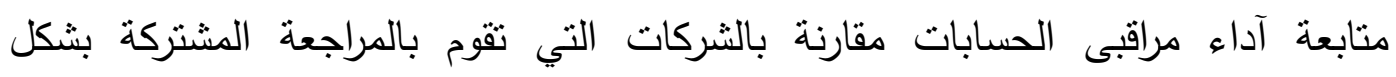

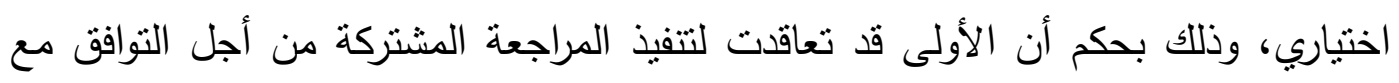

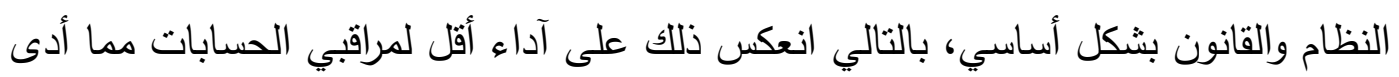

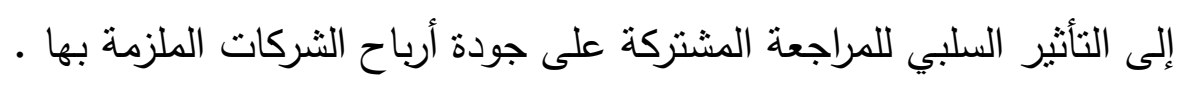

وأيضا دراسة (2014) Azzouzi, والتي توصلت إلى أنه لا يوجد تأثير معنوي لوجود مراقب من مكاتب المراجعة الكبرى ضمن المراقبين المشاركين في عملية المراجعة

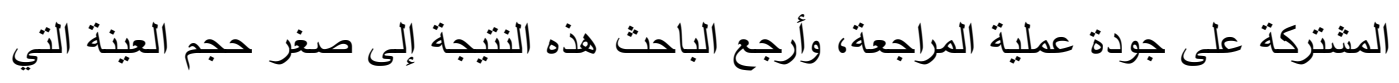

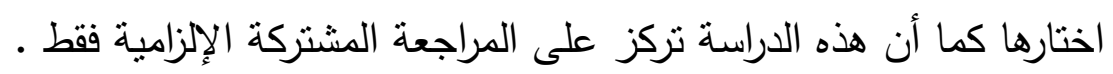

كما توصلت دراسة محمد الديسطى، (ع ا •Y) إلى عدم وجود فروق معنوية فى

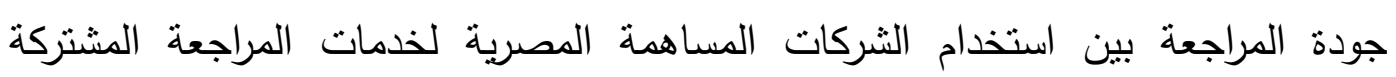
واستخدامها لخدمات المراجعة الفردية .

في حين وجدت دراسة محمد مندور ، (7 ا † ) وجود تأثير ايجابي معنوي لمدخل

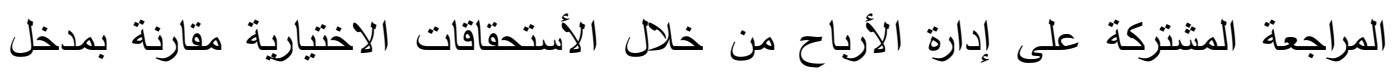
المراجعة الفردية وهذا يعنى وجود تأثير سلبي للمراجعة المشتركة على الدار جودة الألى الأرباح

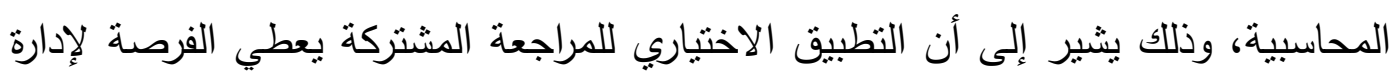

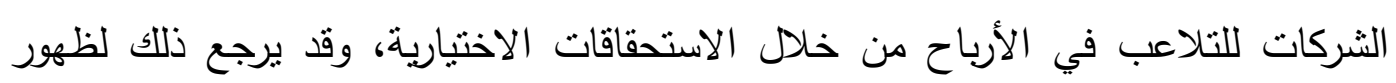

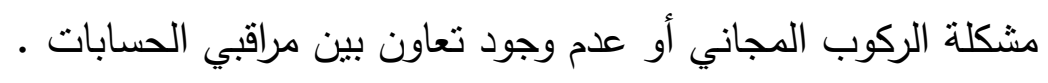

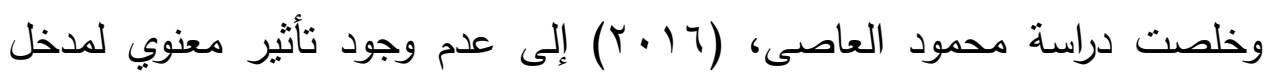
المراجعة الخارجية المشتركة على مستوى إدارة الأرباح مقارنة بمدخل المراجعة الخداد الخارجية الفردية . 
الفريق الثانى : يرى تأثير ايجابي لعدخل المراجعة المشتركة على جودة الأرياح المحاسبية

ويرى أنصار هذا الرأي أن تعيين اثثين من مراقبي الحسابات للقيام بعملية المراجعة سوف يؤدي إلى تحسين جودة الأرباح المحاسبية ولكن اختلف الباحثون من حيث مزيج مراقبى الحسابات الأفضل لتحسين جودة الأرباح • ومن ثم قسمت الدراسات إلى مجموعتين على النحو التالى : على

- دراسات توصلت إلى أن الجمع بين اثثين مراقبين من مكاتب المراجعة الأربعة الكبار خلال عملية المراجعة المشتركة هو الخيار الأفضل حيث يؤدي إلى جودة

$$
\text { أرباح محاسبية أعلى ومنها : }
$$

- دراسة (2009).,Francis , et.al والتي توصلت إلى أن وجود ثنائي مراقبين من الأربعة الكبار لمراجعة القوائم المالية للعميل يرتبط بمستويات أقل من الاستحقاقات غير العادية دلالة على وجود مستويات أقل من إدارة الأرباح مما يعني ارتفاع جودة الأرباح المحاسبية في تللك الثركات وذلك مقارنة بحالة اشتراك مراقب من الأربعة الكبار مع آخر من غير الأربعة الكبار، ويرجع ذلك إلى أن جودة المراجعة تكون أقل عندما تم آدائها بواسطة مراقب من مكاتب المراجعة الكبرى ذات كفاءة تكنولوجية مرتقعة والآخر من مكاتب المراجعة بخلاف الكبرى ذات كفاءة تكنولوجية أقل، في حين أن جودة المراجعة تكون أعلى عندما بتم أدائها بواسطة اثثين مراقبين من مكاتب المراجعة الكبرى متساوبين في نفس الكفاءة التكنولوجية . - دراسة Deng, et. Al.,2014) والتي خلصت إلى أن جودة المراجعة تكون أقل عندما يتم آدائها بواسطة مراقب من مكاتب المراجعة الكبرى ولآخر من مكاتب المراجعة بخلاف الكبرى ، فى حين أن جودة المراجعة تكون أعلى عندما يتم أدائها بواسطة اثثين مراقبين من مكاتب المراجعة الكبرى وبررت الدراسة تلك النتيجة بأن تطبيق المراجعة المشتركة من خلال مكتب من مكاتب المراجعة الكبرى (Big4 ) وآخر (Non-Big4) من شأنه أن يؤدي إلى تخفيض دقة أدلة المراجعة وذلك بسبب ظهور مشكلة الاستقادة 
المجانية، كما أن تطبق هذا الثكل من المراجعة المشتركة قد يؤدي لانخفاض استقلالية

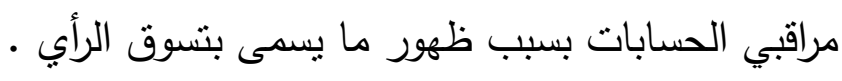
ץ- دراسات نوصلت إلى أن الجمع بين مراقب من مكاتب المراجعة الأربعة الكبار ل

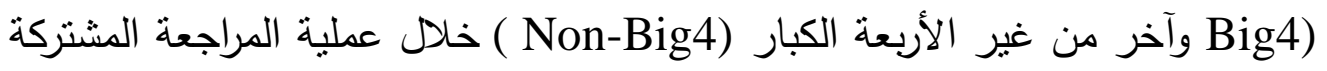

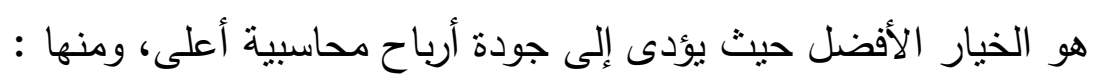

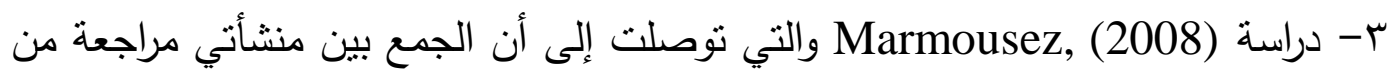

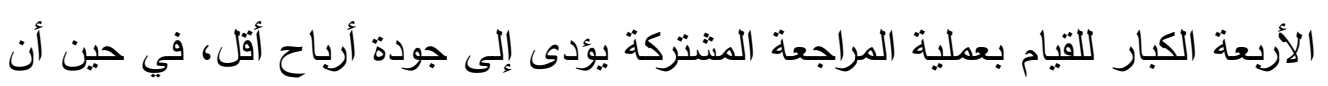

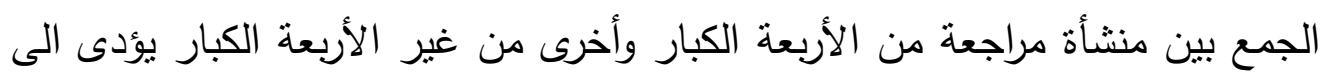

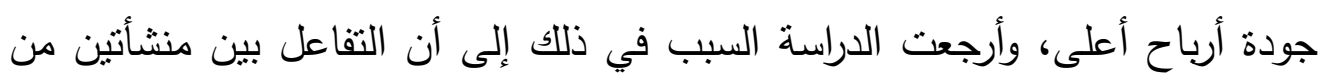

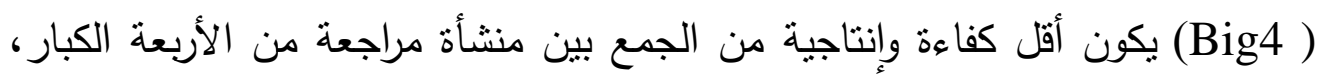

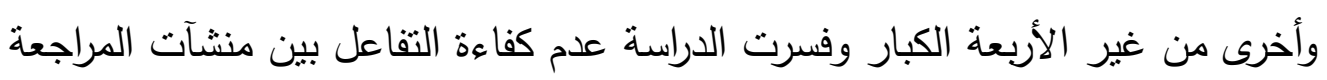

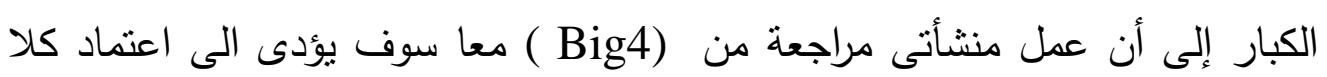

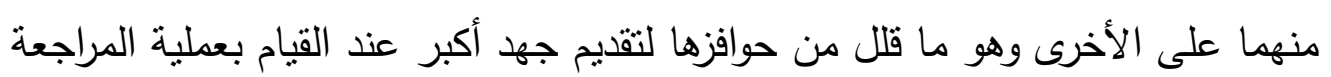

ع - دراسة Paugam \& Casta, 2012) والتي وجدت أن اشتراك مراقب حسابات من

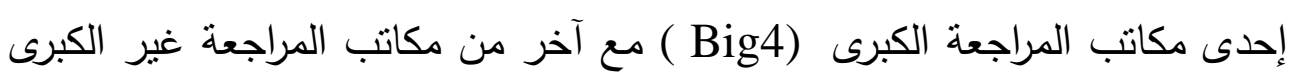
(Non Big4)

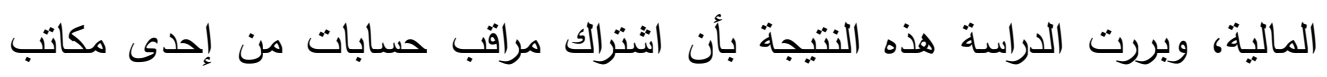

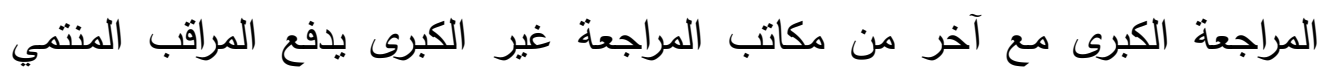

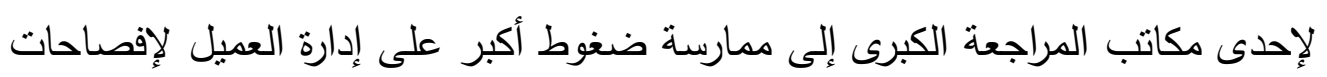

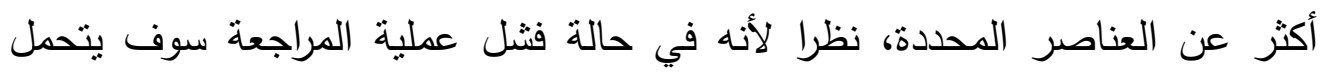

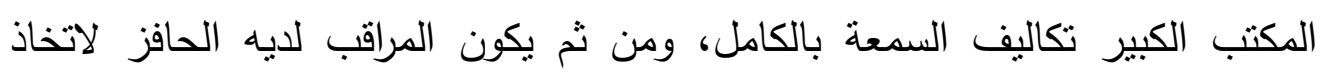
الإجراءات التصحيحية لزيادة مستوى وجودة الافصاحات المالية . 0- دراسة (2012),.رedard, et.,al والتي توصلت إلى أن الثركات التي تقوم بتعيين

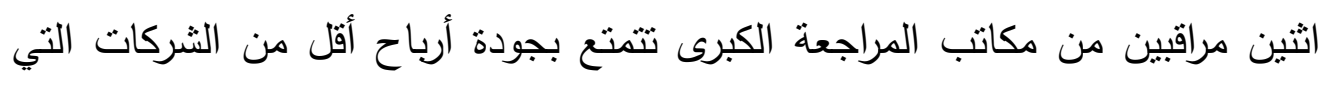

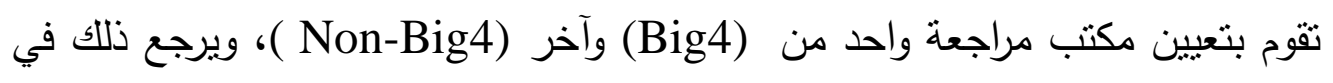


رأي الباحثين إلى أن تعيين اثثين مراقبين من (Big4 ) يؤدى إلى اعتماد كلا منهما

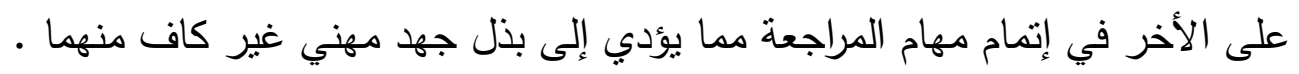

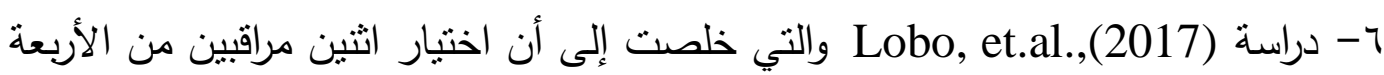

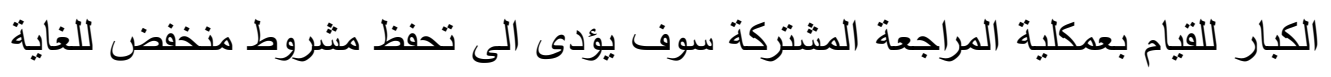

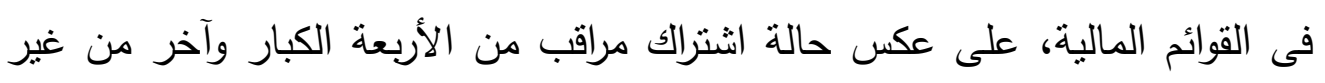
الأربعة الكبار فذلك سوف يحقق مستوى أعلى من التحفظ ويحقق مستوى أكثر شفافية

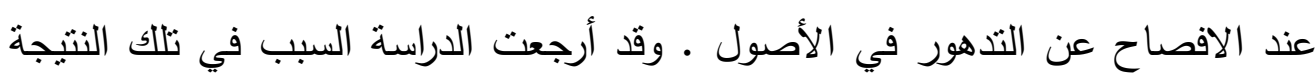

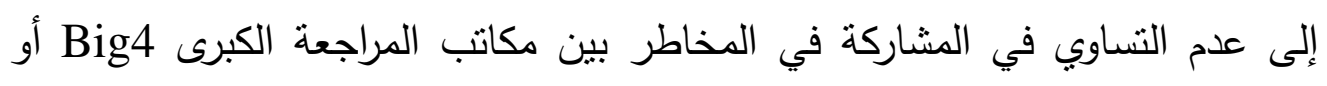

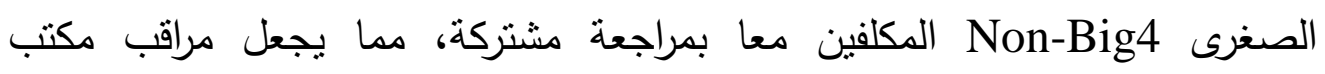

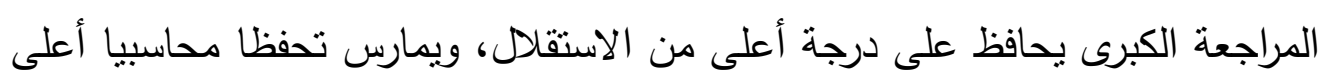

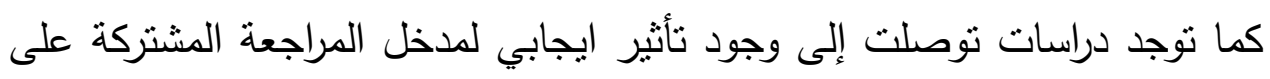

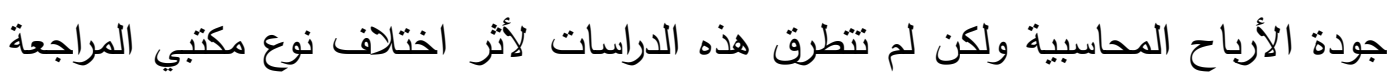

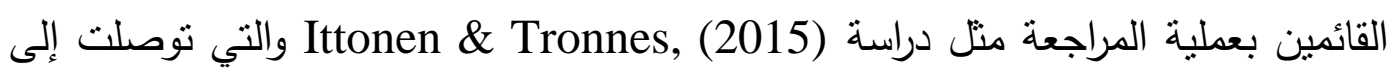

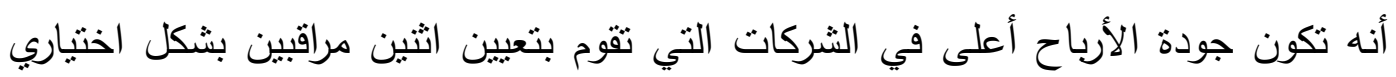

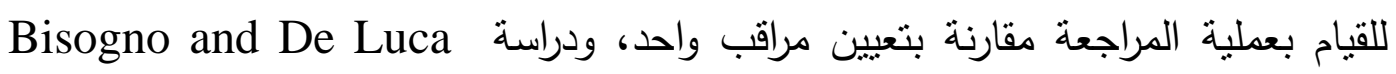

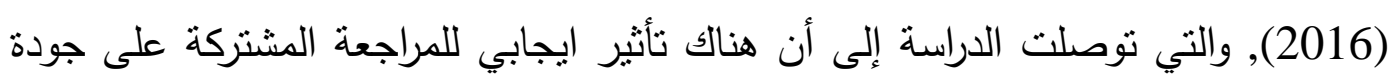

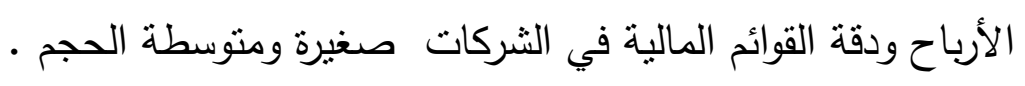

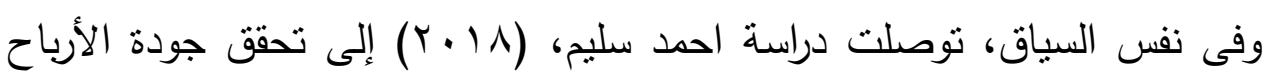

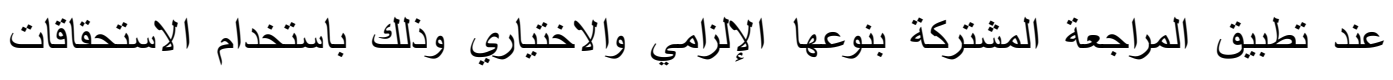

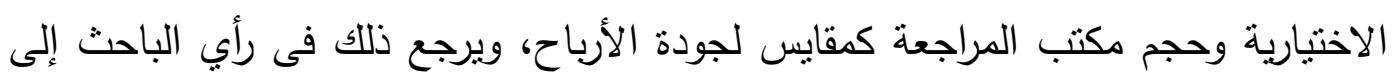

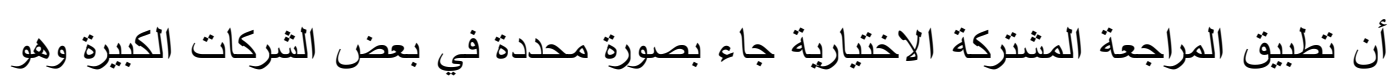

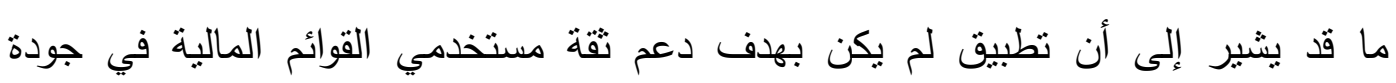

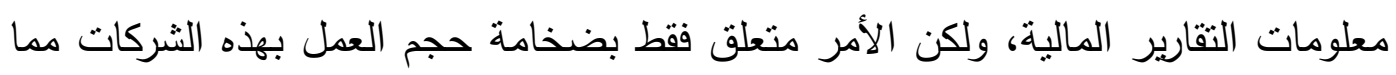

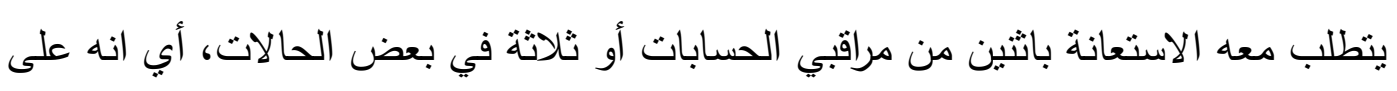

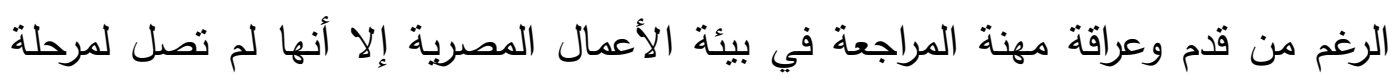


النضج ومواكبة النطور المهني العالمي الذي يجعل الثركات تختار طواعية تطبيق المراجعة

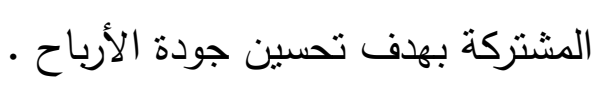

في ضوء ما سبق، تخلص الباحثة إلى أنه على الرغم من اختلاف معظم هذه

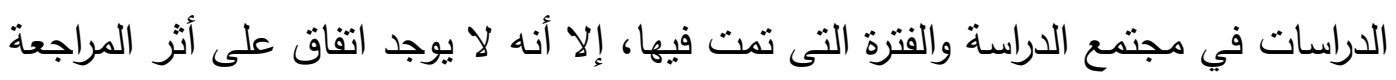

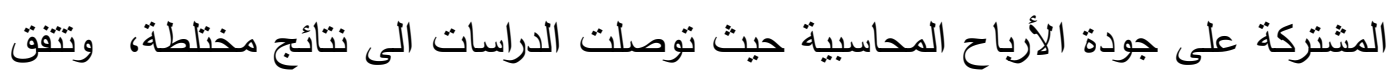
الباحثة مع الفريق الثاني الذي يؤيد وجود تأثنير معنوي للمراجعة المشتركة على جودة الأرباح

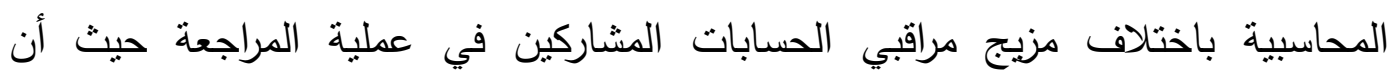
الاستعانة بأكثر من مراقب له العديد من المزايا التي سوف تتعكس بشكل اليجابي على جودة

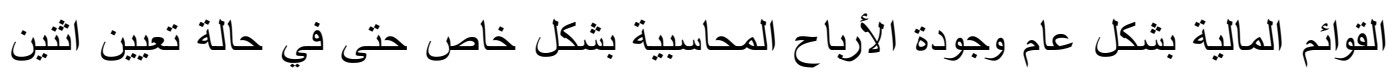
من مراقبي الحسابات المنتمين لمكاتب المراجعة غير الكبرى، وذللك للأسباب النالية :

1- تؤدى تطبيق المراجعة المشتركة الى دعم وتعزيز استقلالية مراقب الحسابات وضمان

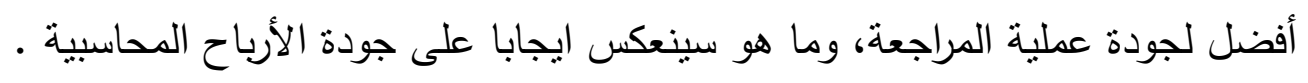

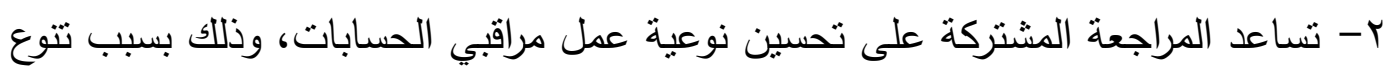

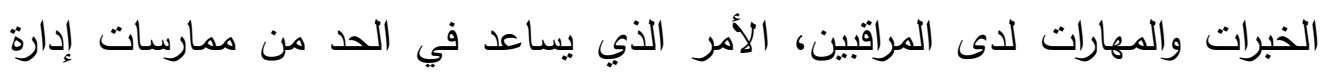

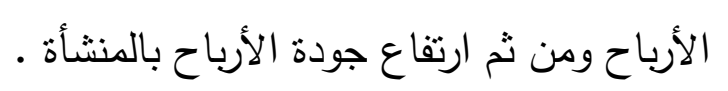

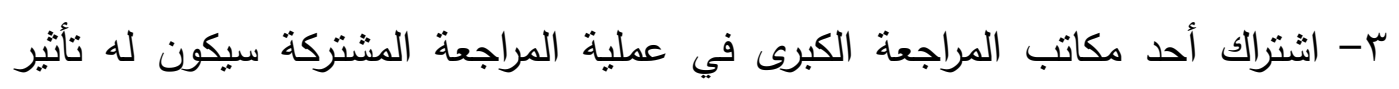

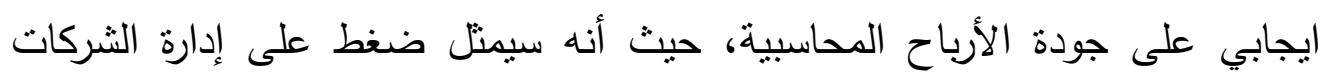

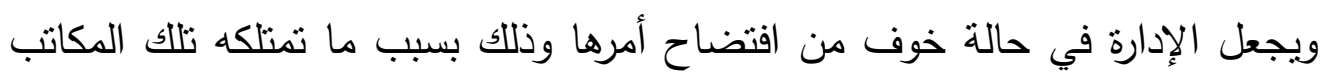

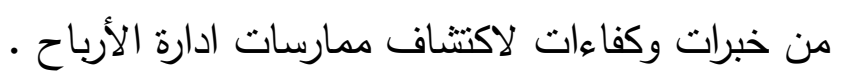

\section{r- أثز تطبيق المراجعة المشتركة على قيمة المنشأة :}

اهتم الفكر المحاسبي بتحديد قيمة المنشأة، لاسيما بعد تغير الهدف الذي تسعى إليه

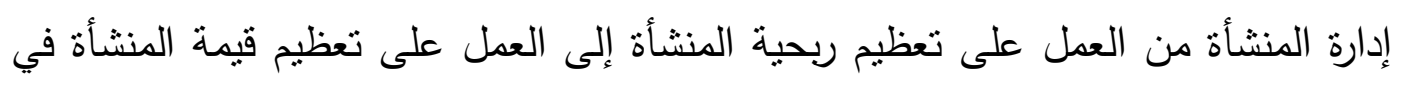
سوق المال . 
وتمثل قيمة المنشأة الترجمة المالية لآداء المنشأة، حيث أن أي تحسن في أداء

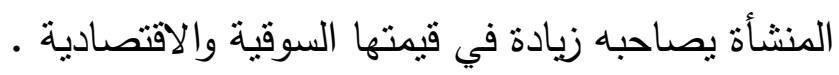

Benali , (2013); وقد تناولت عدد محدود من الدراسات مثل دراسة كل

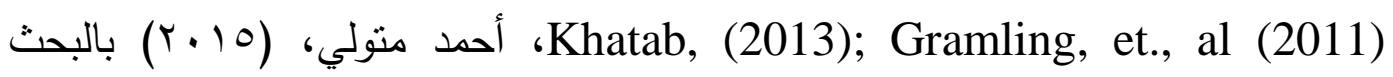

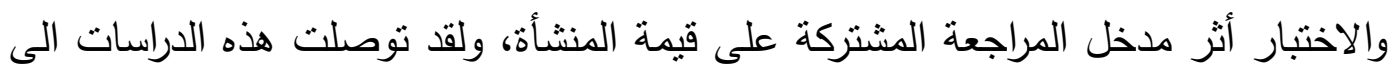
نتائج مختلفة ـ وقد قامت الباحثة بتقسيم تلك الدراسات إلى فريقين وفقاً لنتائج تلك الدراسات

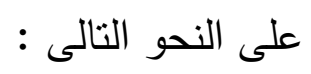

الفريق الأول : يرى عدم وجود تأثير معنوى أو وجود تأثثر سلبي لمدخل المراجعة المشتركة على قيمة المنشأة ومنها : لرئ

دراسة Khatab , (2013) والتي توصلت إلى عدم وجود تأثير معنوي لتطبيق

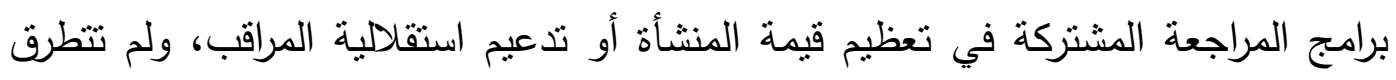

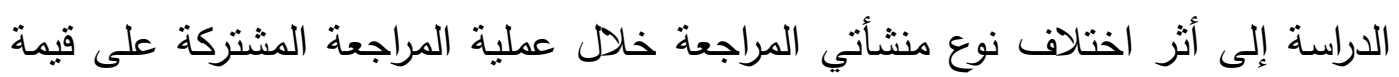

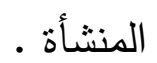

كما وجدت دراسة (2011) Gramling, et.al, أنه يترتب على قيام المراقبين الششتركين في أداء خدمات المراجعة لأكثر من عميل في وقت واحد إلى أن قيمة منشأة

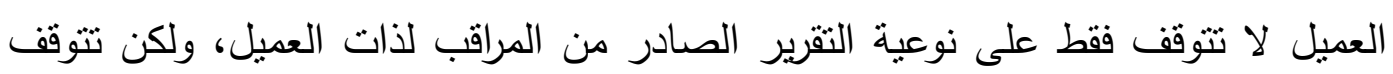

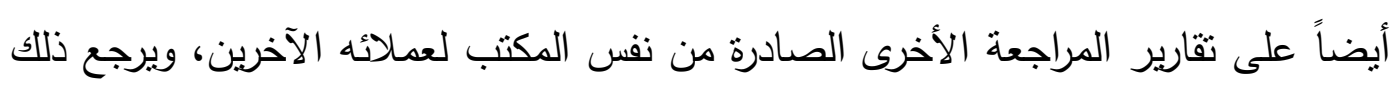

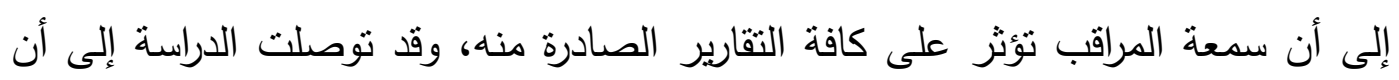

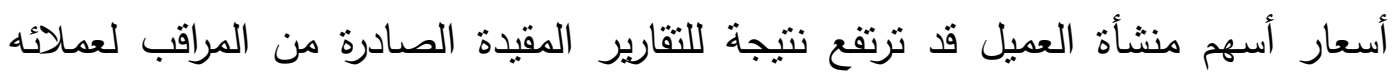

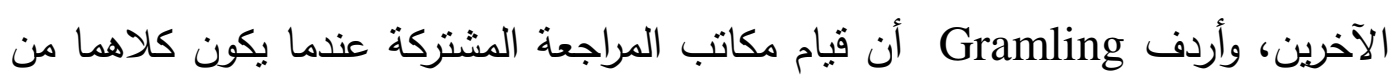
(Non Big4) أسهم منشآت العملاء التي تراجع في الوقت ذاته وبخاصة أسهم العمبل الأول .

الفريق الثاني : يرى وجود تأثير ايجابي لمدخل المراجعة المشتركة على قيمة

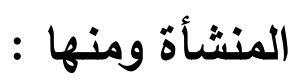


دراسة (2013) , Benali والتي أكدت على وجود نأثنر ايجابي معنوي للمراجعة

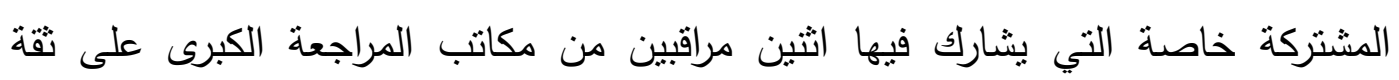

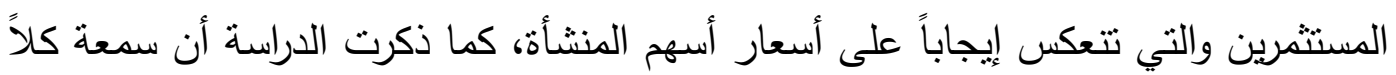

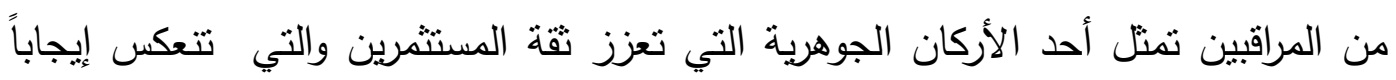
على أسعار أسهم المنثأة، كما ذكرت الدراسة أن سمعة كلا المراقبين تمثل أحد الأركان

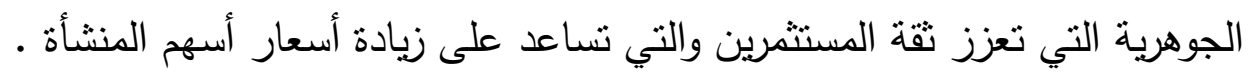

كما خلصت دراسة احمد متولي، (10 • ب) إلى وجود علاقة طردية إلى حد كبير

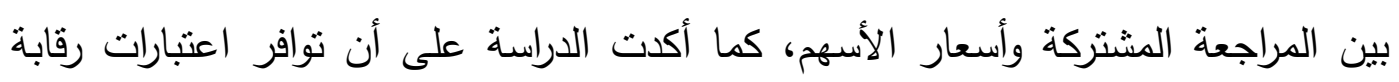

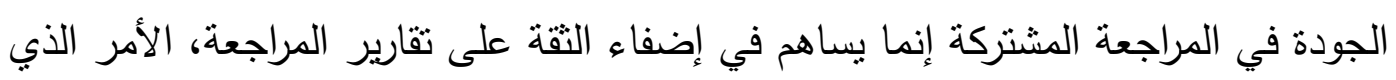

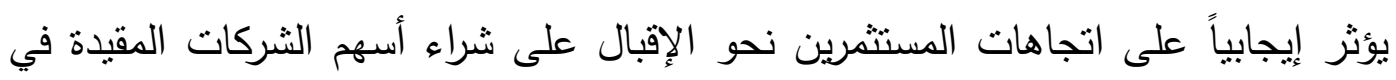

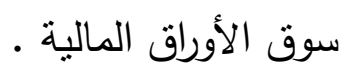

في ضوء ما سبق، تخلص الباحثة إلى أنه على الرغم من اختلاف معظم هذه

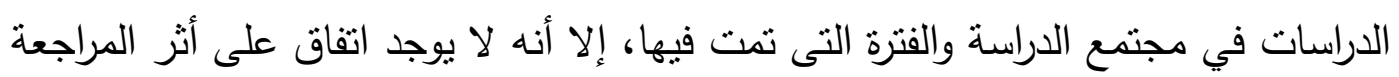

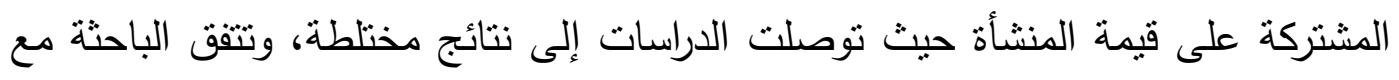

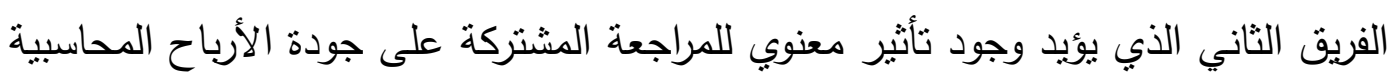

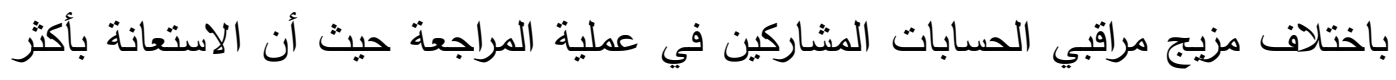

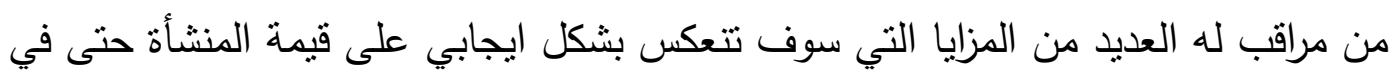

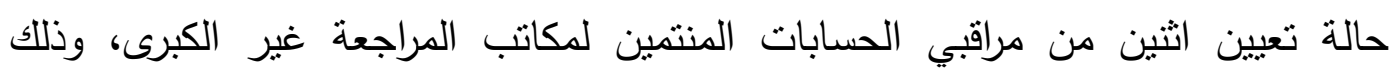

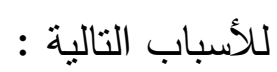

1- تتأثير قيمة المنشأة بالعديد من المتغيرات، فقد يشير الاستعانة بأكثر من مراقب

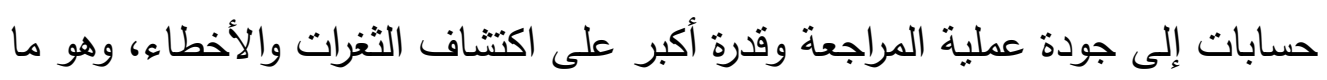

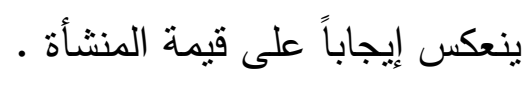
r- كما أن الاستعانة باثثين من مراقبى الحسابات أو أكثر بشكل اختبارى للقيام بعملية

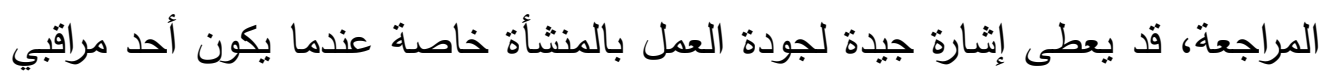

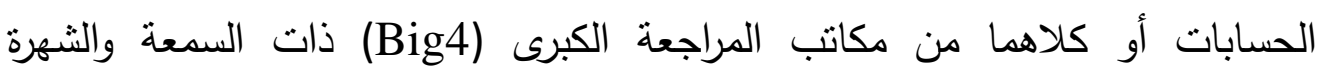
الواسعة، مما يعطى طمأنينة للمستثمرين لمزيد من الاستثمار في أسهم المنشأة . 


\section{ه - أثر المراجعة المشتركة على الحد من فجوة التوقعات :

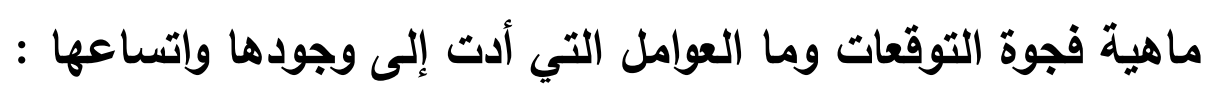

تعتبر فجوة التوقعات للمراجعة هي الثغل الثشاغل لكافة أطراف المجتمع بالأخص

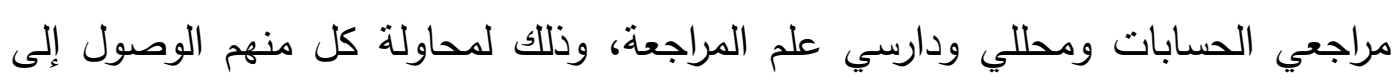
عوامل تساعد على تضييق هذه الفجوة .

وتعبر فجوة التوقعات عن عدم رضاء المستثمر أو المساهم عن عمل المراجعين

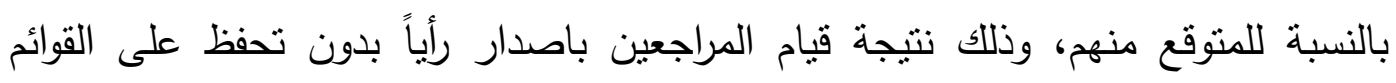

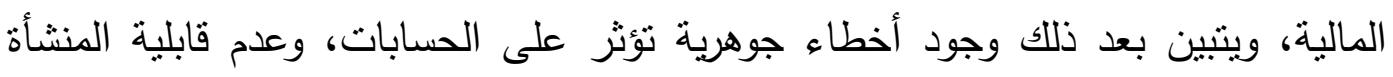
للاستمرار في أعمالها خلال الفترة القادمة، وظهور ضعف فئ في نظام الرقابة الداخلية، ولأنه

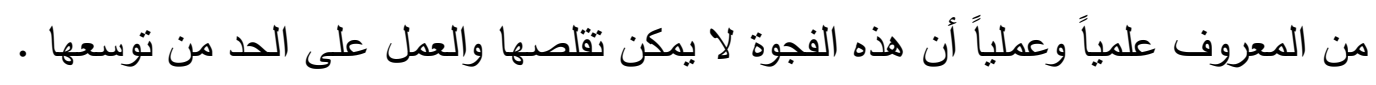
وليس هناك تعريفاً محدداً لمصطلح فجوة التوقعات في المراجعة على الرغم من

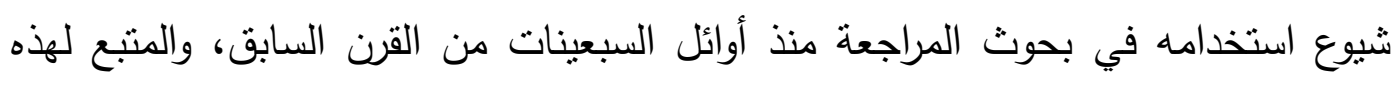
المنطقة البحثية يجد أن مفهوم فجوة التوقعات في المراجعة قد تحدد بطرق مختلفة من خلال

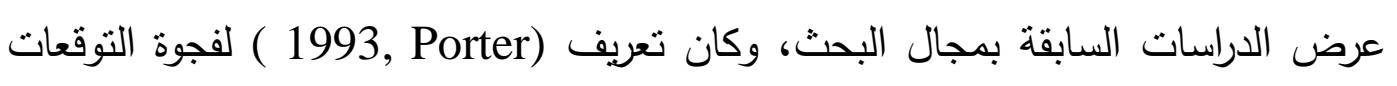

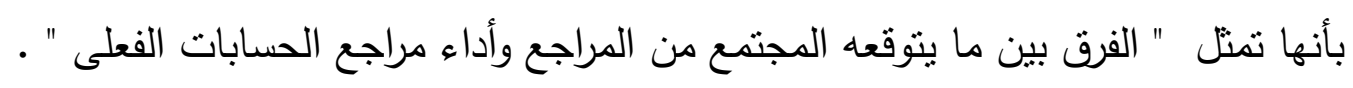
ويشير ( غالى 991 ( ) أنه يقصد بفجوة التوقعات في المراجعة عمليات التباين بين

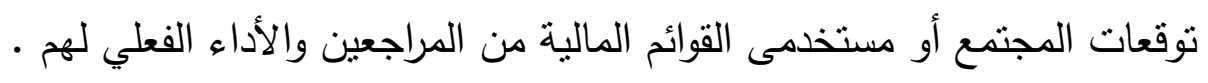
وقال عنها ( السقا، لو99 () أنها الفرق بين ما يقوم به المراجعون، وما ينبغي أن

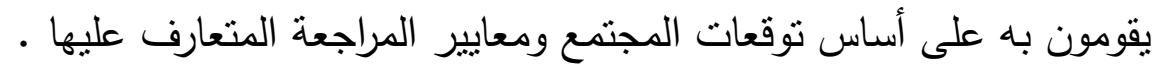
والخلاصة أن فجوة التوقعات تعرف بأنها فجوة دينامكية ساكنة، بطبيعتها لأنها

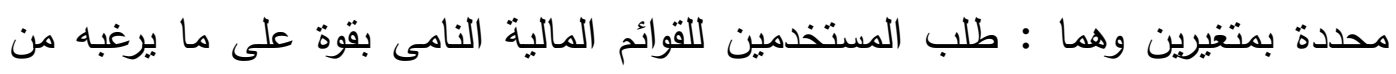

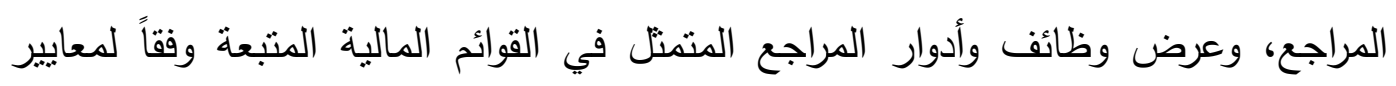
المحاسبة والمراجعة المتعارف عليها ـ وهي فجوة غير صفرية، بمعنى أن القضاء عليها 
نهائياً أمر غير منطقي، وأن تضيقها أمر منطقي، وإنها تتسع لأنها تتأتز أيضاً بطبيعة بيئة

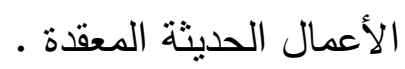

ب-دور المراجعة المشتركة في معالجة والحد من العوامل المؤدية لفجوة المعقولية كجزء من فجوة التوقعات :

إن مستخدمي التقارير المالية لايهم توقعات غير معقولة، بخصوص مسئوليات

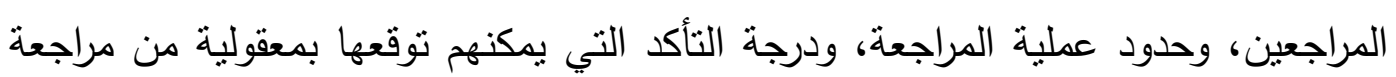

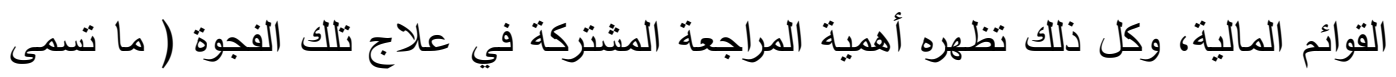
بفجوة المعقولية ) وذلك حتى يتمكن المراجعين من تلاشي الدعاوي المرفوعة ضدهم من قبل

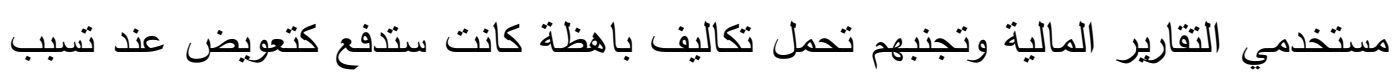

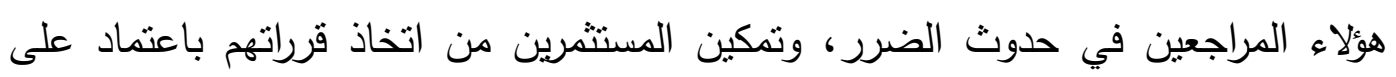

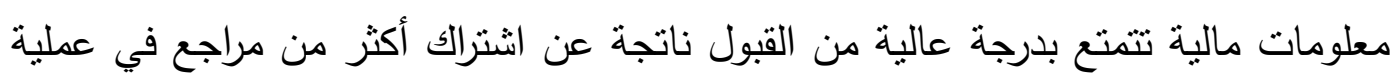

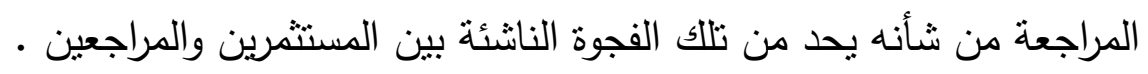
فيمكن القول بأن للمراجعة المشتركة أهمية في التظلب على عامل أو عنصر من

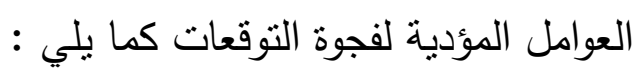

\section{ع - الثك في استقلال وحياد المراجع الخارجى :}

ويقصد به عدم وجود الثقة الكافية لدى كثير من مستخدمي التقارير المالية في استقلالية وحياد المراجع الخارجي، ويمكن أن نتغلب على هذا العنصر من خلال معالجته

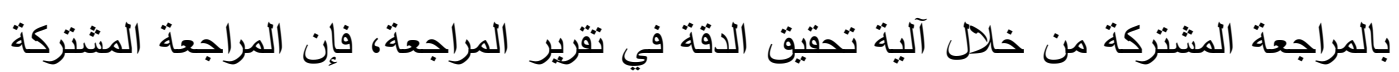

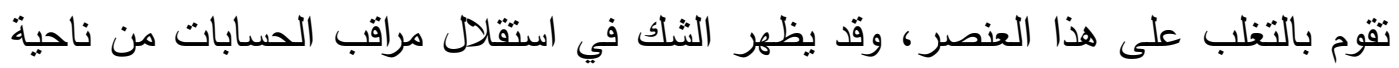
أنه عندما يؤثز أصحاب المصلحة ذو النفوذ القوي على كفاية واستقلال مراقب الحسابات

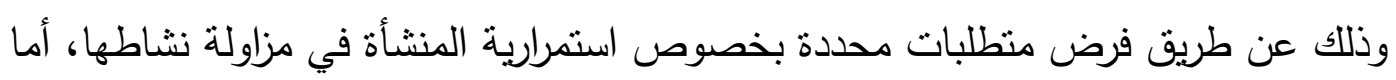

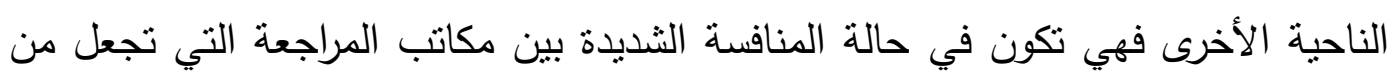

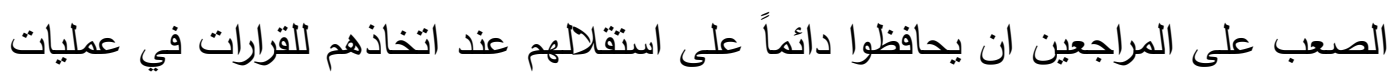

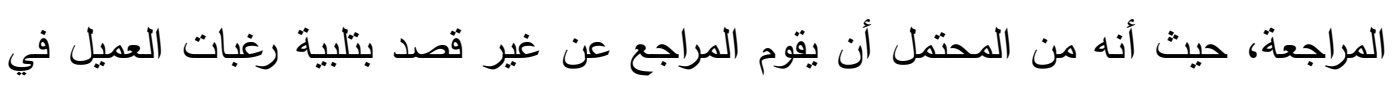


مواجهه المنافسة مع غيره من مكاتب المراجعة والتي لا يمكن إبعادها عن ذهنه أو من تفكيره عند اتخاذ قرارات المراجعة . وترى الباحثة أنه حتى يظهر دور الاستفادة من المراجعة المشتركة لابد من تحقيق

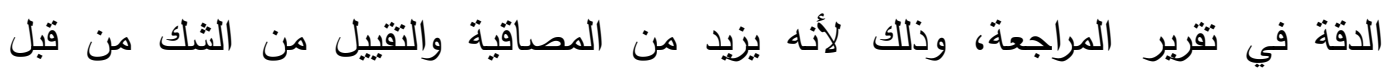

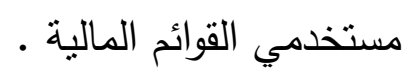

\section{- - نقص الكفاعة المهنية للمراجع :}

يتضمن نقص الكفاية المهنية : نقص العناية، نقص المعرفة، نقص الخبرة، حيث يوجد العديد من العوامل التي تؤدي إلى تقليل جودة آداء عملية المراجعة من جانب البهن المراجعين ومن ثم زيادة عدم رضاء المجتمع عن عمل هؤلاء المراجعين مما بعني زيادة

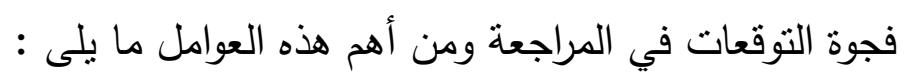

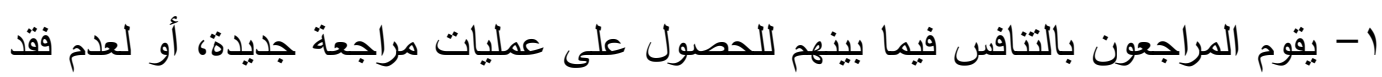

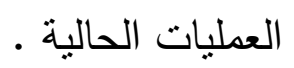
r- قبول اتعاب قليلة عن عمليات مراجعة لا تتتاسب مع المجهود لآدائها وذلك كنتيجة للمنافسة . لمابل r- زيادة عملية الاندماج بين مكاتب المراجعة الكبرى للحصول على عمليات مراجعة كبيرة

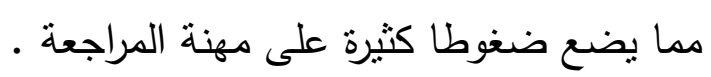

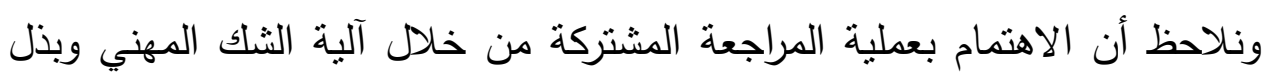

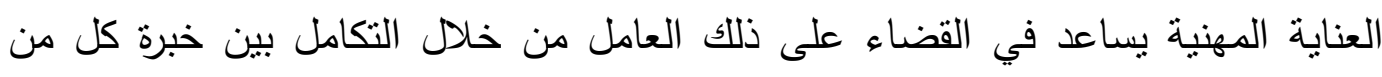
المراجعين المشتركين في عملية المراجعة . ع - الممارسات المحاسبية وإدارة الأرباح :

تنشأ الممارسات المحاسبية نتيجة فرض سلطه الإدارة على المراجع، ومن ثم يكون بتصرفات مستجيبا لرغباتها، وذللك لأن الإدارة هي المسئولة عن إعداد القوائم المالية

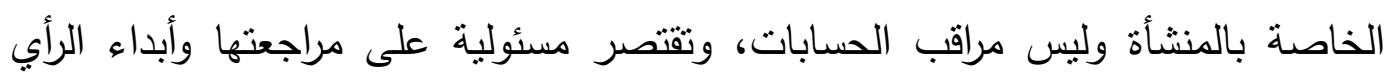

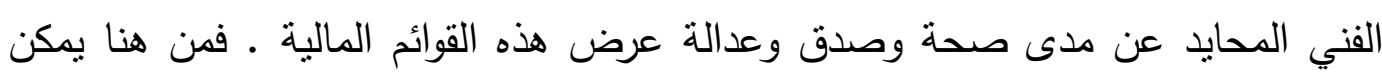
القول بأن المسئولية قد تتضامن في حال وجود مراجع حسابات واحد فقط . ولذلك للتغلب على تلاك الفجوة ومعالجتها والحد منها يمكن من خلاد القيام بعملية

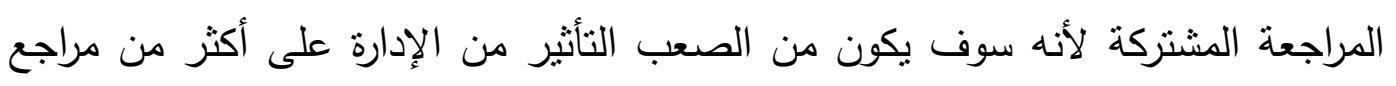


وأن قامت بالتأثير والتواطؤ مع مراجع فمن الصعب التأثير على الاخر • ومن غير المتوقع

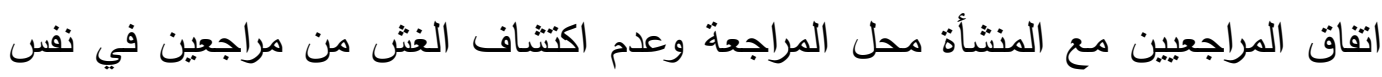

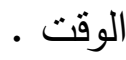

وتؤكد الباحثة على وجود علاقة ايجابية بين تطبيق آليات المراجعه المشتركة

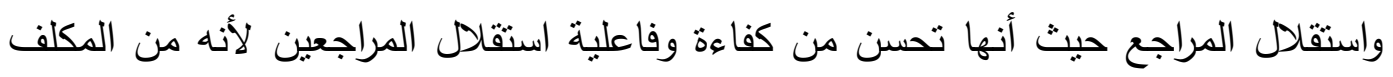

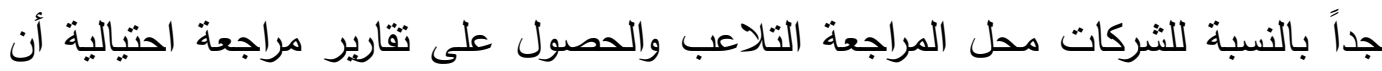

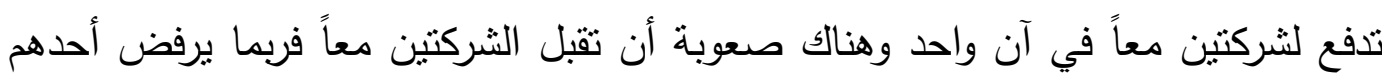

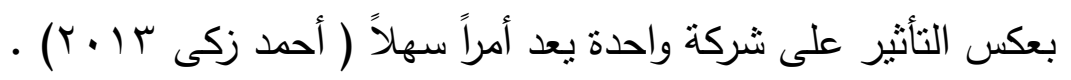

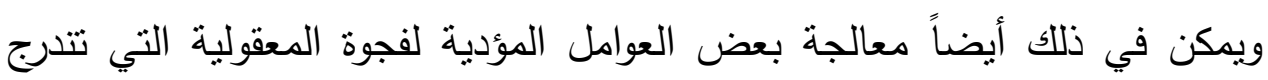

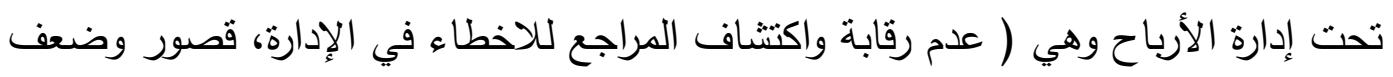
نظام الرقابة الداخلية، وصعوبة الكثف عن الغارة الغش والأخطاء الجوهرية في القوائم المالية،

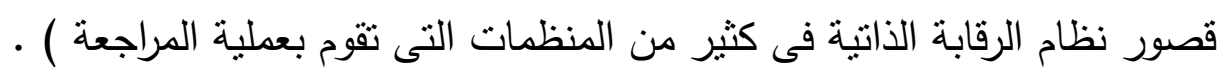
ه - عدم كفاية التشريعات والإصدارات المهنية المنظمة لعمل المراجع : ترجع فجوة التوقعات إلى عدم تطور مسئوليات المراجع طبقاً للتشريعات السائدة

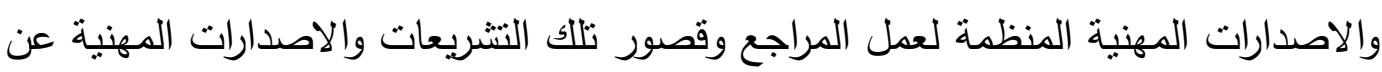
مواكبة التطور في احتياجات مستخدمي الثقارير المالية والسعي لمقابلة تلاك التوقعات

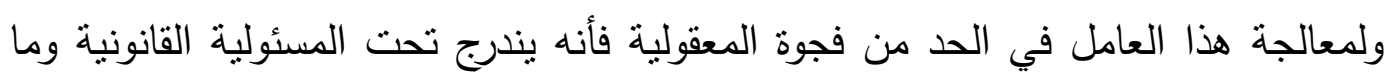
يترتب عليها من قصور في مهام عملية المراجعة .

צ- عدم التحديد الواضح لاور المراجع الخارجي في المجتمع ومسئولياته : يعتقد بعض المستخدمين أن المراجع هو المسئول عن إعداد الثقارير المالية وأنه النه

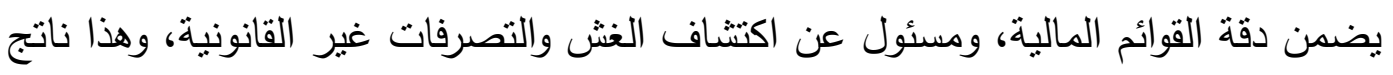

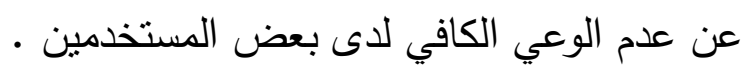
فقامت عملية المراجعة المشتركة على معالجة هذا الاعتقاد من خلال تقسيم مهام

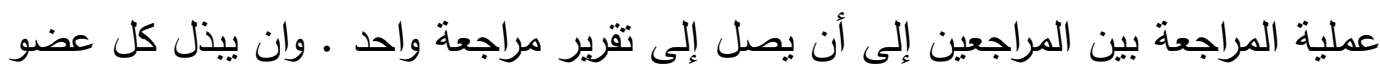

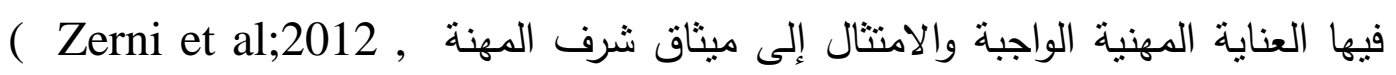
• Baldauf \& Steckel 2012, ) 
ويظهر دور المراجعة المشتركة في ذللك العامل التي تؤدى إلى فجوة المعقولية

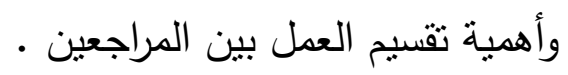

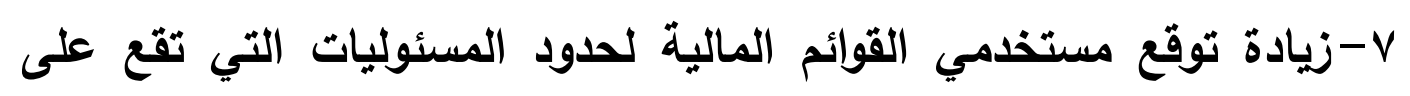
عاتق المراجع الخارجى :

يعتبر مسئولية المراجع عن اكتثاف التصرفات غير القانونية الهامة والمباشرة فقط

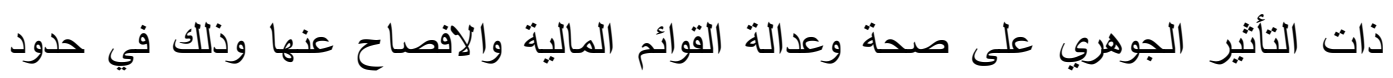
نطاق عملة . فالمراجعة المشتركة تعالج هذه المشكلة وذلك من خلال قيامها على التحديد الواضح والدقيق لدور كل مراجع وتخطيط عملية المراجعة، وبتعريف كل من المراجع والإدارة

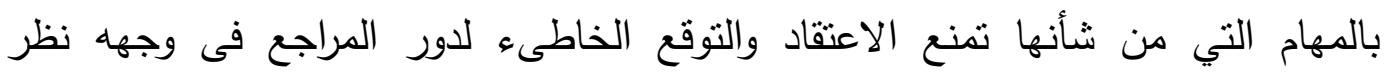

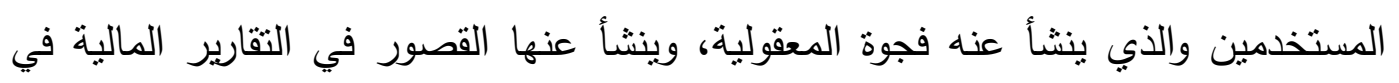

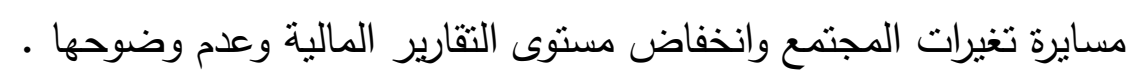
1 - عدم كفاية الافصاح فى تقرير المراجعة المقدم للإدارة والمستخدمين :

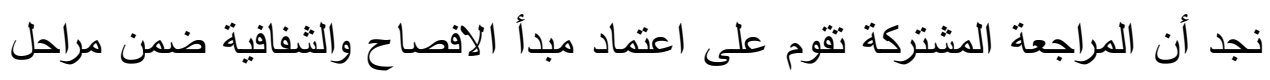

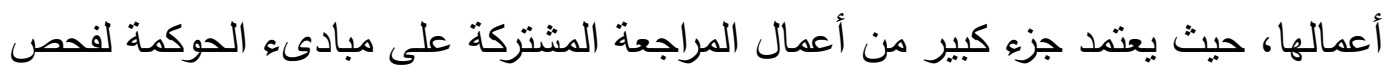

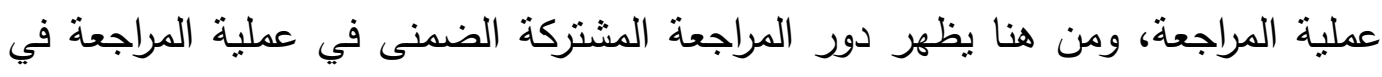

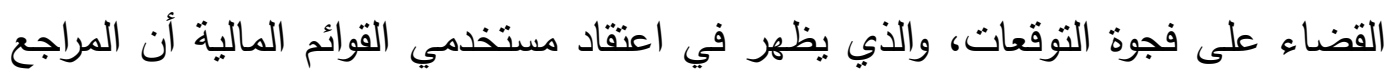

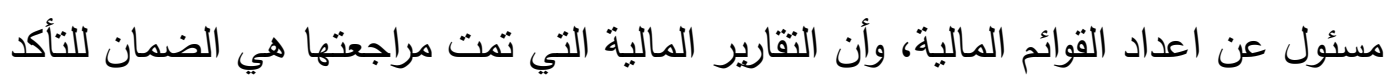
من دقتها . مناع اعن

9 - عدم معقولية توقعات مستخدمى التقارير المالية : يتم ذلك عند مقارنة توقعات مستخدمي التقارير المالية مع ما يجب على المراجع

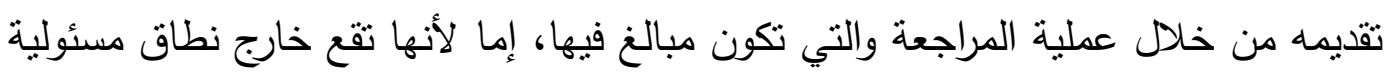

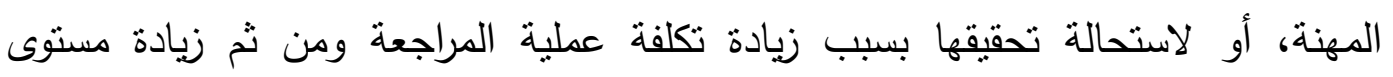

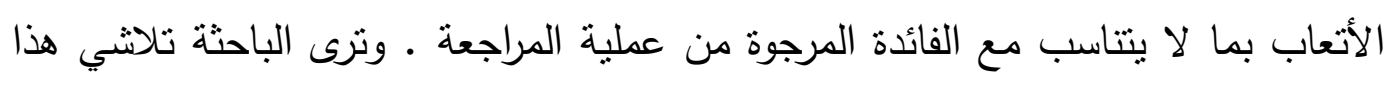

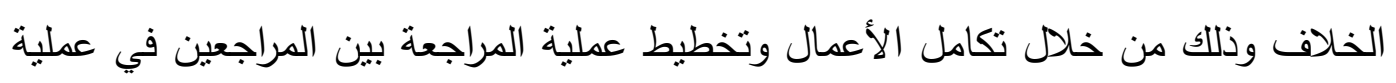

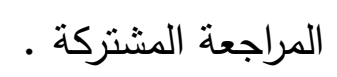

تعنقد الباحثة أن المراجعة المشتركة من شأنها الحد من العوامل التي تؤدى إلى

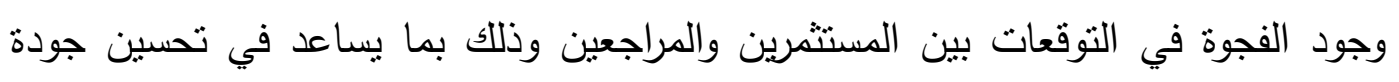


عملية المراجعة ـ حيث أنه من الضروري الحاجة إلى مراجع خارجي آخر كطرف محايد

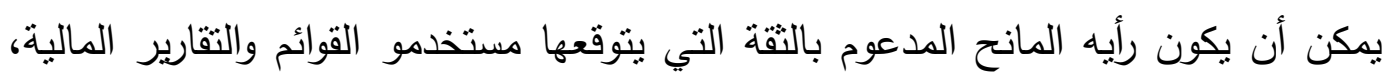

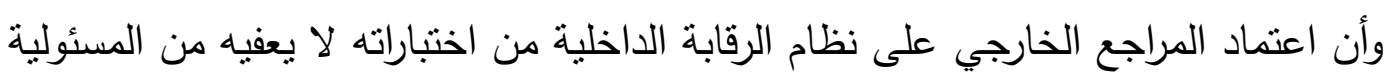
في حالة عدم اكتثاف أي غش أو اختلاس بعد اكتمال عملية المراجعة . • 1 - آليات المراجعة المشتركة فى الحد من فجوة المعقولية :

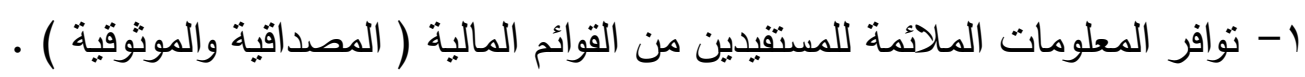
ץ- توفير تأكيدات معقولة من خلال عرض البيانات المالية بشكل عادل وفقا للمبادئ

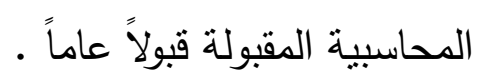

r- الاستفادة من فاعلية الاتصال في بيئة المراجعة وبين فريق عملية المراجعة والعميل .

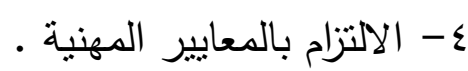

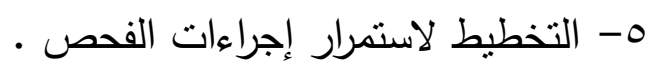

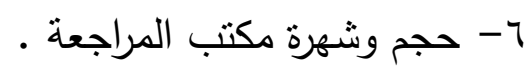
1 - أثر المراجعة المشتركة على تقريز المراجع :

تمنتل الهدف الرئيسي لعملية المراجعة الخارجية في إبداء الرأي الفني بشأن مدى

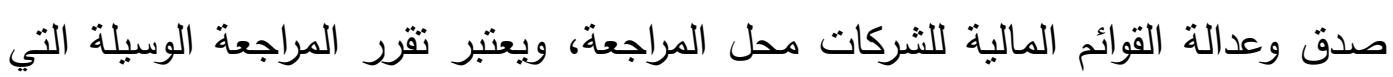

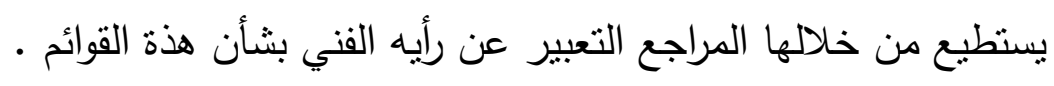

وفى هذا الصدد، فقد ناقتت أحدى الدراسات (Baldauf , J . an Steckel )

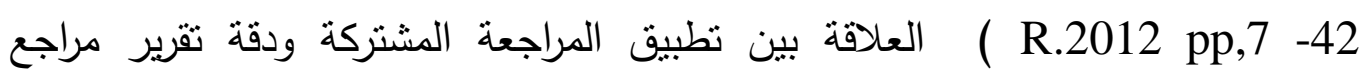

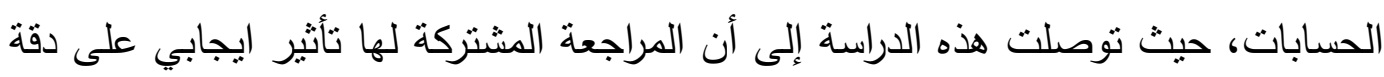

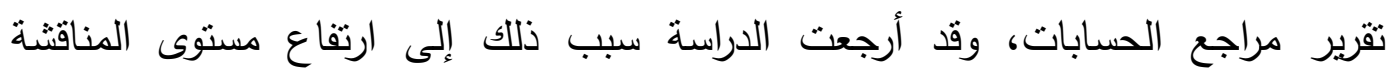

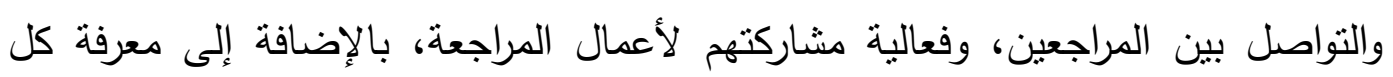

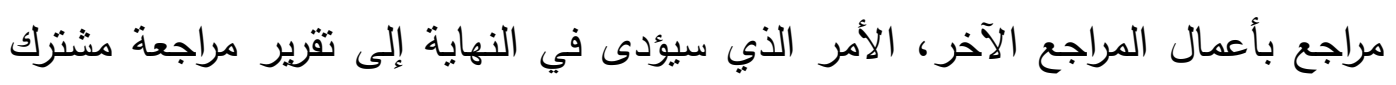
أكثر دقة . مراع باعمال

ومن حيث تأثثر تطبيق المراجعة المشتركة على جودة تقرير مراجع الحسابات من

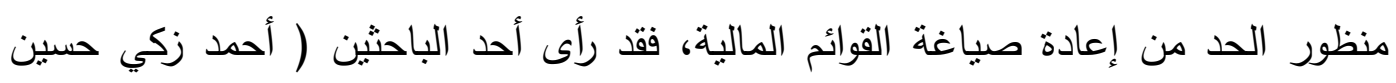




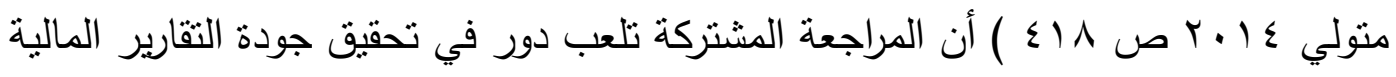

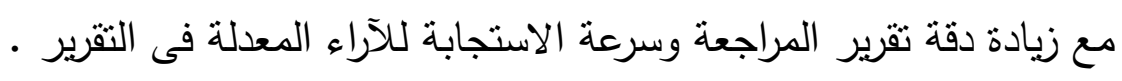

كما تساهم المراجعة المشتركة في الحد من إعادة صياغة القوائم المالية للأسباب التالية :

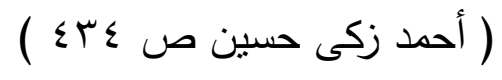

1- تكلف أكثر من مراجع لأداء عملية المراجعة المشتركة بفحص أنظمة الرقابة الداخلية

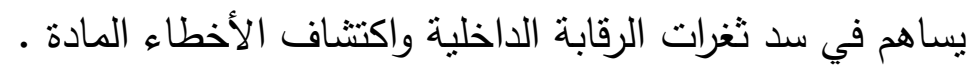

r- التتسيق والتعاون بين فريقي المراجعة المشتركة يحقق الفهم الكافي للأمور الجوهرية

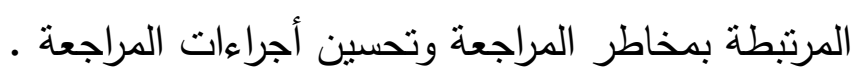

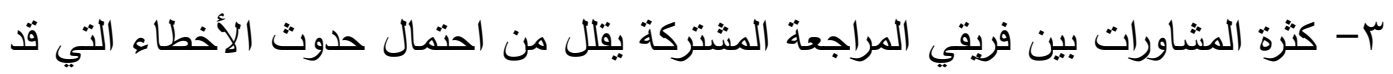

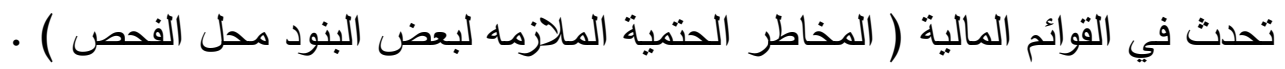
ع- ورأى أحد الباحثين ( Ezat, A . N .M., op. cit, p.52 ) أن المراجعة المشتركة تعتبر وسيلة جيده من أجل أداء عملية المراجعة في الوقت المتاح لها دون تأخير

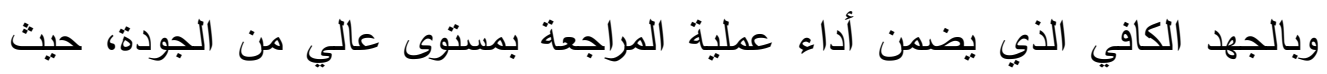

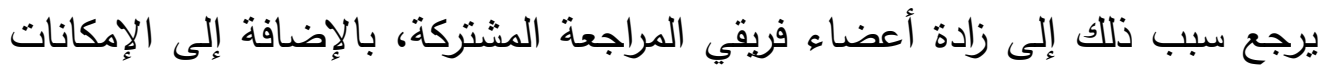

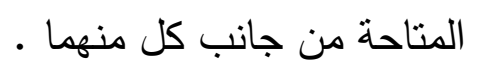

0 - في ضوء ما سبق، فإن المراجعة المشتركة قد نساهم في تخفيض الوقت المستغرق

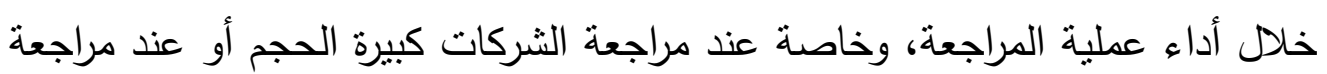
العمليات كبيرة الحجم والمعقده والتي قد تؤدي إلى زيادة الوقت الماهنة المستغرق عند أداء

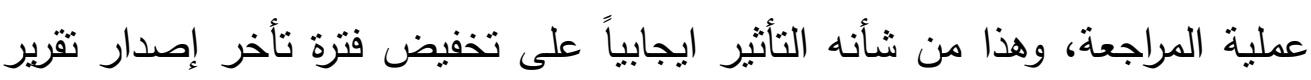
المراجعة . المعانه צ- وترى الباحثة أن المسؤولية التضامنية التي توفرها المراجعة المشتركة هى من أهم العوامل للوصول إلى تقرير مراجعة مشترك عالي الدقة وبالتالي تتعكس هذه المسؤولية

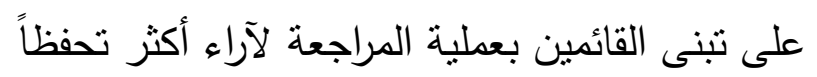


هدف البحث إلى تحليل دور مدخل المراجعة المشتركة على زيادة جودة عملية

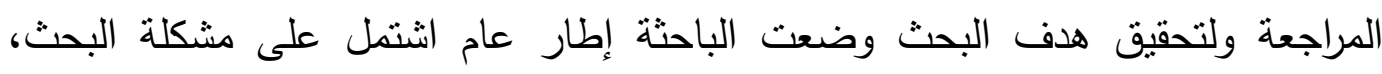

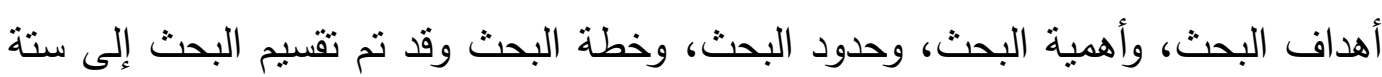
نقاط كما يلى : أولاءً : تتاولت بها الباحثة الإطار المفاهيمي للمراجعة المشتركة وتتاولت الباحثة الإطار النظري للاستفادة من المراجعة الخارجية المشتركة في تحسين جودة عملية

$$
\text { المراجعة. }
$$

ثانياًً :تتاولت بها الباحثة مفهوم جودة مراجعة القوائم المالية من حيث المفهوم وكذلك أثر

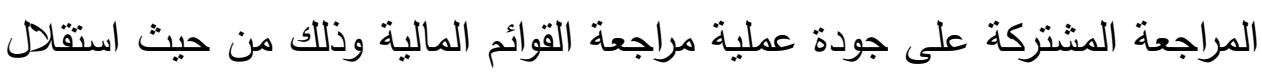

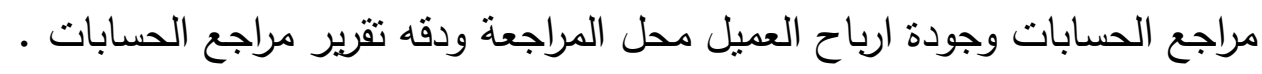

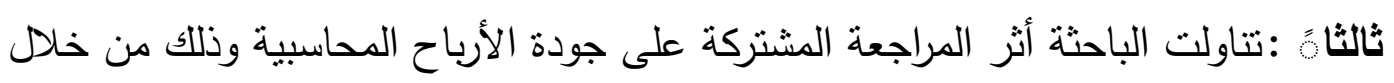

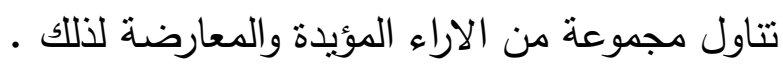

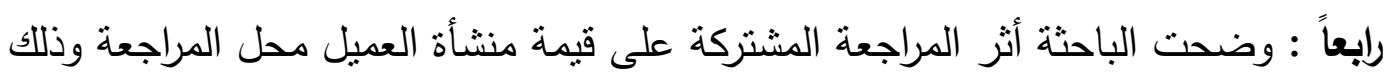

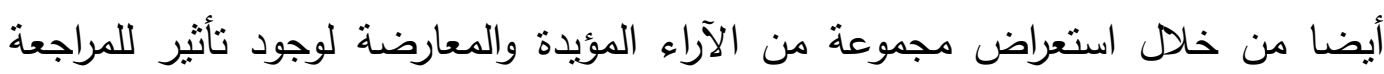
المشتركة على قيمة منشأة العميل محل المراجعة .

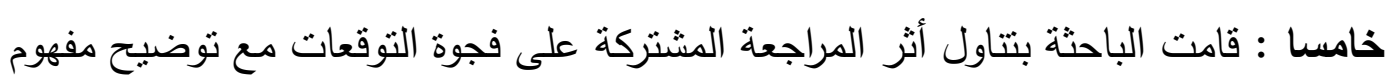

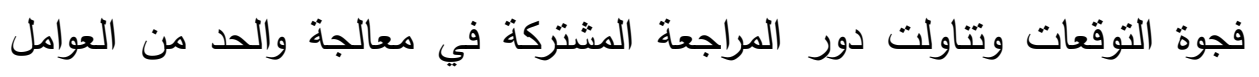

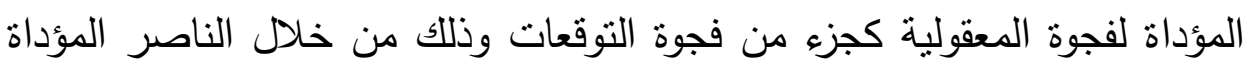

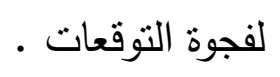
سادسا : تتاول البحث دور المراجعة المشتركة في زيادة دقة تقرير مراقب الحسابات وإعادة

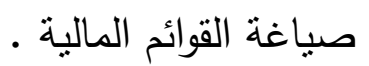




\section{توصيات البحث :}

أخيراً توصى الباحثة بضرورة استمرار الاهتمام في الدراسات المستقبلية الخاصة

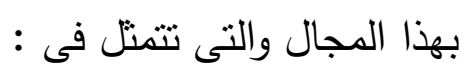
1- دور المراجعة المشتركة في تحسين جودة المراجعة وخاصة في شركات القطاع العام

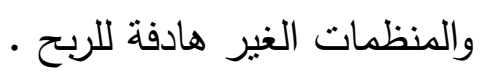

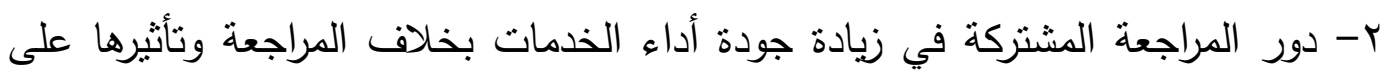

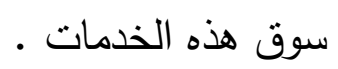
r- ضرورة وضع معيار للمراجعة المشتركة ينظم عمل المراجعين ويحفظ حقوقهم. ع- على الجهات المعنية ضرورة إقامة الدورات والندوات التنريبية اللازمة لتعريف دور

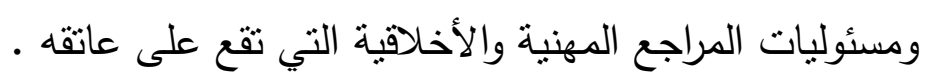

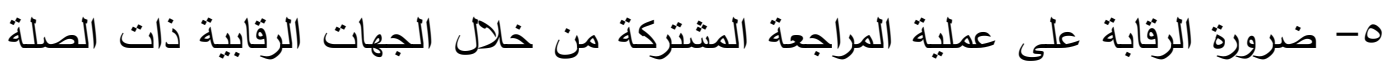

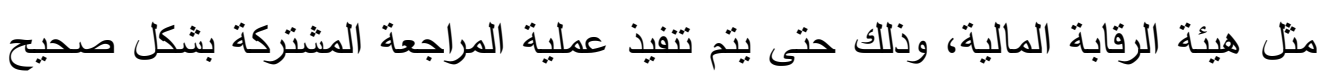

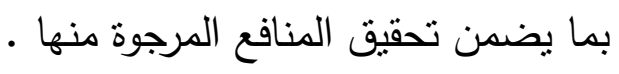
צ- ضرورة تشجيع مكاتب المراجعة غير الأربعة الكبرى على تدريب مراقبي الحسابات لديها

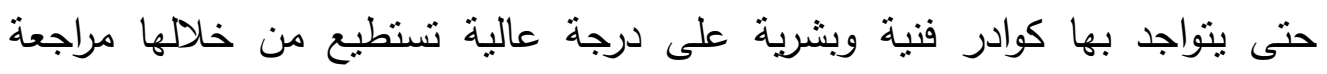

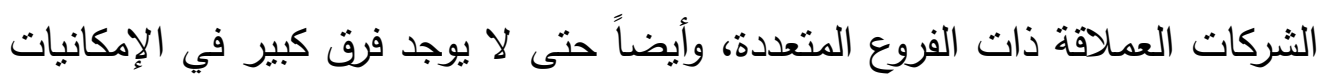

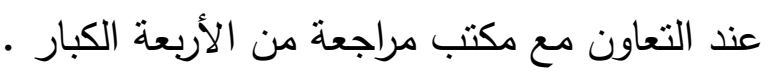




\section{قائمة المراجع}

\section{أولاً : المراجع العربية :}

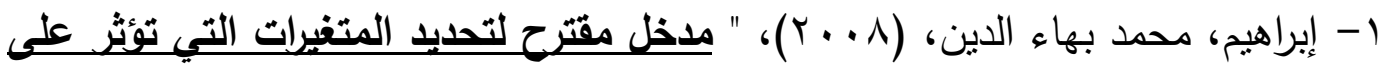

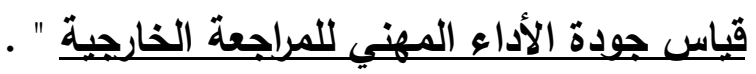

r- إسماعيل، طارق حسنين وقطب، أحمد سباعي، ( ب. (ץ)، " دراسة تحليليه لعوامل

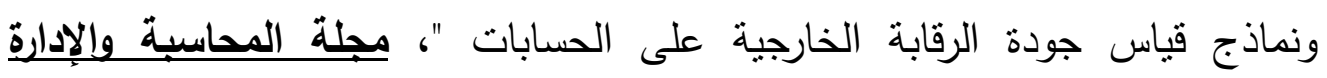

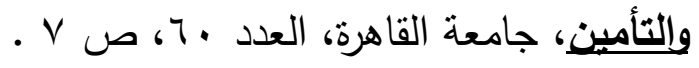

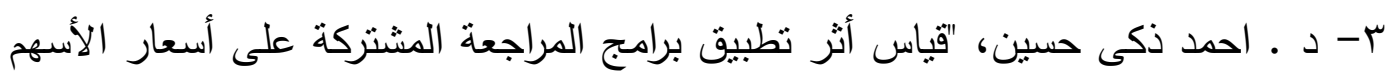

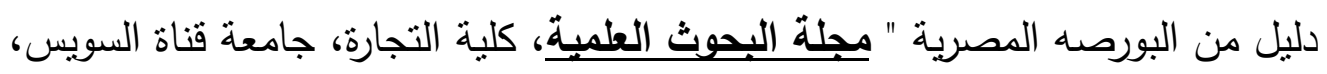
r. r

ع - د ـ أحمد سليم محمد سليم، " نموذج مقترح لتفسير العلاقة بين تقديم الخدمات بخلاف كاف

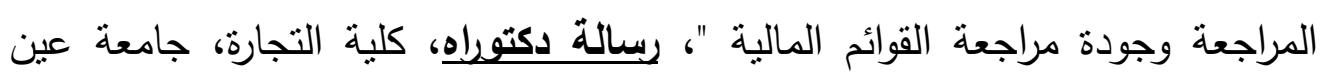

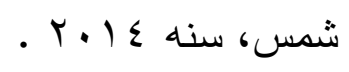

0- على، محمود أحمد، " دراسة واختبار العلاقة بين مداخل المراجعة الخارجية وجودة

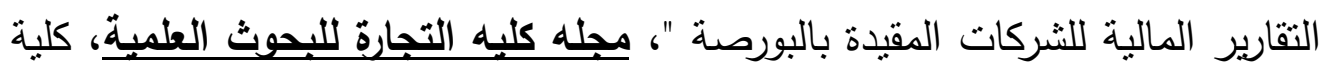

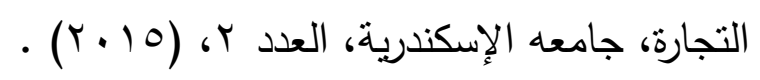

7- عيسى، سمير كامل محمد، " أثز جودة المراجعة الخارجية على عمليات إدارة الأرباح

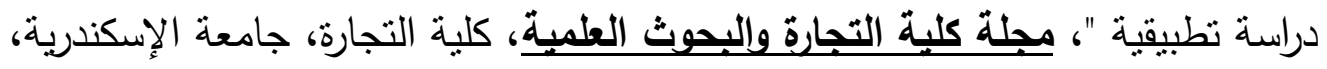

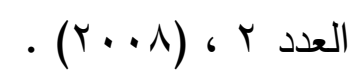

ثانياً : المراجع الأجنبية :

1- Holm, c. \& thinggssrd, F . 2011, "Joint audits - benefit or burden"? http 11 papers . ssrn .com 1 so13 1 papers . cfm ? abstract - id : 1702867 , accessed 3110812012 
2- Arens, A. A, et. al, (2012)," Auditing and Assurance Services : an Integrated Approach ", prentice- hall, inc., fourteenth Edition ,new Jersey, p.32 .

3- AICPA, (2005), PEEC ( Professional Ethics Executive committee ). Requirements of non - audit services, Available at : www. aicpa . org,. ( Accesse : 2012, February 20 )

4- Baldauf, J. and steckel, R., " Joint Audit and Accuracy of the Auditor repot : An Empirical study " in durational Journal of Economic sciences and Applied Research, vol 5 (2012).

5- Deng, m., lu, T., simunic, D.A. and ye, m., " Do joint Audits improvers impair Audit quality ?", working paper, CAAA Annual conference, (2013).

6- Zerni, m., Jarvinen, T., Niemi, L. and Haapamaki , E., " Do Joint Audit improve Audit quality ? Evidence from voluntary Joint Audits", European Accounting Review, vol21, march (2012).

7- Lobo, G., paugam,L., Zhang, D.andcasta, J.F., " Effect of Joint Auditor pair composition on conservatism : Evidence From payment Tests ", Accepted paper series, American Accounting Association (2013).

8- Audousset - coulier, s., " Two Bigor not two Big ? the consequences of Appointing Two Big 4 Auditors on Audit pricing in a joint Audit setting, Available at : http : \ ssrn . com , (2012).

9- Francis, J. R., Richard, C., and vanstaelen, A., "Assessing France joint Audit Requirement : Are Two Heads Better than one ?" Auditing :A journal of practice \& theory, vol 28(2009).

10-Ittonen, K. and Tronnes, P.C., " Benefits and costs of Appointing Joint Audit Engagement partners ", Auditing : A journal of practice and theory, vol 34(2014).

11-Harris, K., " Mandatory Audit Rotation : An international investigation " ph. D thesis, Bauer college of Business, the university of Houston, (2012). 
12-Bedard, J., piot, C. and Schatt, A., " Was the European commission Green paper right ? An Evaluation of the French Experience with joint Auditing ", Available at http : ॥ ssrn . com , (2012) .

13-ChihiH . and Mhirsi N., " joint Audits and Audit quality : A matter of size an \ or seniority ", working paper, university Paris Dauphine, (2013).

14- vele , P. and Azibi, J., " Are Joint Audits A proper instrument for increased Audit quality ", British Journal of Applied science \&technology, vol (2015) .

15-Piot , C., " Auditor concentration in a Joint - Auditing Environment : the French market 1997 - 2003 ", managerial Auditing Journal, vol 22 (2007) .

16-S. SEC, (2003), Final Rule : strengthening the commission Requirements Regarding Auditor Independence, u .S . SEC Issues, available at www. sec . gov, ( Accessed : 2012, feb 20).

17-Bjuliabuldauf \& rudolf Stacker " Joint audit and accuracy of the auditors-2 report " : an empirical study, international Journal of economic sciences and applied research, 2012

18-European commission, " Green paper - Audit policy : Lessons from the crisis ", Brussels , (2010)

19-Ezat, A.N.M., " the impact of Audit - Related factors on Audit Report lag for the Egyptian listed Non - financial companies ", Journal of faculty of commerce for scientific Research, vol . 52 .(2015) . 